\title{
Maternal and newborn health behaviors in rural Uttar Pradesh: Findings from learning phase baseline survey 2013
}

\author{
M.E. Khan \\ Population Council \\ Praween Kumar Agrawal \\ Population Council \\ Avishek Hazra \\ Population Council \\ Anvita Dixit \\ Population Council \\ Isha Bhatnagar \\ Population Council
}

See next page for additional authors

Follow this and additional works at: https://knowledgecommons.popcouncil.org/departments_sbsr-rh

Part of the Demography, Population, and Ecology Commons, Family, Life Course, and Society Commons, International Public Health Commons, Maternal and Child Health Commons, and the Women's Health Commons

How does access to this work benefit you? Let us know!

\section{Recommended Citation}

Khan, M.E., Praween Kumar Agrawal, Avishek Hazra, Anvita Dixit, Isha Bhatnagar, Jaleel Ahmad, and D.N. Ahmad. 2014. "Maternal and newborn health behaviors in rural Uttar Pradesh: Findings from learning phase baseline survey 2013." New Delhi: Population Council. 


\section{Authors}

M.E. Khan, Praween Kumar Agrawal, Avishek Hazra, Anvita Dixit, Isha Bhatnagar, Jaleel Ahmad, and D.N. Ahmad 


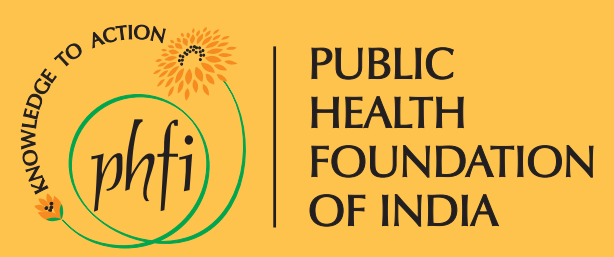

\section{Maternal and Newborn Health Behaviors in Rural Uttar Pradesh}

Findings from Learning Phase Baseline Survey, 2013

M.E. Khan, Praween K. Agrawal, Avishek Hazra, Anvita Dixit, Isha Bhatnagar, Jaleel Ahmad, Danish Ahmad 
The Population Council confronts critical health and development issues from stopping the spread of HIV to improving reproductive health and ensuring that young people lead full and productive lives. Through biomedical, social science, and public health research in 50 countries, we work with our partners to deliver solutions that lead to more effective policies, programs and technologies that improve lives around the world. Established in 1952 and headquartered in New York, the Council is a non-governmental, nonprofit organization governed by an international board of trustees.

Population Council Zone, 5-A, Ground Floor, India Habitat Center Lodhi Road, New Delhi - 110003, India

Tel: 91-11-24642901/02, Fax: 91-11-24642903

email: info.india@popcouncil.org

www.popcouncil.org

Suggested Citation: Khan, M. E., Agrawal, P. K., Hazra, A., Dixit, A., Bhatnagar, I., Ahmad, J., \& Ahmad, D. 2014. "Maternal and Newborn Health Behaviors in Rural Uttar Pradesh: Findings from Learning Phase Baseline Survey, 2013."

New Delhi: Population Council. 


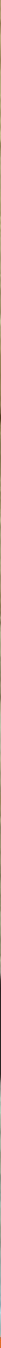

Acknowledgments

List of Abbreviations

Summary and Implications of the Findings

Key Indicators at a Glance

Chapter 1: Introduction and Methodology

Chapter 2: Background Characteristics of Surveyed Women

Chapter 3: Maternal Health Knowledge and Practices

Chapter 4: Newborn Health Knowledge and Practices

Conclusion

References

Appendix 


\section{Acknowledgment}

We are thankful to Dr. Dileep Mavalankar, Principal Investigator of the Uttar Pradesh Community Mobilization Project, all consortium partners of the project, Katherine Hay and other colleagues from the Bill \& Melinda Gates Foundation for their valuable feedback during the development of the questionnaire and the preliminary results of the survey. Our special thanks to Mr. P. Sampath Kumar, Chief Executive Office (CEO) and Mr. P.S. Mohanan, Acting CEO of the Rajiv Gandhi Mahila Vikas Pariyojana and their colleagues, Mr. Anoop Pant, Ms. Pritika Ojha and Mr. Vivek Chaurasia, as well as their field staff who extended their full support during the planning and implementation of the fieldwork, especially in the critical task of identifying the selected Self-Help Groups. We thank the Public Health Foundation of India for having the report edited and printed. 


\section{List of Abbreviations}

\begin{tabular}{|c|c|}
\hline AAA & ANM, Anganwadi worker, ASHA \\
\hline ANC & Antenatal care \\
\hline AWW & Anganwadi worker \\
\hline AWC & Anganwadi Centre \\
\hline ASHA & Accredited Social Health Activist \\
\hline ANM & Auxiliary Nurse Midwives \\
\hline $\mathrm{BCC}$ & Behavior Change Communication \\
\hline $\mathrm{BCM}$ & Behavior Change Management \\
\hline BMGF & Bill \& Melinda Gates Foundation \\
\hline BO & Block Organization \\
\hline CAPI & Computer Assisted Personal Interview \\
\hline CCT & Conditional Cash Transfer \\
\hline CEL & Community Empowerment Lab \\
\hline CGHD & Centre for Global Health and Development \\
\hline $\mathrm{CHC}$ & Community Health Center \\
\hline CS Pro & Census and Survey Processing System \\
\hline FLW & Field Level Worker \\
\hline FP & Family Planning \\
\hline GP & Gram Panchayat \\
\hline IFA & Iron Folic Acid \\
\hline IPC & Interpersonal Communication \\
\hline JSY & Janani Suraksha Yojana \\
\hline KMC & Kangaroo Mother Care \\
\hline LHV & Lady Health Visitor \\
\hline MDG & Millennium Development Goal \\
\hline MLE & Monitoring Learning and Evaluation \\
\hline MMR & Maternal Mortality Ratio \\
\hline
\end{tabular}




\begin{tabular}{|c|c|}
\hline MoHFW & Ministry of Health and Family Welfare \\
\hline NGO & Non-Governmental Organization \\
\hline NMR & Neonatal Mortality Rate \\
\hline NRHM & National Rural Health Mission \\
\hline PC & Population Council \\
\hline $\mathrm{PHC}$ & Primary Health Centre \\
\hline PHFI & Public Health Foundation of India \\
\hline PNC & Postnatal care \\
\hline RGMVP & Rajiv Gandhi Mahila Vikas Pariyojana \\
\hline RKS & Rogi Kalyan Samiti \\
\hline RMNCHN & Reproductive, Maternal, Newborn and Child Health and Nutrition \\
\hline SHG & Self-Help Groups \\
\hline SRS & Sample Registration Survey \\
\hline SC & Scheduled Caste \\
\hline SS & Swasthya Sakhi \\
\hline ST & Scheduled Tribes \\
\hline STSC & Skin to Skin Care \\
\hline UP & Uttar Pradesh \\
\hline VHND & Village Health and Nutrition Day \\
\hline VHSC & Village Health and Sanitation Committee \\
\hline VHSNC & Village Health, Sanitation and Nutrition Committee \\
\hline VO & Village Organization \\
\hline
\end{tabular}




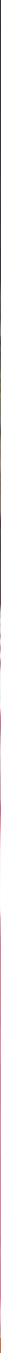

\section{Summary and \\ Implications of the Findings}




\section{Summary and Implications of the Findings}

\section{Background}

The Uttar Pradesh Community Mobilization Project is a five-year initiative (2011-2016), funded by the Bill \& Melinda Gates Foundation, that aims to develop and scale up evidence-based interventions to achieve the goal of improving RMNCHN health behaviors by an average of 10 percent points among marginalized population in the state of Uttar Pradesh, India. The goal of the project is to reduce neonatal mortality by improving maternal and child health behaviors through developing and scaling up a package of family health interventions and strengthening the management of Behavior Change Communication (BCC) using Self- Help Groups (SHG) as the platform. The project is being carried out in two phases - a learning phase covering 10 blocks and a scale-up phase covering 100 additional blocks. It is being implemented by a consortium led by the Public Health Foundation of India (PHFI) and funded by the Bill \& Melinda Gates Foundation (BMGF). The other members of the consortium are the Rajiv Gandhi Mahila Vikas Pariyojana (RGMVP), Population Council (PC) and the Centre for Global Health and Development (CGHD) of Boston University.

As part of the monitoring, learning and evaluation system for the project, a baseline survey for ten learning phase blocks was planned to measure the key maternal and newborn health indicators of the project of currently married women aged $15-49$ years who had delivered a baby during the last one year. 


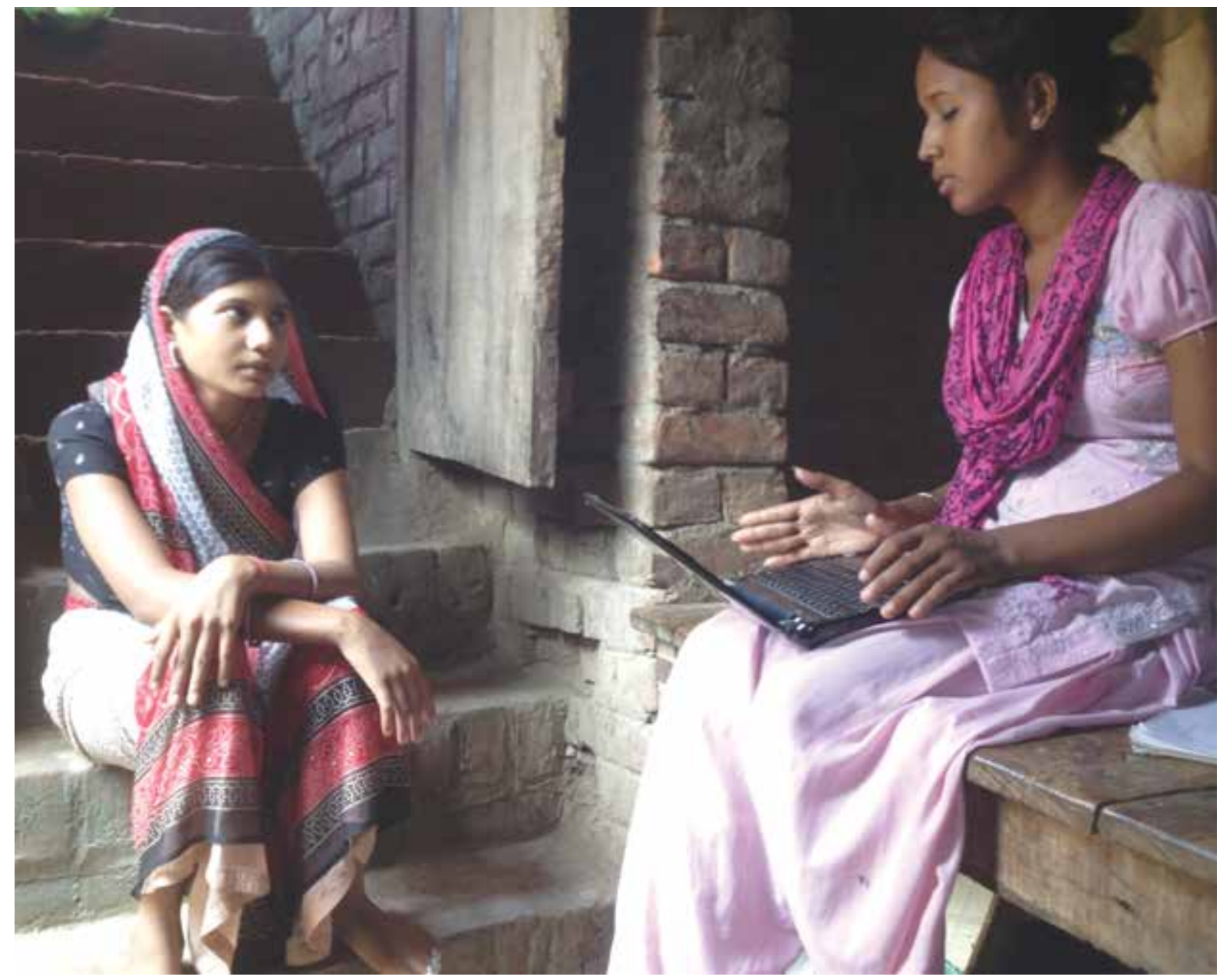

\section{Objective and Methodology}

The objectives of the learning phase baseline survey were to (a) establish equivalence of the intervention and control areas with respect to their background characteristics and (b) assess the level of knowledge and status of maternal and child health practices in the intervention and control area. The study design was a pre-post experimental-control design. A sample of 878 women from SHG households ${ }^{1}$ who had given birth to a child in the 15 months prior to the survey was required in each arm (experimental/intervention arm and control arm). Further, to assess the diffusion effect in the adoption of healthy behaviors, half of the sample, that is, 439 women, with the same criteria would be taken as a third study sample area from the intervention areas from households without any SHG member. Thus, the total sample size required was 2,195 eligible women (878+878+439). Finally, 2,208 women were interviewed.

The intervention and control blocks were taken from the same district to ensure homogeneity in socioeconomic and cultural aspects between the two study arms. During the learning phase, RGMVP was working in 100 Gram Panchayats (GPs) spread over 10 blocks of eight districts. Five districts (Hardoi, Rae Bareli, Mirzapur, Maharajganj and Sultanpur), covering more than 60 percent of the GPs, were selected based on geographical diversity and the level of the maturity, that is the period of existence, of the SHGs. 


\section{Results}

\section{Marginalized population}

The baseline survey results show that all the three arms of the study were fairly matched in terms of the socioeconomic background characteristics of the interviewed women. In some cases small differences were observed but they were not significant enough to influence the study results. More than two-thirds of women members belonged to marginalized groups. Many of them faced double or multiple marginalization because of the presence of two or multiple categories of marginalization. This is a confirmation that RGMVP works with the poor and marginalized population, often located in small purvas (hamlets) of a gram panchayat.

\section{Reaching the marginalized population}

Around two-thirds of women in the study areas were not exposed to any media, hence reaching them with family health messages is a challenge. The best way to educate them on issues is through interpersonal communication (IPC), with the SHG members and community-based frontline healthcare providers, such as Accredited Social Health Activists (ASHAs), Auxiliary Nurse Midwives (ANMs) and Anganwadi worker (AWWs) as potential channels. Of the surveyed women, 81 percent reported contact with ANMs, 78 percent with ASHAs and about one-third with AWWs. However, the quality of contact remained poor: 28 percent of the women did not receive any advice during their last pregnancy and among those who received any advice, the average number of interactions in which such advice was given was only $2.3(\mathrm{SD}=1.18)$. Although mobile phone ownership was high at the household level, only one-third of women had their own mobile phone which they could use anytime, thus making contact with them a challenge.

\section{SHG membership}

Out of the 1,729 eligible women who were interviewed from SHG households, two-thirds were members of RGMVP SHGs. Hence information provided during SHG meetings would directly reach the intended audience. However, not enough of this information was provided through SHGs. While it is accepted that new SHGs could take about six months to start organizing regular weekly meetings, one-fifth of the established SHGs, were either not organizing any meeting or held only one meeting a month. The reason for this need to be investigated, as the success of the program, particularly the heath intervention, depends on the regularity of SHG meetings.

\section{Maternal health: knowledge and practice}

The interviewed women across the three study arms showed a lack of knowledge of maternal care and a poor record of following healthy practices. Although there were a few statistically significant differences between the study arms for a few behavior patterns, in programmatic terms these differences were of no consequence and had no real impact on maternal health.

The study reveals that only less than half of the women had ever attended a Village Health and Nutrition Day (VHND). The use of Anganwadi Centres (AWCs) was also very limited. Even those women who had taken supplementary food from an AWC, did not consume it themselves but gave it to other family members. In such cases, the whole purpose of providing food supplements to these marginalized women was not served. Similarly, very few got 100 tablets of Iron Folic Acid (IFA) during their pregnancy and even among those who got them, only one-third consumed all 


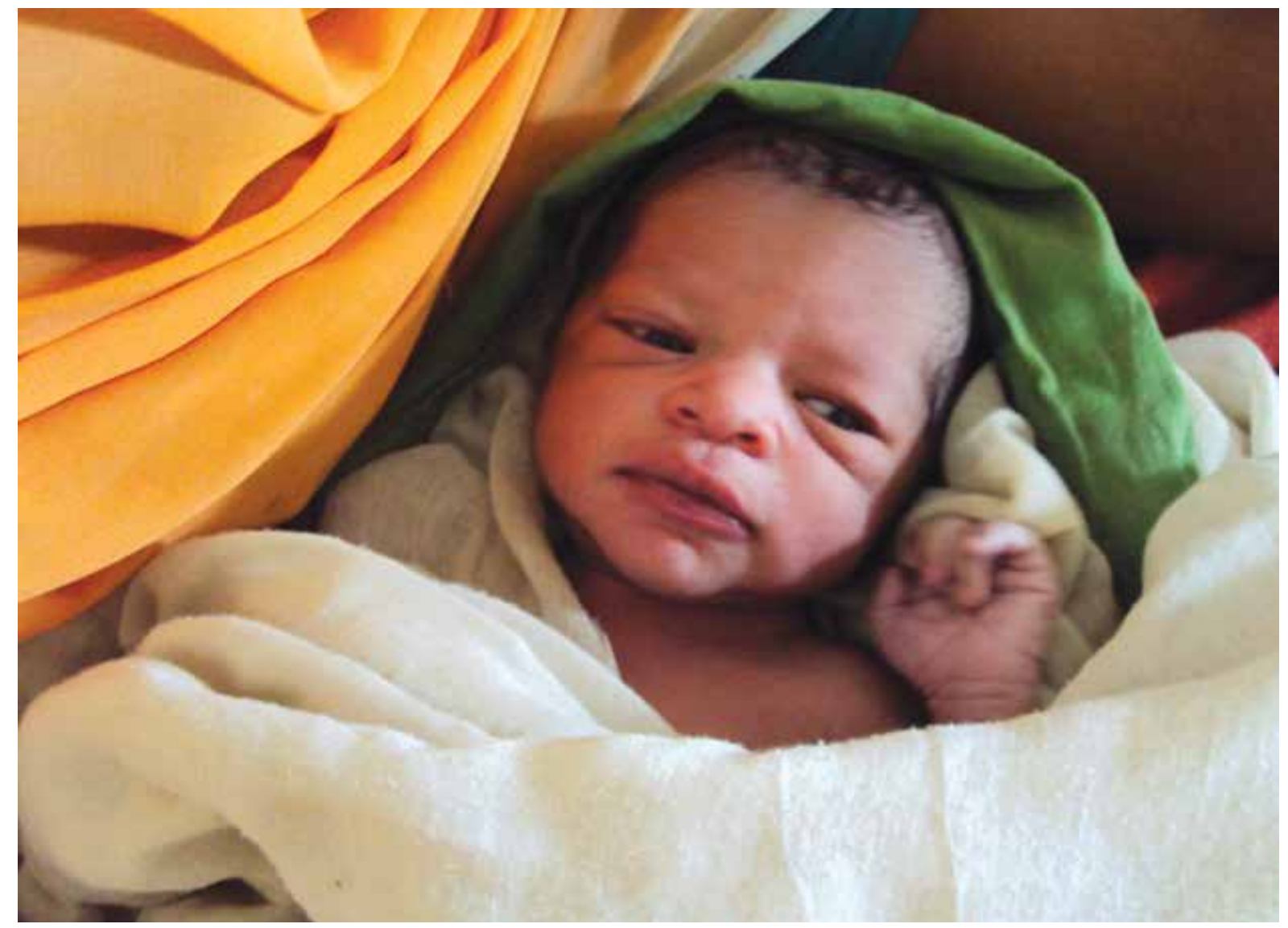

the tablets. It is important to understand the reason for such non-consumption and address those reasons along with providing the women information about the importance of consuming 100 IFA tablets during pregnancy.

The study also shows that women received very limited advice on maternal healthcare and practices. Consequently maternal health behavior was largely poor, except in cases of uptake of antenatal care (ANC) services and institutional deliveries. There was poor knowledge of danger signs during pregnancy, delivery and after delivery among most of the women, There were also many common misperceptions: that three ANC interventions are not necessary for a normal pregnancy; that postnatal care (PNC) service is not required for a healthy mother and newborn. Such wrong perceptions and lack of information on healthy behaviors acted as strong barriers for healthy practices like three or more ANC visits and availing PNC services within the first week of delivery. The women also showed a poor knowledge of factors that could delay the first or future pregnancies return of fertility, unsafe period and proper contraceptive use.

\section{Newborn health knowledge and practice}

The findings demonstrate that women lacked knowledge of newborn care and their newborn care practices were, in general, not healthy. The behavior patterns were similar both in the experimental and control arms. The two important predictors for early breastfeeding were three or more contacts with field level workers (FLWs) and institutional delivery. Pre-lacteal feeding, which exposes newborns to the risk of diarrhea and other sicknesses quite early, was quite common. Similarly, feeding water and animal milk to the newborn were done soon after birth, based on the perception that newborns feel thirsty and hence water is essential to save their lives. Very few were aware of 
the fact that more than 80 percent of breast milk is water and it is sufficient to quench the thirst of the baby.

The women appreciated the need of thermal care for the newborn, but lacked the knowledge on what needs to be done to keep the baby warm and often their practices were unhealthy. For example, half of the newborns were given a bath soon after birth and in one-fourth of the cases almost immediately after birth. Knowledge of Kangaroo Mother Care (KMC) or Skin to Skin Care (STSC) was almost non-existent and only 2 percent did it correctly.

Clean cord care was practiced by about one-fourth of the women. Most of the rest applied ghee, oil, ash or similar substances, which can prove harmful, on the cord stump as they believed they would help in drying the cord sooner. The study also reveals that the main influencers, who often recommend harmful practices or put barriers in the adoption of healthy behaviors, were the elderly women in family and traditional birth attendants (dai). This indicates that the right information must also reach the elderly persons in the family and the family should be taken as a unit when planning interventions for social change.

A more serious concern is the lack of knowledge about danger signs in a newborn, which results in a delay in starting the treatment. The baseline survey results show that the average delay was often one to two days. Unqualified healthcare providers for treatment were a preferred choice. Thus the focus should be on educating women about the importance of seeking early treatment and using trained healthcare providers, including government health facilities.

Logistic regression results confirm that marginalization was one of the significant independent factors that negatively influenced the health behaviors among the women interviewed. This suggests that special attention needs to be given to the marginalized segments of the population for attainment of universal health coverage. Scheduled Caste/Scheduled Tribe (SC/ST) households and illiteracy were strong predictors of poor maternal health behaviors. For programmatic purpose in the field, segmentation can be done on the basis of caste (SC/ST women) and illiteracy. These segments of women should be the main focus of the intervention. 


\section{Implications of the Findings}

Besides the results discussed above, the findings also had some key implications specific to the Behavior Change Management (BCM) agenda of the project.

\section{Proposed project targets}

The project proposal has assumed a 20 percentage point increase in most of the targeted behaviors except the use of modern contraceptive methods, where only a 7 percentage point increase was expected during the project period from the level observed in the Population Council's landscaping study (Khan et al. 2010). The findings of the learning phase baseline survey show that institutional delivery has increased from 44 percent in 2009 to 68 percent in 2013, early breastfeeding has gone up from 19 percent in 2009 to 49 percent in 2013. Thus both these indicators have already exceeded the 20 percentage point increase targeted for the project (Table 1). However, in making assumptions about the expected value at the end of the project period, it is important to factor in that any increase after a threshold level may be slower than assumed. For example, in the present survey, institutional delivery was already around 70 percent; expecting it to increase to 90 percent in two years would be unrealistic. Along with the increase in institutional delivery, other related behaviors like at least three ANC visits and early initiation of breastfeeding have also increased at an accelerated rate. Can we assume a similar accelerated increase in the next year?

On the other hand, despite incentives provided to the ASHAs under the Janani Suraksha Yojana (JSY) to provide home-based postnatal care for the mother and the newborn, the improvement in using PNC services was quite slow. An analysis of large-scale survey data indicates that the natural increase for PNC usage is about 1 percentage point per year. Therefore, it may not be rational to expect that Swasthya Sakhi (SS) and/or ANM, Anganwadi worker, ASHA (AAA) visits will cover 60 percent of postpartum women within 48 hours of delivery, as mentioned in the proposal.

Further, the Ministry of Health and Family Welfare (MoHFW) Operational Guidelines for Home Based Newborn Care (2011), mention that ASHAs are entitled to an incentive of Rs. 250 for making six PNC home visits ${ }^{2}$ within 42 days of delivery. They also highlight the importance of at least three visits within a week (GoUP, 2012). So in the current intervention, there is confusion about what should be promoted - at least one visit within 48 hours or three visits within a week or six visits within 42 days? The number of those following the correct practice of KMC has remained extremely low. Although, some studies suggest that there is a great potential to improve such health behavior, can a 20 percentage point increase in this indicator be achieved by 2015? The percent increase to be achieved for the use of modern contraceptive methods by the end of the project also needs to be critically determined.

All these findings thus imply that (a) the targets need to be re-visited and reset; (b) some of the definitions of the indicators like postnatal check-up and delayed bathing need to be modified as per latest Government guidelines; and (c) the sample size needs to be adjusted for the scale-up phase. 
Table 1: Trends in health indicators from the PC landscaping study, expected values at the end of the current project and current value from the learning phase baseline survey

\begin{tabular}{|l|c|c|c|}
\hline Indicators & $\begin{array}{c}\text { Baseline } \\
\text { value from PC } \\
\text { landscaping } \\
\text { study in 2009 }\end{array}$ & $\begin{array}{c}\text { Expected value } \\
\text { at the end of } \\
\text { the project } \\
\text { in 2015 }\end{array}$ & $\begin{array}{c}\text { Current value as } \\
\text { per the learning } \\
\text { phase baseline } \\
\text { survey in 2013 }\end{array}$ \\
\hline Institutional delivery & 44 & 64 & 68 \\
\hline PNC within 48 hours of delivery & $14^{*}$ & 60 & $17^{\star \wedge}$ \\
\hline Kangaroo mother care & 2 & 22 & 3 \\
\hline Clean cord care & 19 & 39 & 33 \\
\hline Delayed bathing newborn by a day & 32 & 52 & 39 \\
\hline Early breastfeeding & 19 & 39 & 49 \\
\hline Full immunization & 50 & 70 & NA \\
\hline Use of modern contraceptive methods & 18 & 25 & 24 \\
\hline
\end{tabular}

*PNC within seven days of delivery,

$\triangle P N C$ within 48 hours of delivery is 7 percent

\section{Intervention messages}

Based on the findings, there is a need to review and reframe the messages that have been designed for the intervention. Some suggestions have already been shared during a meeting of all the partners and a review of the annual progress. The implications of the findings for messages on different issues are highlighted below.

\section{Maternal health}

Pregnancy period: The PC landscaping study reveals that having at least three ANC check-ups is a gateway behavior as it influences the adoption of many other healthy practices (Khan et al. 2010). In the present study, while about 56 percent of women knew that at least three ANC check-ups are necessary, 49 percent women still did not follow this practice. The main reason for such behavior was a poor risk perception on pregnancy and its related complications. There is a general belief that if the pregnancy is normal, three ANC check-ups are not required. The elderly women in the family, who mostly control the decision on ANC visits, also believe that three ANC check-ups are not required unless a pregnancy complication is observed or reported by the pregnant woman. Women do not anticipate that any normal pregnancy could turn into a complicated pregnancy. Overall, only 22 percent women had been advised to undergo at least three ANC check-up during pregnancy. A major source of such advice was elders in the family or friends (56 percent).

Therefore, for the present study, the intervention should contain this message and the SS should have the competency to explain why at least three ANC check-ups are recommended and the risks involved if a woman does not have them (Box 1). A message such as "Go for at least three ANC" may not be effective unless women are explained the reasons why they should do so. Further, the message should emphasize that the perceived normalcy of the pregnancy is no guarantee that there might not be any complications and that having at least three ANC check-ups, one of which should be in the third trimester, is the only way to ensure that the pregnancy is normal. Additionally, there should be a message that if there is any risk in the pregnancy, the ANC check-ups could detect it early and ensure that it is managed till the baby is delivered safely. 
The study also shows that the quality of ANC that the women received was poor and twothirds of them did not undergo the three key ANC tests/examinations blood test, blood pressure measurement and abdominal examination. Hence, the content of the messages emphasizing the need for at least three ANC check-ups should shift towards (a) explaining why a woman should undergo a minimum of three ANC check-ups, (b) dispelling the widely prevalent belief that a normal pregnancy does not require ANC, (c) clearly spelling out key tests and examinations that should be done as a part of ANC and (d) giving information on where to go for these tests.

Delivery period: Delivery preparedness is crucial for ensuring a hassle-free and safe delivery. It also helps in deciding in favor of institutional delivery. The baseline data, however, reveals that though 58 percent families did not do any of the three key delivery preparedness steps i.e. saving money, advance arrangement of transport and identification of institution yet 62 percent of them opted for institutional delivery. Thus, in the presence of conditional cash transfer (CCT) schemes to ASHAs under JSY, delivery preparedness acts more as a facilitating factor rather than a necessary factor for institutional delivery. However, it was also observed that among the one-third women (701) who delivered their last child at home, 16 percent could not arrange transportation at the time of need for transferring the pregnant woman to a health facility and 17 percent could not arrange the money required immediately at that time for meeting transportation and medicine costs. This shows that putting out messages on delivery preparedness is still needed for some of the families. But it is important to decide whether the five messages presently included in the BCM routine should be retained or should be reduced to only three focused messages on advance arrangement of transport, saving money and identification of the place to go to in case of an emergency.

Maternal danger signs: The findings reveal that the interviewed women's knowledge of danger signs during pregnancy, delivery or post-delivery was poor. Since these danger signs are different during pregnancy, delivery and the postnatal period, the question arises whether the messages should focus on each stage separately (as per its chance of occurrence during pregnancy, delivery or post-delivery) or should there be a common one, irrespective of the stages? One option may be to highlight the key common danger signs that may occur in all the three stages and then provide stage-specific danger signs according to the pregnancy status of the woman (during pregnancy, at the time of delivery or soon after delivery).

Postnatal period: As in the case of ANC, the major barrier to compliance on the advice given to the women on PNC was low risk perception or a lack of understanding of the danger signs. Of the women who did not receive PNC within seven days of delivery, 72 percent reported that since everything was normal for mother and child, a PNC check-up was not required. At SHG meetings, women should be told about the importance of routine PNC irrespective of the absence or presence of any complications. They should be informed that identification of danger signs is best done by trained providers; that PNC helps in early detection of any complication; and that if there is a complication, early detection and treatment could save a life more surely than if it is identified at an advanced stage.

Family planning: Only one-fourth of the currently non-pregnant women were using any modern contraceptive methods after their last delivery. Among the 34 women who were pregnant at the time of the survey, two-thirds reported either that they wanted another child later or that they did 
not want any more children. The main reasons reported for not using any modern contraceptive method were:

- Side effects/ fear of side effects (34 percent)

- Child very young/ menstrual cycle has not started (10 percent)

- Family opposed (9 percent)

- Not aware about where to get the necessary resources/ services to adopt those methods (6 percent).

The survey also shows that 80 percent of women lacked correct knowledge about the return of fertility after delivery and the safe period during menstruation. This ignorance often lead to closely spaced unwanted pregnancies. The messages need to address each of these aspects as short birth interval is an important cause of both maternal and neonatal death.

Another problem area was the poor spousal discussion on timing of first pregnancy and birth interval. The PC landscaping study showed that the likelihood of use of contraception was five times higher with increased spousal discussion (Khan et al. 2012). So, there is a need to plan interventions on how to increase spousal communication on family planning. The BCC messages, which presently lack these aspects, could be a useful medium and so should incorporate content that highlights the importance of spousal discussions on family planning issues.

\section{Newborn care}

Breastfeeding: The record of early initiation of breastfeeding was far from satisfactory. Half the women in the study population did not breastfeed their baby within an hour (Box 2), the main reason being their belief that "milk does not come in the mother's breast" that early (54 percent). Presently, the intervention messages mention the advantages of early breastfeeding, including colostrum feeding, but do not address the root cause of delayed initiation of breastfeeding nor explain how the mother should start breastfeeding the newborn. Therefore, the messages must emphasize tips like: "Put the baby on your breast and help it in suckling" and "Breast suckling by the baby is the key to stimulating the flow of breast milk". The regression analysis reveals that women who had at least three contacts during pregnancy with the ASHA were two times more likely to deliver in an institution and breastfeed within an hour. So, the strategies should ensure that a woman is contacted during pregnancy at least three times by the ASHA or the SS and advised to put the baby on her chest immediately so that it starts suckling the breast.

Thermal care: The poor and incorrect knowledge of thermal care and the very rare practice of KMC clearly indicate a need to improve this behavior. The intervention messages are correct and in the right direction on this issue.

The study reveals that half of the newborns were given a bath soon after birth, in one-fourth cases almost immediately. Presently, the BCM strategy does not include any message on delaying the first bath to the newborn, which is an important component of thermal care. The messages should clearly state: "Do not bathe a newborn till 48 hours after birth". The harmful effect of sudden transition from a warm environment to a cold one or vice versa is well understood in rural areas so it will not be difficult for them to understand why delaying the first bath of the newborn for at least 48 hours is recommended. The indicators for postnatal check-up and delayed bathing need to be re-defined as per the latest Government guidelines. Boxes 1 and 2 below illustrate the implications of the survey findings on messages for both maternal and newborn care. 
Box 1: Findings and their implications related to maternal health message component

\begin{tabular}{|c|c|}
\hline Findings & Implications \\
\hline $\begin{array}{l}\text { The main reason women gave for not } \\
\text { going for at least three ANCs was poor risk } \\
\text { perception: Pregnancy was normal/did not feel } \\
\text { it was necessary' ( } 66 \text { percent). }\end{array}$ & $\begin{array}{l}\text { Intervention message should include risks involved } \\
\text { if women do not go for ANC and emphasize that } \\
\text { any normal delivery could become complicated. } \\
\text { ANC helps identify risks involved, if any, at an } \\
\text { early stage. }\end{array}$ \\
\hline $\begin{array}{l}76 \text { percent women did not receive three key } \\
\text { ANC tests blood test, BP measurement and } \\
\text { abdominal examination. }\end{array}$ & $\begin{array}{l}\text { Women should be told about (a) importance of } \\
\text { these three tests, and (b) the sources from where } \\
\text { they could avail them. }\end{array}$ \\
\hline $\begin{array}{l}58 \text { percent women did not do any of the key } \\
\text { three delivery preparedness steps; among } \\
\text { them } 62 \text { percent went for institutional } \\
\text { delivery. } 33 \text { percent women could not go for } \\
\text { institutional delivery as they could not arrange } \\
\text { transportation ( } 16 \text { percent) and could not } \\
\text { arrange money ( } 17 \text { percent) on time. }\end{array}$ & $\begin{array}{l}\text { A decision is needed on whether all the five } \\
\text { messages included in the BCM should be retained } \\
\text { or only three components -- advance arrangement } \\
\text { of transport, saving money and identification of } \\
\text { place to go to in case of emergency. }\end{array}$ \\
\hline $\begin{array}{l}\text { The average number of danger signs a } \\
\text { woman knew ranged from } 0.5 \text { to } 0.7 \text { during } \\
\text { pregnancy, delivery and post-delivery. }\end{array}$ & $\begin{array}{l}\text { Danger signs are different by stages. A decision } \\
\text { needs to be taken on: Should danger signs be } \\
\text { told as per the stage or common for all stages? }\end{array}$ \\
\hline $\begin{array}{l}\text { The major barrier of not receiving PNC was } \\
\text { perceived low risk of complication in postnatal } \\
\text { period - 'Everything was normal' ( } 72 \text { percent). }\end{array}$ & $\begin{array}{l}\text { Make women aware that even if things are } \\
\text { normal, PNC is required and everyone may not } \\
\text { identify danger signs at early stage. Hence, PNC is } \\
\text { necessary irrespective of the status of the mother } \\
\text { and newborn. }\end{array}$ \\
\hline $\begin{array}{l}\text { Main reason for not using any modern } \\
\text { method was side effects/fear of side effects } \\
\text { (34 percent). }\end{array}$ & $\begin{array}{l}\text { Intervention messages should include method- } \\
\text { specific side effects; the fact that they are normal } \\
\text { and only of short duration; and counselling on } \\
\text { how to manage them. }\end{array}$ \\
\hline $\begin{array}{l}81 \text { percent women had incorrect knowledge } \\
\text { about return of fertility after delivery and } 88 \\
\text { percent had incorrect knowledge on safe } \\
\text { period leading to unwanted pregnancies. }\end{array}$ & $\begin{array}{l}\text { Intervention messages could address these and } \\
\text { disseminate accurate knowledge. }\end{array}$ \\
\hline $\begin{array}{l}\text { Spousal discussion on timing of first } \\
\text { pregnancy was } 25 \text { percent and on future } \\
\text { pregnancy or method to use was } 41 \text { percent. }\end{array}$ & $\begin{array}{l}\text { How to increase spousal communication on these } \\
\text { aspects? A feasibility study may help in answering } \\
\text { this question. }\end{array}$ \\
\hline
\end{tabular}

Cord care: A substantial proportion of women applied ghee/oil (37 percent), ash (16 percent) and talcum powder (14 percent) on the cord stump of the baby. Presently, the messages mention that infection may happen by applying soil or cow-dung on the cord. The message should be revised to say: "Applying anything on the cord stump could cause infection. Do not apply anything on the cord and keep it clean and dry." The following line could be added: "The cord stump will dry and fall off automatically."

Newborn danger signs: The women's knowledge about various danger signs that a newborn may face was poor. They knew only one or two among the 10 danger signs listed in the SHG toolkit. While the list of danger signs for newborn in the BCM strategy covers almost all the critical ones, danger signs like: "Baby is very small or has low birth weight", may also be included. 


\section{SHG activities}

The study reveals that SHGs mostly consist of marginalized segments of the population, particularly SC/ST, and they primarily join to avail of the loan facility and improve their financial position. The secondary reasons are empowerment and creating a stronger social network with other community members. However, these factors were not well articulated and projected in the answers of SHG members. Older SHGs (12 or more months) generally organized three meetings every month and, on an average, each SHG member attended two meetings. However, 25 percent of the older SHGs were organizing lesser number of meetings. Newer SHGs (less than 12 months old) organized, on an average, two meetings per month.

As the SHG's monthly meetings are the main forum for dissemination of health information and educating their members, the number of monthly meetings and regular participation by members is crucial for the success of the intervention. This needs close monitoring by Village Organizations (VOs), both on the number of meetings organized and whether health issues were discussed or not in each meeting. This will be more critical in the case of newer SHGs.

However, each member may not attend each meeting and thus all women will not be equally exposed to the intervention messages. This will impact knowledge gain and behavior change. But given the volunteer nature of the SHGs and the independence of SHG members, expecting all members to attend each SHG meeting may be a challenge. RGMVP could be the best guide for suggesting how these operational issues should be addressed.

\section{Box 2: Findings and their implications related to newborn care message components}

\begin{tabular}{|l|l|}
\hline Findings & Implications \\
\hline $\begin{array}{l}51 \text { percent did not start breastfeeding within } \\
\text { an hour of delivery; the most frequent reason } \\
\text { reported, was "Milk does not come in mother's } \\
\text { breast" (54 percent). }\end{array}$ & $\begin{array}{l}\text { Messages should emphasize the following- } \\
\text { "As soon as the baby is put on breast, it } \\
\text { starts suckling and milk will start coming } \\
\text { automatically"..."Breast suckling by the baby is } \\
\text { key to stimulating flow of breast milk." }\end{array}$ \\
\hline $\begin{array}{l}\text { Women having at least three contacts during } \\
\text { pregnancy with ASHA were two times more } \\
\text { likely to start breastfeeding within an hour. }\end{array}$ & $\begin{array}{l}\text { Ensure every woman is contacted during } \\
\text { pregnancy at least three times by ASHA or } \\
\text { Swasthya Sakhi and given appropriate advice. }\end{array}$ \\
\hline Only three percent women practiced KMC. & $\begin{array}{l}\text { The intervention messages are clear and there is } \\
\text { opportunity to improve this behavior. }\end{array}$ \\
\hline $\begin{array}{l}51 \text { percent women bathed the newborn within } \\
48 \text { hours of birth. }\end{array}$ & $\begin{array}{l}\text { Presently no message on delaying the first bath } \\
\text { is included in the BCM. Decision needs to be } \\
\text { taken on whether to include it in the BCM } \\
\text { strategy. }\end{array}$ \\
\hline $\begin{array}{l}73 \text { percent women applied substance (oil/ghee, } \\
\text { ash, talcum powder or other substance) on } \\
\text { baby's cord stump. }\end{array}$ & $\begin{array}{l}\text { Messages should state, "Applying anything on } \\
\text { cord stump could cause infection. Do not apply } \\
\text { anything on cord. Keep cord dry and clean". }\end{array}$ \\
\hline $\begin{array}{l}\text { Poor knowledge about various danger signs } \\
\text { (1-39 percent) that a newborn may face, except } \\
\text { for knowledge about fever (72 percent). }\end{array}$ & $\begin{array}{l}\text { List of danger signs in the BCM strategy is quite } \\
\text { exhaustive. This one may also be included: } \\
\text { "Baby is very small or low birth weight" may be } \\
\text { included. }\end{array}$ \\
\hline
\end{tabular}


The move to create links with the public health system and functionaries for better utilization of health services is neither well conceptualized nor has the baseline survey collected any information on this. These issues require further discussion and operational details needs to be worked out. The Management Information System (MIS) managed by RGMVP, Lot Quality Assurance Sampling (LQAS) surveys by RGMVP and PHFI, and concurrent evaluation by the Population Council will examine community side barriers and performance. Documentation of the processes will help monitor these crucial aspects.

It has been further planned that in the baseline survey of Scale -Up Phase I, interviews will be conducted with the key informants of SHGs (such as the president or secretary of the SHG) and selected VOs who have received BCM training and are supposed to take the lead role in supporting SHGs. This will help in understanding the functioning of the SHGs and deciding how they could best contribute to this project without vitiating from their prime function of economic inclusion and social empowerment of the marginalized population so as to protect their rights and ensure that they avail their entitlements.

\section{Box 3: Findings and their implications on SHG activities}

\begin{tabular}{|l|l|}
\hline Findings & Implications \\
\hline Average meetings held per month: 3 & $\begin{array}{l}\text { VO or Sakhi should ensure SHG members attend } \\
\text { meetings or organize a meeting for health and } \\
\text { avk them to attend. }\end{array}$ \\
$\begin{array}{l}\text { The key messengers and change agent will be } \\
\text { SS. They need sustained support, supervision } \\
\text { and competency-based training. }\end{array}$ & $\begin{array}{l}\text { MIS managed by RGMVP, LQAS and concurrent } \\
\text { evaluation should be effectively used to } \\
\text { generate relevant data base on supervision, } \\
\text { quality of training, competency of the SS and } \\
\text { quality of messages given and the extent to } \\
\text { which VOs are playing their role in supportive } \\
\text { supervision. } \\
\text { How to ensure VHNDs are being held regularly } \\
\text { and women are attending them? Messages are } \\
\text { silent on this. }\end{array}$ \\
\hline
\end{tabular}




\section{Key Indicators at a Glance}

\begin{tabular}{|c|c|c|c|c|}
\hline Indicator & \begin{tabular}{|} 
Intervention \\
SHG arm \\
$(\mathrm{N}=858)$
\end{tabular} & $\begin{array}{l}\text { Intervention } \\
\text { non-SHG } \\
\operatorname{arm}(\mathrm{N}=479)\end{array}$ & $\begin{array}{l}\text { Control } \\
\text { arm } \\
(\mathrm{N}=\mathbf{8 7 1})\end{array}$ & $\begin{array}{c}\text { Total } \\
(\mathrm{N}=2,208)\end{array}$ \\
\hline \multicolumn{5}{|l|}{ Women's background } \\
\hline - Age in years (mean) & 25.6 & 25.4 & 25.6 & 25.6 \\
\hline - Working (percent) & $20.6^{\wedge}$ & 15.9 & 23.4 & 20.7 \\
\hline - Hindu ( percent) & 93.5 & 92.5 & 92.0 & 92.7 \\
\hline - SC/ST ( percent) & 49.1 * & 46.1 & 60.8 & 53.1 \\
\hline - Literate (percent) & 52.7 & 53.2 & 49.0 & 51.4 \\
\hline $\begin{array}{l}\text { - Poorest/poorer wealth quintiles } \\
\text { (percent) }\end{array}$ & 40.4 & 36.2 & 41.8 & 40.0 \\
\hline $\begin{array}{l}\text { Marginalized (any of the three } \\
\text { variables wit) (percent) }\end{array}$ & $76.1^{*}$ & 72.0 & 80.6 & 77.0 \\
\hline \multicolumn{5}{|c|}{ Exposure to media and health workers } \\
\hline $\begin{array}{l}\text { Exposed to any media (TV, radio, } \\
\text { newspaper) (percent) }\end{array}$ & 30.5 & 32.2 & 26.3 & 29.2 \\
\hline - Contact with ANM (percent) & 81.4 & 80.2 & 81.4 & 81.1 \\
\hline - Contact with ASHA (percent) & 79.5 & 76.2 & 77.8 & 78.1 \\
\hline - Contact with AWW (percent) & 37.2 & 35.9 & 33.2 & 35.3 \\
\hline \multicolumn{5}{|l|}{ Maternal health indicators } \\
\hline $\begin{array}{l}\text { At least three ANC: } \\
\text { Knowledge (percent) }\end{array}$ & $58.2^{\wedge}$ & 52.4 & 55.3 & 55.8 \\
\hline $\begin{array}{l}\text { At least three ANC: Practice } \\
\text { (percent) }\end{array}$ & 51.5 & 50.1 & 51.0 & 51.0 \\
\hline $\begin{array}{l}100 \text { or more IFA consumption: } \\
\text { Knowledge (percent) }\end{array}$ & 27.5 & 27.1 & 29.6 & 28.3 \\
\hline $\begin{array}{l}\text { - } 100 \text { or more IFA consumption: } \\
\text { Practice (percent) }\end{array}$ & 7.9 & 8.6 & 7.6 & 7.9 \\
\hline $\begin{array}{l}\text { At least three ANC tests/ } \\
\text { examination (blood test, BP } \\
\text { measurement and abdominal } \\
\text { examination) (percent) }\end{array}$ & 25.4 & 24.2 & 22.0 & 23.8 \\
\hline $\begin{array}{l}\text { Deworming tablets consumed } \\
\text { at least once (percent) }\end{array}$ & 3.5 & 3.5 & 4.4 & 3.8 \\
\hline - Delivery preparedness (percent) & $45.0 * \wedge$ & 39.5 & 39.5 & 41.6 \\
\hline - Institutional delivery (percent) & 68.9 & 69.7 & 65.4 & 67.7 \\
\hline $\begin{array}{l}\text { - Postnatal stay at facility for at } \\
\text { least } 24 \text { hours (percent) }\end{array}$ & $35.5^{*}$ & 35.3 & 29.5 & 33.2 \\
\hline - PNC within a week (percent) & 17.1 & 16.5 & 17.8 & 17.3 \\
\hline $\begin{array}{l}\text { Current use of modern FP } \\
\text { methods (percent) }\end{array}$ & 24.9 & 24.2 & 23.1 & 24.0 \\
\hline
\end{tabular}




\begin{tabular}{|c|c|c|c|c|}
\hline Indicator & $\begin{array}{c}\text { Intervention } \\
\text { SHG arm } \\
(\mathrm{N}=858)\end{array}$ & $\begin{array}{l}\text { Intervention } \\
\text { non-SHG } \\
\operatorname{arm}(\mathrm{N}=479)\end{array}$ & $\begin{array}{l}\text { Control } \\
\text { arm } \\
(\mathrm{N}=\mathbf{8 7 1})\end{array}$ & $\begin{array}{c}\text { Total } \\
(\mathrm{N}=2,208)\end{array}$ \\
\hline \multicolumn{5}{|l|}{ Newborn and child health indicators } \\
\hline $\begin{array}{l}\text { Breastfeeding within an hour } \\
\text { (percent) }\end{array}$ & 50.3 & 44.9 & 48.8 & 48.6 \\
\hline - Clean cord care (percent) & $27.9 * \wedge$ & 33.2 & 23.3 & 27.2 \\
\hline $\begin{array}{l}\text { Delayed bathing of newborn } \\
\text { for } 48 \text { hours (percent) }\end{array}$ & 50.0 & 52.0 & 45.4 & 48.6 \\
\hline - KMC (percent) & 3.3 & 2.9 & 3.2 & 3.2 \\
\hline $\begin{array}{l}\text { - Exclusive breastfeeding for first } \\
\text { six months (percent) }\end{array}$ & 23.0 & 22.1 & 21.4 & 22.1 \\
\hline $\begin{array}{l}\text { - Complementary food initiation } \\
\text { at six months (percent) }\end{array}$ & 31.5 & 26.6 & 35.0 & 32.0 \\
\hline \multicolumn{5}{|l|}{ SHG platform indicators } \\
\hline $\begin{array}{l}\text { - Duration of SHG in months } \\
\text { (mean) }\end{array}$ & $22.0^{*}$ & NA & 15.0 & 18.0 \\
\hline $\begin{array}{l}\text { - Meetings organized in a } \\
\text { month (mean) }\end{array}$ & 2.8 & NA & 2.8 & 2.8 \\
\hline $\begin{array}{l}\text { - Meetings attended in a month } \\
\text { (mean) }\end{array}$ & 1.9 & NA & 2.0 & 1.9 \\
\hline $\begin{array}{l}\text { - Meetings held at eligible } \\
\text { woman's home (percent) }\end{array}$ & 28.0 & NA & 25.7 & 26.8 \\
\hline $\begin{array}{l}\text { - Ever taken loan by woman } \\
\text { (percent) }\end{array}$ & $43.6^{*}$ & NA & 28.7 & 35.9 \\
\hline
\end{tabular}

* Significant difference between intervention and control arm, $p<0.05$

^ Significant difference between intervention SHG and intervention non-SHG arm, $p<0.0$

@ any three: saved money, arranged transport and identified institution to rush in case of emergency 



\section{Introduction}

In India each year, of the 27 million babies born, about 0.88 million die in the first 28 days of life and 1 million die before their first birthday (MoHFW, 2011). The target for India's Millennium Development Goal (MDG) \# 4 is to reduce Infant Mortality Rate (IMR) by two-thirds between 1990 and 2015, that is from 80 infant deaths per 1,000 live births in 1990 to 28 by 2015. India's MDG 5 target is to reduce Maternal Mortality Rate (MMR) by three-quarters between 1990 and 2015 from 437 maternal deaths per 100,000 live births to 109 (GOI, 2010). As per the latest available estimate, 178 mothers die every year per 100,000 live births in India and large inter-state variations exist (ORGI, 2013). The latest Sample Registration Survey (SRS) (2012) estimates IMR as 42 per 1,000 and neonatal mortality rate (NMR) as 29 per 1,000, which suggests that the percentage of neonatal deaths to total infant deaths is 69 percent (ORGI, 2012).

According to the 2011 Census, Uttar Pradesh (UP) is the most populous state of India, with a population of 200 million, of which 78 percent is rural and only 22 percent is urban (Census, 2011). UP contributes to 17 percent of India's total population. It is one of the most backward states, with high levels of poverty and low levels of social and economic development (Bajpai and Sachs, 2011). The state contributes to one-fifth of India's annual birth cohort and has a share of 28 percent of neonatal deaths and 35 percent of maternal deaths in the country and almost 10 percent of the global burden (RGMVP, 2014). Accelerating the progress in reducing maternal and neonatal mortality in UP can significantly contribute to meet MDGs 4 and 5.

The Government of India and the Government of UP are implementing the National Rural Health Mission (NRHM), a major objective being to reduce maternal and child mortality. Health service delivery is being strengthened through designated health centers, improved management, flexible financing, innovations in human resource management and setting of standards and norms with monitoring (MoHFW, GOI, 2013).

One of NRHM's key approaches is increasing participation and ownership by the community through "communitization". This calls for an Accredited Social Health Activist at each village and constituting committees at each level including Village Health, Sanitation and Nutrition Committees (VHSNCs) and patient welfare societies, known as Rogi Kalyan Samitis (RKS), at the health facilities. It also includes community-based monitoring as one of the sources of information for monitoring the progress and achievements of the mission.

A major initiative is the conditional cash transfer scheme called Janani Suraksha Yojana under which the pregnant woman and the ASHA of that village receive a cash incentive for delivering the child at a public health facility. JSY has resulted in a considerable increase in institutional deliveries. However, ASHAs are unable to reach all women and so the practice of most good maternal and child health behaviors continues to be lower than the national average, as confirmed by the landscaping study conducted in UP during 2009-2010 by the Population Council and funded by the Bill \& Melinda Gates Foundation (Khan et al. 2012).

Along with other key findings, the landscaping study has identified barriers and facilitating factors for adoption of healthy behaviors. Eight of the selected barriers have a direct bearing on maternal health, newborn care and neonatal mortality. The study also provides a list of selected messages that need to be delivered in an integrated manner using mainly interpersonal communication, as 
58 percent of the rural women interviewed were not exposed to any form of mass media. The study provides the framework for an integrated and aligned communication strategy to the most disadvantaged families. It also reiterates that efforts need to be made to implement demand side community-based interventions.

Many community-based family health interventions have resulted in reduction of neonatal mortality and an improvement in maternal and child health. Darmstadt et al. (2006) showed that up to two-thirds of neonatal deaths can be prevented if mothers and newborns receive most effective identified interventions. However, there is a dearth of interventions which have been taken to scale and which could thereby ensure a rapid and sustainable impact on family health outcomes.

The Shivgarh trial, which was carried out in Rae Bareli district in UP, aimed at developing and testing a package of preventive essential newborn care interventions delivered through a BCM approach by community mobilizers and volunteers specially identified and trained for the project. The study documented a 54 percent reduction in the NMR (Kumar et. al. 2008). The Shivgarh and Ekjut trials (Tripathy et al. 2010) and other community mobilization efforts (Manadhar et al. 2004; Azad et al. 2010) identified key elements like a participatory approach, community mobilization and provision of service as the way forward to reducing neonatal mortality and improving maternal and child health (Khan et al. 2014). However, there is a need to develop effective scale-up strategies to bridge the gap between evidence and impact at scale.

One of the most promising and scalable demand side social platforms for scaling up family health interventions is the SHG model. In Uttar Pradesh, the Rajiv Gandhi Mahila Vikas Pariyojana has developed a rapidly scalable SHG model that can serve as a platform for building up family health interventions. RGMVP's SHGs usually consist of 10 to 12 women from a poor socioeconomic background. RGMVP uses a participatory approach for identifying the most disadvantaged families, who usually belong to the Scheduled Caste and socially and economically disadvantaged groups, often living in small and isolated hamlets or small villages. All the SHGs mobilized at the village level are federated into Village Organizations representing 150 to 250 women drawn from 10 to 20 SHGs. These VOs, in turn, are federated into Block Organizations (BOs) representing 5,000 to 7,000 women. This federal structure, which RGMVP has developed, is presented in Figure 1.1.

Figure 1.1: Structure of the Social Platform Developed by RGMVP

\begin{tabular}{|c|c|c|c|}
\hline Social Platforms & Agenda & Actors: & Activities \\
\hline & $\begin{array}{l}\text { - Resource Organization } \\
\text { Cathlyzing government } \\
\text { Systems } \\
\text { - Lesdership development }\end{array}$ & $\begin{array}{l}\text { Field Officer, Community Health } \\
\text { Trainers, BO leaders, BO } \\
\text { Committees }\end{array}$ & 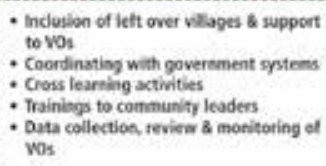 \\
\hline & $\begin{array}{l}\text { - Convergence and linkage } \\
\text { with government syatem } \\
\text { - Access \& entiticments } \\
\text { through collectivization } \\
\text { - Information Management }\end{array}$ & $\begin{array}{l}\text { Vo Leaders, vo } \\
\text { Committees, Bank Sakhis, } \\
\text { vo Swasthya Sakhis, } \\
\text { Community Resource } \\
\text { Persons, Volunteers }\end{array}$ & 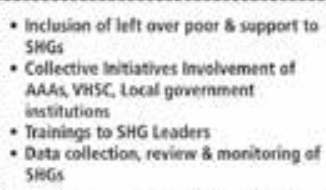 \\
\hline & $\begin{array}{l}\text { Financial indusion } \\
\text { - tivelihood enhancement } \\
\text { Bhaviour change } \\
\text { Management }\end{array}$ & $\begin{array}{l}\text { SHG Leaders, Samooh Sakhis } \\
\text { (group volunteers), Book } \\
\text { Keepers, Swasthya Sakhis }\end{array}$ & 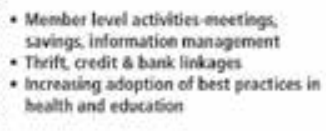 \\
\hline
\end{tabular}




\section{The project and learning phase}

Considering the potential of community mobilization in improving selected healthy behavior which has a direct bearing on RMNCH outcomes, particularly in reducing the neo-natal mortality rate, BMGF is funding an implementation project for a consortium of five institutions, led by PHFI. Other consortium members are RGMVP, Community Empowerment Lab (CEL), Population Council and the Centre for Global Health and Development of Boston University. The project aims to accelerate the decline in neonatal mortality and improve maternal and child health through changes in family health behaviors and improve access, utilization and quality of services by activating SHGbased social platforms. Box 1.1 describes the objectives of the project. It will be carried out in 160 blocks (with a total population of 32 million) in four years and will directly reach 1.2 million poor households with SHG members. The project is being implemented in three phases:

1. Learning phase in 10 blocks

2. Scale up phase one in 50 Blocks

3. Scale-up phase Two in additional 100 blocks

The learning phase is being implemented in 100 Gram Panchayats of 10 blocks from eight districts where SHGs are being leveraged using the behavior change management model by:

- Providing evidence-based messages to the SHG and community by Swasthya Sakhis (members of SHGs) trained in discussing family health messages

- Strengthening counseling skills of SSs to counsel women and family members

- Building community norms for behavior change through dialogue and sharing of experiences

- Linking social platforms to service delivery mechanisms including the ASHA and the Village Health and Sanitation Committee to align the messages.

The Population Council, which is responsible for the Monitoring Learning and Evaluation (MLE) activities of the project, carried out a baseline study in the learning phase to (a) establish equivalence of the intervention and control areas with respect to their background characteristics, and (b) assess the level of knowledge and practice of healthy maternal and newborn health behavior in the intervention and control areas. 


\section{Methodology}

\section{Survey instruments and key indicators}

Data were collected from the head of the household and women using two different questionnaires, named the household and the woman questionnaires. Both the survey instruments were prepared by PC, pre-tested and translated into Hindi, the local language of UP. All the partners were provided draft questionnaires for review, comments and suggestions before finalization. The household questionnaire was used to collect information on socioeconomic and demographic information of each household member, such as age, sex, education, marital status and the household's ownership of different durables, goods and housing conditions to measure its wealth status. The woman questionnaire was used to collect information on background characteristics of eligible women; knowledge, awareness and practice of healthy antenatal, natal, postnatal care, newborn care; use of family planning methods; exposure to mass media; access to mobile phone, as well as on characteristics and functioning of SHGs.

The following key indicators were measured in the survey using the above instruments:

- Percentage of women who were advised during pregnancy

- Percentage of women who received at least three ANC checkups

- Percentage of women who consumed 100 IFA tablets

- Percentage of women who consumed deworming tablets at least once

- Percentage of women who made delivery preparations

- Percentage of women who delivered their last child in an institution

- Percentage of women who stayed at the child delivery facility for at least 24 hours

- Percentage of women who received a PNC checkup within a week of delivery of their last child

- Percentage of women who initiated breastfeeding within an hour

- Percentage of women who did not apply anything on the cord stump of the baby

- Percentage of women who delayed the first bath to their baby by at least 48 hours

- Percentage of women with correct knowledge of KMC

- Percentage of women who practiced KMC correctly

- Percentage of women who exclusively breastfed their baby in the first six months

- Percentage of women using any modern method of family planning

- Percentage of women with exposure to newspaper, radio and TV.

The detailed list of indicators is given in Appendix $\mathbf{1}$.

\section{Study Area}

For the learning phase, RGMVP concentrated on 10 blocks of eight districts: Sultanpur, Raebareli, Mirzapur, Amethi, Jhansi, Banda, Maharajganj and Hardoi. Among these, intervention was implemented only in one block each of six districts and in two blocks each of the remaining two districts (Sultanpur and Raebareli). In these eight districts, RGMVP covered 100 Gram Panchayats. In these $100 \mathrm{GPs}, 37$ percent households had at least one member belonging to a SHG.

For the baseline survey, initially four districts (Hardoi, Raebareli, Mirzapur and Maharajganj) were selected covering almost 50 percent of the GPs of the learning phase. The selection of districts was 
based on geographical diversity of the learning phase area and the duration of the SHGs. Figure 1.2 shows a map with the location of learning phase districts and selected districts for the baseline survey. Raebareli had the oldest SHGs and Maharajganj the newer ones. The SHGs of the other two districts were at an intermediate stage of duration. During the survey, a substantial number of SHGs were found to be non-functional and many were non-traceable. Since this led to a shortage of the targeted sample size, an additional district (Sultanpur) was taken for the survey. Thus, a total of five districts out of the eight learning phase districts were covered in the baseline survey.

\section{Sample Size}

In order to obtain a sample size that is required to measure the desired changes in all the project indicators, a detailed exercise was done considering 11 different indicators of family health behaviors (Appendix 2). Except for the indicator of modern contraceptive use (which assumes a change of only 7 percentage points as compared to 20 percentage points for other indicators during the project period), the largest sample size required was found for institutional delivery. Estimates from the Population Council's landscaping study were taken as the base value for sample size calculation. According to this study, 44 percent of women had delivered their child in an institution. Assuming a change of 7 percentage points in the first year (assuming a 20 percentage point increase over three years), with 80 percent power, 95 percent confidence level and 10 percent non-response rate, a sample of 878 eligible women from SHG households was required in each arm (intervention arm and control arm).

\section{Figure 1.2: Location of Learning Phase Districts Selected for Baseline Survey}

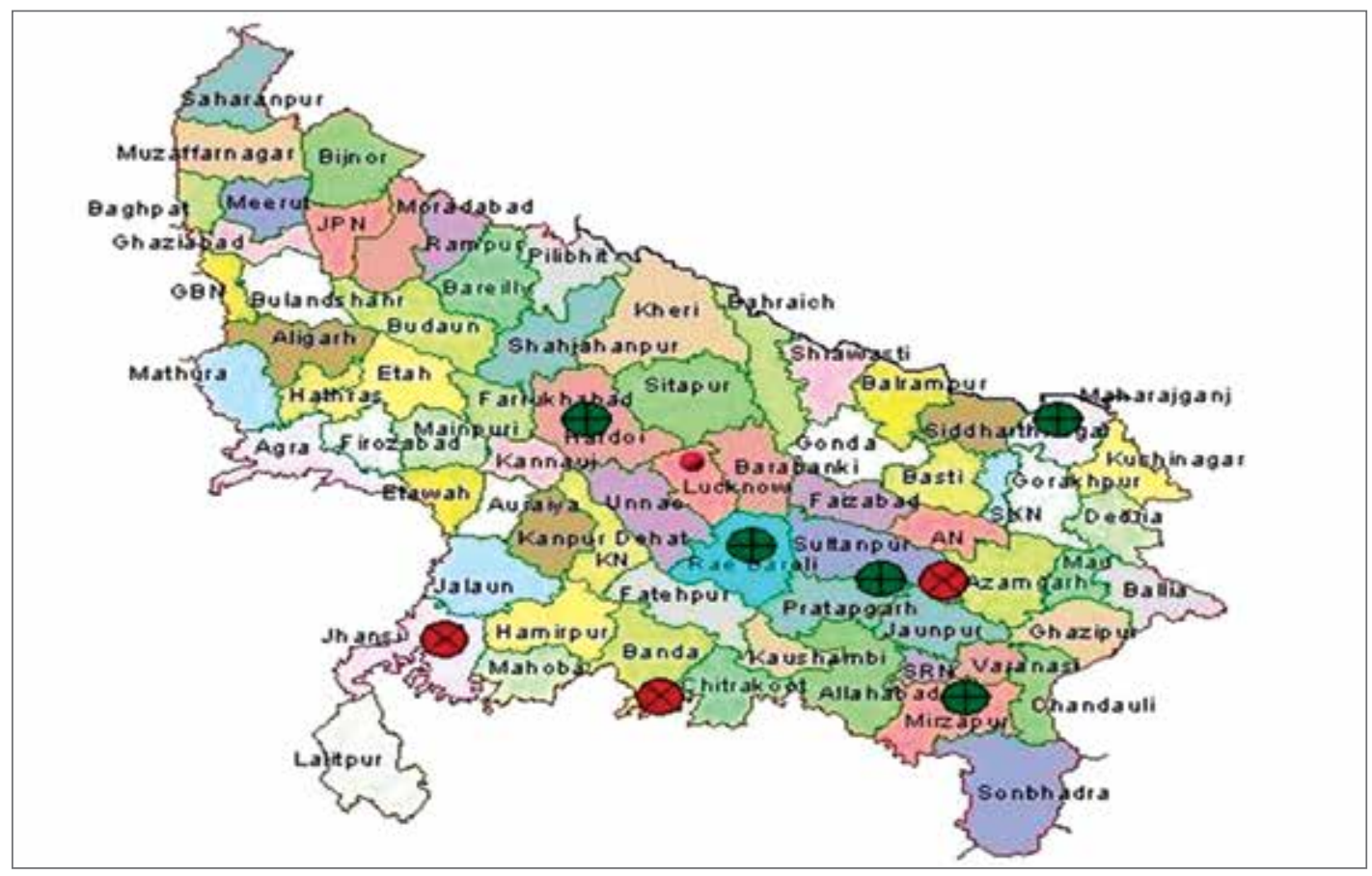

Selected districts for baseline survey (Hardoi, Rae Bareli, Mirzapur, Maharajganj and Sultanpur)

$\bigotimes$ Districts not selected for baseline survey (Amethi, Jhansi and Banda)

Besides this, to assess the diffusion effect in adoption of healthy behaviors, half of the sample number (i.e. half of 878 - 439) was required in the intervention area from households without any SHG member. Thus, the total sample size for the baseline survey was 2,195 eligible women (Table 1.1). 
Table 1.1: Sample Size by Study Arm

\begin{tabular}{|l|c|c|}
\hline Study arm & Type of household & Sample size \\
\hline $\begin{array}{l}\text { Intervention arm } \\
\text { GPs where SHG households would be } \\
\text { exposed to the project's health intervention }\end{array}$ & SHG & 878 \\
\hline $\begin{array}{l}\text { Control arm } \\
\text { GPs where SHG households would not be } \\
\text { exposed to the project's health intervention }\end{array}$ & SHG & 439 \\
\hline Total & & 878 \\
\hline
\end{tabular}

\section{Sampling Design and Selection Procedure}

The sample was selected in two stages: first the selection of districts and then of the required number of households for the study. In each block of the five selected districts, a house listing was done in all villages/purvas of the listed GPs to identify eligible women among SHG households. The house listing included the name of the household's head, the woman's name and the age of her last child to reach during the survey. The initial house listing was done by RGMVP among SHG households revealed that the total number of eligible women was close to the target sample size. Therefore, a complete enumeration of the listed eligible women was done for the task of interviewing eligible women from SHG households in the intervention and control areas.

The eligibility criteria for women to be included in the sampling frame were (a) currently married women aged 15 to 49 years and (b) those who had delivered a baby during 12 months prior to the survey. However, by the end of the survey, when getting the required sample size was becoming difficult, the eligibility criteria was extended to all women who had delivered a baby till 15 months prior to the survey. To identify eligible women from non-SHG households in the intervention area, a listing of non-SHG households was done in the neighborhood of SHG households in each selected village/purva to ensure similar socioeconomic characteristics of women in both the groups. The required number of non-SHG households (half of the sampled SHG households) was selected randomly from each village/purva.

\section{Data Collection}

To ensure quality of data and to avoid time loss in identifying and selecting a survey agency, the Population Council staff themselves conducted the baseline survey. Most of the research investigators had a Masters' degree and experience in carrying out demographic and health surveys. The fieldwork was done from June to August 2013. Data was collected using mini-laptops rather than paper based-questionnaires, which substantially reduced the time that would have gone into data entry. Both the questionnaires were transformed in to a Computer Assisted Personal Interview (CAPI) package using the Census and Survey Processing System (CSPro) software compatible with mini -laptops for the survey. The CAPI package, developed internally by PC, had a series of internal consistency checks and logics to maintain the quality of data. 


\section{Training and Field Work}

All investigators and supervisors received intensive training on the survey questionnaires for 12 days. Three senior professionals from PC conducted the training. A researcher from PHFI also participated in the training as a resource person. The training was divided into three parts:

- Four days for reviewing the paper questionnaire to understand concepts and each question and the respective codes

- Four days for using mini-laptops, getting familiar with CAPI and practice using it

- Two days of field practice and one day of debriefing to get the investigators acquainted with the practical aspects of the training received.

The $12^{\text {th }}$ day of the training was used to orient supervisors about their roles and responsibilities, ethical considerations, the methods of data flow from the field to Population Council's New Delhi office every alternate day and quality assurance measures.

Four teams were formed for data collection. Each team consisted of five female research investigators and one male supervisor. Two teams covered one district. To lead the data collection for every two teams, one senior PC professional was present throughout the survey. One of the PHFI researchers also contributed significantly in the field, along with the PC colleagues, to supervise the progress of data collection. Throughout the survey field staff of RGMVP collaborated and facilitated fieldwork. Table 1.2 gives the targeted and achieved sample size.

Table 1.2: Achievement of Sample Size by Study Arms

\begin{tabular}{|l|c|c|c|}
\hline Study arm & $\begin{array}{c}\text { Type of } \\
\text { household }\end{array}$ & Target sample & Achieved sample \\
\hline $\begin{array}{l}\text { Intervention arm } \\
\text { GPs where SHG households } \\
\text { would be exposed to the } \\
\text { project's health intervention }\end{array}$ & SHG & 878 & $858(98 \%)$ \\
\cline { 2 - 4 } $\begin{array}{l}\text { Control arm } \\
\text { GPs where SHG households } \\
\text { would not be exposed } \\
\text { to the project's health } \\
\text { intervention }\end{array}$ & SHG & 439 & $479(109 \%)$ \\
\hline \multicolumn{1}{|c|}{ Total } & & 878 & $871(99 \%)$ \\
\hline
\end{tabular}

\section{Quality Assurance}

Regular back-checking was done to ensure data quality. A research officer at PC's New Delhi office reviewed data sent from the field and provided appropriate feedback every alternate day to their professional coordinating the teams in the field. Each investigator's performance, skipping pattern and consistency of responses were reviewed and communicated to the supervisors on a weekly basis as part of quality assurance. 


\section{Challenges}

During the survey the field teams faced many challenges, some of which are summarized below:

- The decision to change the eligibility criteria for the sample and include women who had given birth in the last year instead of the last three years reference period as originally planned, forced the survey to cover almost 2.5 times more households.

- The decision to include both type of GPs as the study area -- which had older SHGs, as well as those with recently started SHGs - also created some problems as many of the newer SHGS were non-functional or were difficult to trace in the village. This made covering the required sample size difficult and an additional district had to be included in the baseline survey.

- Many of the selected women were not available as they had gone to their parental home for delivery or for the Raksha Bandhan festival. Besides, many women were working as contracted laborers in the paddy fields and were only available in the evening, so the team had to do data collection till late evening.

Other findings from the baseline survey are presented in the next three chapters. 



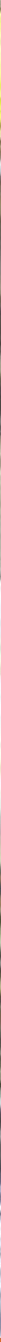

\section{Chapter 2}
Background Characteristics of
Surveyed Women 
This chapter describes the background characteristics of the interviewed women, including their exposure to the media and participation in SHG activities. It also examines the extent to which the intervention and control groups are similar or different in terms of these characteristics. To establish the extent of equivalence between the different arms, comparisons were made between the intervention SHG arm and the control arm as well as between the two intervention arms - members of SHG households and member of the non-SHG households of the same village/purva. Table 2.1 presents the background characteristics of the women interviewed.

\section{Background Characteristics}

Table 2.1. Background Characteristics of Women by Study Arms (percentage)

\begin{tabular}{|c|c|c|c|c|}
\hline Characteristics & $\begin{array}{l}\text { Intervention } \\
\text { SHG arm }\end{array}$ & $\begin{array}{l}\text { Intervention } \\
\text { non-SHG arm }\end{array}$ & $\begin{array}{c}\text { Control } \\
\text { arm }\end{array}$ & Total \\
\hline Mean age of women (years) & $25.6(4.9)$ & $25.4(5.0)$ & $25.6(4.9)$ & $\begin{array}{l}25.6 \\
(4.9)\end{array}$ \\
\hline Mean age of cohabitation (years) & $17.4(2.3)$ & $17.5(2.3)$ & $17.3(2.3)$ & $\begin{array}{l}17.4 \\
(2.3)\end{array}$ \\
\hline Mean number of living children & $2.6(1.5)$ & $2.5(1.4)$ & $2.7(1.7)$ & $\begin{array}{c}2.6 \\
(1.6) \\
\end{array}$ \\
\hline Mean number of total live births & $2.9(1.8)$ & $2.8(1.8)$ & $3.1(2.0)$ & $\begin{array}{c}2.9 \\
(1.9)\end{array}$ \\
\hline $\begin{array}{l}\text { Literate (can read or write or attended } \\
\text { school more than four years) }\end{array}$ & 52.7 & 53.2 & 49.0 & 51.4 \\
\hline $\begin{array}{l}\text { Mean years of } \\
\text { schooling among literate }\end{array}$ & $7.9(3.4)$ & $8.1(4.0)$ & $7.6(3.4)$ & $\begin{array}{l}7.8 \\
(3.5)\end{array}$ \\
\hline Working for cash or kind & 20.6 & 15.9\# & 23.4 & 20.7 \\
\hline \multicolumn{5}{|l|}{ Religion } \\
\hline - Hindu & 93.5 & 92.5 & 92.0 & 92.7 \\
\hline - Muslim & 6.5 & 7.5 & 8.0 & 7.3 \\
\hline \multicolumn{5}{|l|}{ Caste } \\
\hline - Scheduled caste/Scheduled tribe & $49.1 *$ & 46.1 & 60.8 & 53.1 \\
\hline - Other backward classes & $40.3^{*}$ & 40.9 & 26.4 & 35.0 \\
\hline - Others & 10.6 & 13.0 & 12.8 & 11.9 \\
\hline \multicolumn{5}{|l|}{ Wealth index } \\
\hline - Highest & $20.6 * *$ & 23.8 & 17.3 & 20.0 \\
\hline - Second & 21.7 & 17.5 & 19.8 & 20.0 \\
\hline - Middle & $17.4^{*}$ & $22.6 \#$ & 21.1 & 20.0 \\
\hline - Fourth and lowest quintile combined & 40.4 & 36.1 & 41.8 & 40.0 \\
\hline \multicolumn{5}{|l|}{ Type of family } \\
\hline - Nuclear & 43.6 & 51.8 & 42.5 & 44.9 \\
\hline - Non-nuclear & 56.4 & 48.3 & 57.5 & 55.5 \\
\hline Number of women & 858 & 479 & 871 & 2208 \\
\hline
\end{tabular}

1. Note: Figures given in brackets along with the mean are standard deviation

2. * Significant difference between intervention SHG arm and control arm at $<0.05$ level

3. ** Significant difference between intervention SHG arm and control arm at $<0.01$ level

4. \# Significant difference between intervention SHG arm and intervention non-SHG arm at $<0.05$ level 
The mean age was 26 years for all groups. The mean number of living children was 2.6. Half of the women were not literate. Women who were literate had, on an average, completed eight years of schooling. Most of the women were Hindu (93 percent). Around half of the women belonged to SC/ ST and one-third belonged to other backward classes.

Significant differences between the intervention SHG arm and control arm were found for only a few background characteristics such as caste composition and wealth index. For instance, the SC/ ST groups was significantly lower in the intervention arm (49 percent) compared to the control arm (61 percent) $(p<0.05)$. Families with middle and higher wealth indices were in a slightly higher proportion in the intervention arm than in the control arm (Table 2.1). Within the intervention arm, there was a slight difference among categories of working status and wealth index. Besides these variables, the two arms were similar and comparable for socioeconomic background characteristics. Similarly, no significant difference was observed between the SHG households and non-SHG households in the intervention area.

\section{Level of marginalization}

Certain groups have been marginalized and socially excluded from social and economic opportunities. An attempt was made to understand the proportion of marginalized women in the study sample. Marginalization has been defined as those women who belong to SC/ST, are illiterate or belong to the two lowest quartiles of the wealth index. Those who did not belong to any of the three criteria were taken as non-marginalized households. The levels of marginalization were determined by the presence of two criteria, making them doubly marginalized; or by the presence of three criteria, which indicated that they were facing multiple forms of marginalization.

Table 2.2 shows that taking into account all forms of marginalization, a slightly lower proportion of women were marginalized in the intervention SHG arm (76 percent) compared to the control arm (81 percent).

\section{Table 2.2: Level of Marginalization by Study Arms and Distribution of Doubly Marginalized Women (percentage)}

\begin{tabular}{|c|c|c|c|c|}
\hline Levels of marginalization & $\begin{array}{l}\text { Intervention } \\
\text { SHG arm }\end{array}$ & $\begin{array}{l}\text { Intervention } \\
\text { non-SHG arm }\end{array}$ & $\begin{array}{c}\text { Control } \\
\text { arm }\end{array}$ & Total \\
\hline $\begin{array}{l}\text { Marginalized (belonged to any one of the } \\
\text { categories defining marginalization) }\end{array}$ & $76.1^{*}$ & 72.0 & 80.6 & 77.0 \\
\hline \multicolumn{5}{|l|}{ Percent of women with } \\
\hline - Any one form of marginalization & 30.7 & 28.4 & 29.3 & 29.6 \\
\hline - Any two forms of marginalization & 30.3 & 30.3 & 29.6 & 30.0 \\
\hline - Multiple marginalization (all three Forms) & $15.2 * *$ & 13.4 & 21.7 & 17.3 \\
\hline - Not marginalized & 23.9 & 28.0 & 19.4 & 23.0 \\
\hline Number of women & 858 & 479 & 871 & 2208 \\
\hline \multicolumn{5}{|l|}{ Distribution of doubly marginalized women } \\
\hline - SC/ST and not literate & $34.6^{*}$ & 37.9 & 43.4 & 38.7 \\
\hline - SC/ST and lowest two wealth quintiles & 26.2 & 24.1 & 32.6 & 28.2 \\
\hline $\begin{array}{l}\text { Not literate and belong to lowest two } \\
\text { wealth quintiles }\end{array}$ & $39.2 * *$ & 37.9 & 24.0 & 33.0 \\
\hline Number of women doubly marginalized & 260 & 145 & 258 & 663 \\
\hline
\end{tabular}

Note: * Significant difference between intervention SHG arm and control arm at $<0.05$ level

** Significant difference between intervention SHG arm and control arm at $<0.01$ level 
A higher percentage of households in the intervention area (24 to 28 percent) were not marginalized compared to those in the control area (19 percent). Around one-third of women (30 percent) were doubly marginalized or marginalized because of the presence of two forms of marginalization (Table 2.2). There was a significant difference between the intervention SHG arm and control arm with reference to multiple marginalization. The higher marginalization in the control arm was due to a higher proportion of SC/ST population and illiteracy.

\section{Exposure to mass media}

Table 2.3 shows that 71 percent of women were not exposed to any media. Exposure to more than one form of media was very low; less than 10 percent. Around 76 percent households did not have a TV. Even in households that owned a TV (N=537), 15 percent women from the intervention arms, 18 percent from control arm and 13 percent from non-SHG group still did not watch TV. However, the figure for those who own a radio but do not listen to it was much higher, ranging from 47 to 55 percent. A comparison of different arms shows that a slightly higher percent of women in the control arm were not watching TV or reading newspapers (about 5 percentage points in each case) than the experimental arm. No difference was observed in radio listenership.

Table 2.3: Exposure to Mass Media (percentage)

\begin{tabular}{|l|c|c|c|c|}
\hline Responses & $\begin{array}{c}\text { Intervention } \\
\text { SHG arm }\end{array}$ & $\begin{array}{c}\text { Intervention } \\
\text { non-SHG arm }\end{array}$ & $\begin{array}{c}\text { Control } \\
\text { arm }\end{array}$ & Total \\
\hline Not exposed to any media@ & 69.5 & 67.8 & 73.7 & 70.8 \\
\hline TV & 74.9 & 72 & 78.4 & 75.6 \\
\hline - Do not own TV & $73.4^{*}$ & 71.2 & 78.6 & 75 \\
\hline - Do not watch TV & \multicolumn{5}{|l}{} \\
\hline Radio & 88.9 & 90.6 & 89 & 89.3 \\
\hline - Do not own radio & 89.6 & 90.6 & 91.3 & 90.5 \\
\hline - Do not listen to radio & $93.8^{*}$ & 93.7 & 96.3 & 94.8 \\
\hline - Do not read newspapers & $6.8^{*}$ & 7.3 & 4.2 & 5.8 \\
\hline Exposed to any two media & 2.9 & 2.5 & 1.6 & 2.3 \\
\hline Exposed to all three media@ & $\mathbf{8 5 8}$ & $\mathbf{4 7 9}$ & $\mathbf{8 7 1}$ & $\mathbf{2 2 0 8}$ \\
\hline Number of women &
\end{tabular}

Note: * Significant difference between intervention SHG arm and control arm at $<0.05$ level @ $T V$, radio or newspaper

\section{Ownership of mobile phone}

While 90 percent of households owned a mobile phone, only 34 percent of women owned and used their own mobile phone (Figure 2.1). No significant difference was found in ownership of mobile phone at the household level or among women between the study arms. Overall, 76 percent women had access to the mobile phone either through their own phone or through their husband's. Among those who use a mobile phone, around 50 percent mentioned that they could be reached anytime, while around 10 percent said that they could only be reached in the evening or at night (Table 2.4). 
Figure 2.1: Ownership and Use of Mobile Phone among Women, N=2,208

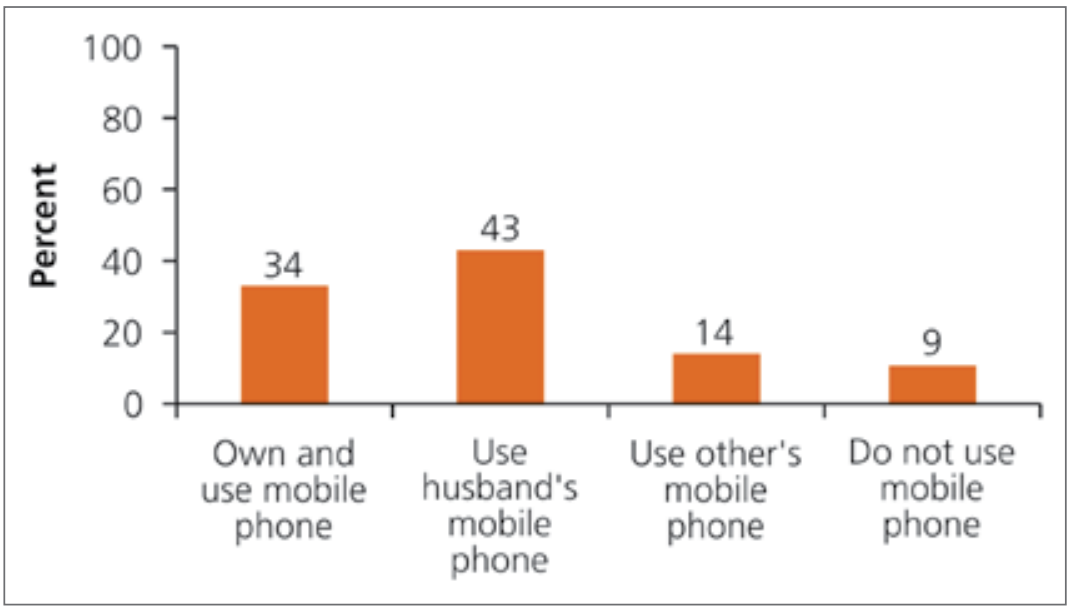

Table 2.4: Timing When Women have Access to Phone (percentage)

\begin{tabular}{|l|c|c|c|c|}
\hline Indicators & $\begin{array}{c}\text { Intervention } \\
\text { SHG arm }\end{array}$ & $\begin{array}{c}\text { Intervention } \\
\text { non-SHG arm }\end{array}$ & $\begin{array}{c}\text { Control } \\
\text { arm }\end{array}$ & Total \\
\hline Women who use a phone & 92 & $86.8 \# \#$ & 90.7 & 91.3 \\
\hline Number of women & 858 & 479 & 871 & 2208 \\
\hline Timing when women can be reached: & & & & \\
\hline - Anytime & 51.9 & 56.7 & 49.4 & 51.9 \\
\hline - Only during morning or night & 11.4 & 10.4 & 14.1 & 12.3 \\
\hline Depends upon the person who owns the phone & 36.7 & 32.9 & 36.5 & 35.8 \\
\hline Number of women & $\mathbf{7 9 0}$ & $\mathbf{4 1 6}$ & $\mathbf{7 9 0}$ & $\mathbf{2 2 0 8}$ \\
\hline
\end{tabular}

Note: Does not add to 100, as few responses were 'others'.

\#\# Significant difference between intervention SHG arm and intervention non-SHG arm at $<0.01$ level

\section{SHG membership and SHG-related activities}

Of the total sample interviewed from SHG households, 66 percent $(N=1,144)$ women were themselves members of SHGs; 65 percent $(\mathrm{N}=555)$ of women from the intervention SHG arm and 68 percent $(N=589)$ from the control arm were SHG members (Table 2.5). From among the rest, in 90 percent of the cases the mother in-law was a SHG member and in 10 percent cases the sister inlaw was a member. The primary reason for joining SHG was expected financial support/ loan. Other reasons were: encouragement from people; their name was added when an SHG was formed; and the elders in the family and the community encouraged them to join a SHG (Figure 2.2). Very few women mentioned reasons such as personal empowerment and/or to increase self-respect in their family and community.

On an average, women had been members of an SHG for 18 months (Table 2.5). The mean duration of SHG membership in the intervention arm (22 months) was significantly higher compared to the control arm (15 months). 35 percent women in the intervention SHG arm and 57 percent women of the control arm had joined an SHG within the last one year. All SHGs are expected to organize weekly meetings that is four meetings per month. Analysis of the baseline data shows that on an average three meetings a month were organized and members reported that they attended two meetings per month. This indicates that not all women attended all the meetings organized 
by their SHG. Around 10 percent reported that a health message had been discussed in the SHG meeting. A significantly higher proportion of women from the intervention SHG arm had taken a loan compared to those belonging to the control arm (44 percent versus 29 percent; $p<0.05$; Table 2.5). SHGs of the intervention arm were relatively of a longer duration than the SHGs of the control arm (Table 2.5). This difference was significant.

Figure 2.2: Reasons for Joining SHG, N=1,144

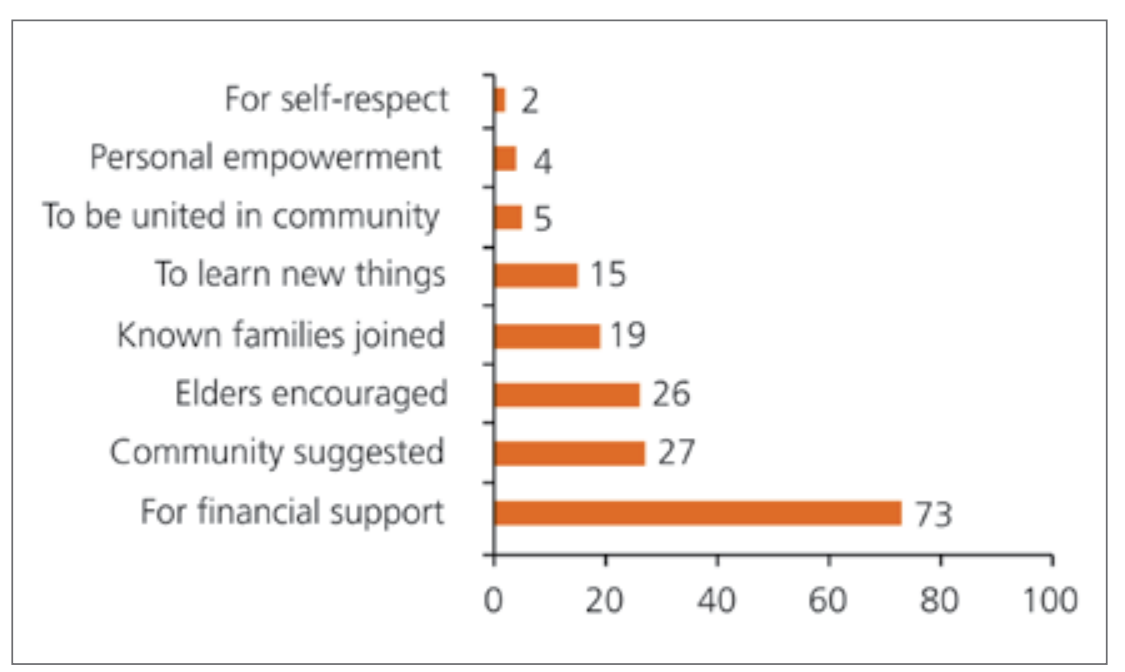

Table 2.5: SHG Membership and SHG-Related Activities

\begin{tabular}{|c|c|c|c|}
\hline Indicators & $\begin{array}{l}\text { Intervention } \\
\text { SHG arm }\end{array}$ & $\begin{array}{l}\text { Control } \\
\text { arm }\end{array}$ & Total \\
\hline Women herself a SHG member & 64.7 & 67.6 & 66.2 \\
\hline Mean duration of SHG membership of women in months & $22.0(17.9) *$ & $15.0(13.9)$ & $18.0(16.4)$ \\
\hline Mean number of meetings organized in a month & $2.8(1.4)$ & $2.8(1.4)$ & $2.8(1.4)$ \\
\hline Mean number of meetings attended in a month & $1.9(1.5)$ & $2.0(1.5)$ & $1.9(1.5)$ \\
\hline Any health message in SHG meeting & 10.5 & 8.3 & 9.4 \\
\hline SHG meeting held at woman's home & 28.0 & 25.7 & 26.8 \\
\hline $\begin{array}{l}\text { Ever met any member/NGOs working for water and } \\
\text { sanitation }\end{array}$ & 3.8 & 4.1 & 4.0 \\
\hline Ever taken loan & $43.6^{*}$ & 28.7 & 35.9 \\
\hline Average number of loans taken & 1.6 & 1.7 & 1.6 \\
\hline \multicolumn{4}{|l|}{ Purpose of loan } \\
\hline $\begin{array}{l}\text { - Livelihood (purchase livestock, agriculture, start } \\
\text { grocery shop, purchase vehicle) }\end{array}$ & 44.2 & 42.6 & 43.6 \\
\hline - Treatment of illness & 31.0 & 32.5 & 31.6 \\
\hline - Delivery/complications & 5.8 & 7.7 & 6.6 \\
\hline $\begin{array}{l}\text { - Welfare (marriage, education of } \\
\text { children, house repairing) }\end{array}$ & $26.1 * \star$ & 21.3 & 24.1 \\
\hline Total & 555 & 589 & 1729 \\
\hline
\end{tabular}

Note: Figures given in brackets along with the mean are standard deviation

* Significant difference between intervention SHG arm and control arm at $<0.05$ level

** Significant difference between intervention SHG arm and control arm at $<0.01$ level 
A significantly higher proportion (13 percent) of women who had been SHG members for up to six months had taken loans in the intervention arm compared to the control arm (4 percent) (Figure 2.3). Data analysis also revealed that in both the arms, SHGs with members of a longer duration had organized and attended more meetings in a month. In other words, the number of meetings per month increases with the duration of SHGs. Similarly, the number of meetings organized and attended by the members also increases with the duration of SHG membership (Figure 2.4 and Table 2.6). No significant difference was found in the mean number of meetings organized by longer duration SHGs of the intervention arm compared to the control arm.

The mean number of meetings organized by SHGs of shorter duration also had no significant differences.

Figure 2.3: Percentage of SHG Members Who Have Taken Loan by Duration of SHG Membership

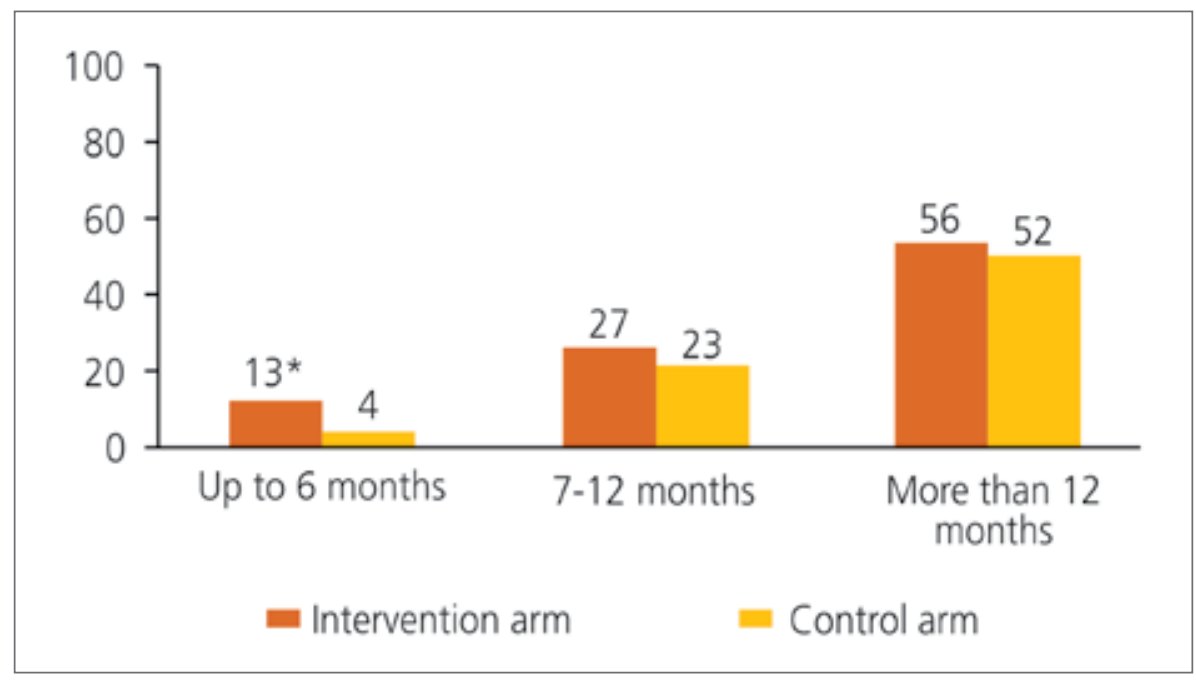

*Significant difference between intervention SHG arm and control arm at $<0.05$ level

However, it is important to point out that around 20 percent SHGs in the experimental and 12 percent in the control arm were organizing none or only one meeting in a month, even though they were 12 or more months old. An investigation is needed to identify the reasons for such deviation from the norms.

Figure 2.4: Average Number of Meetings Organized Per Month by Duration of SHG Membership

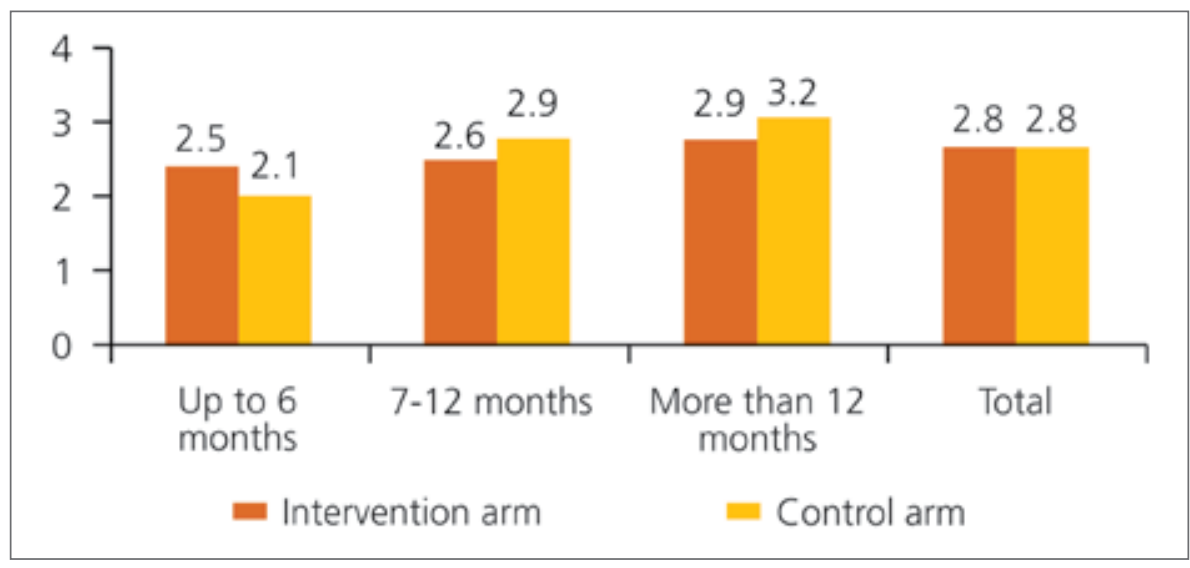


Table 2.6: Average and Median Number of Meetings Attended in a Month by Duration of SHG Membership

\begin{tabular}{|l|c|c|c|c|}
\hline $\begin{array}{l}\text { Mean duration of } \\
\text { SHG membership }\end{array}$ & \multicolumn{2}{|c|}{ Intervention SHG arm } & \multicolumn{2}{c|}{ Control arm } \\
\hline & Mean & Median & Mean & Median \\
\hline Up to 6 months (SD) & $1.4(1.45)$ & 1.0 & $1.4(1.40)$ & 1.0 \\
\hline 7-12 months (SD) & $1.7(1.49)$ & 1.0 & $1.9(1.51)$ & 2.0 \\
\hline$>12$ months (SD) & $2.0(1.48)$ & 2.0 & $2.3(1.42)$ & 2.0 \\
\hline Total (SD) & $1.9(1.50)$ & 2.0 & $1.9(1.49)$ & 2.0 \\
\hline Number of women & \multicolumn{2}{|c|}{$\mathbf{5 5 5}$} & \multicolumn{2}{|c|}{$\mathbf{5 8 9}$} \\
\hline
\end{tabular}

\section{Conclusion}

The analysis shows that in general, all the three arms of the study were fairly matched with respect to the socioeconomic background characteristics of the women interviewed. In some cases small differences were observed but those were not significant and may not affect the study results. For example, the percentage of SC/ST population was lower in the intervention arm than in the control arm. More than two-thirds of SHG members belonged to the marginalized segment of the population. Many of them were doubly marginalized or marginalized because of the presence of multiple forms of marginalization. Hence, the survey also confirms RGMVP's effort to work largely with the marginalized population.

Around two-thirds of women were not exposed to any mass media and hence reaching them with family health messages is a challenge and the only way to inform them could be through interpersonal communication. In such situations SHG members and community-based healthcare providers (e.g. ASHA and AWW) could be a potential channel.

Mobile ownership was high at the household level; but only one-third of women had their own mobile phone which they could use at any time. The rest of the women felt that they could access their husband's or some family member's mobile phone but mostly in the morning and night since their husbands or family members were away from the family for work during the daytime. The extent to which mobile phones should be used to disseminate messages on family health behaviors or stimulate discussion within the family by providing messages to men needs further investigation.

It was initially anticipated that most women who were members of SHGs were the elderly women of the family, since SHGs are primarily a forum to promote financial inclusion of the most disadvantaged women through micro-financing and such decisions are made by the elders of the family. The survey results show that out of the surveyed women who had delivered a child 15 months prior to the survey, around two-thirds were members of RGMVP SHGs themselves. This is an encouraging finding, as the messages discussed during the SHG meetings will directly reach the intended audience. Newly developed SHGs take about six months to start organizing regular weekly meetings. Further, more than half of the SHGs which were older than 12 months were organizing around three meetings and the women members were attending two meetings every month. One worrying observation was that around one-fifth of the SHGs despite being 12 or more months old either were not organizing any meeting or organizing just one meeting in a month. The reasons for such differences between SHGs need to be investigated as these meetings (and attendance at the 
meetings) are important both for the RGMVP program as well as for the BCM health intervention. Working with SHG forums which have little activity may not yield effective results.

Understandably, for two-thirds of the SHG members, the financial support/ loan which they could get from banks by participating in SHGs, was the most important motivational factor to join an SHG. The analysis also shows that two-thirds of the women were members of SHGs for 12 months or more and had availed a loan on an average 1.6 times; 40 percent of these loans were taken for starting livelihood activities. However, around one-third of women had also taken a loan for medical treatment/ emergencies. It is still helpful as the interest they pay to the SHG on the loan taken is much less than the interest on the loan they would have to give to money lenders in the absence of SHGs. 

This chapter aims to study the status of maternal health behaviors by study arms. It also explores the possible reasons and socioeconomic and cultural barriers that lead to people not practicing healthy behaviors and brings out the key determinants of healthy behaviors to provide feedback to strengthen the intervention.

Given the nature of the intervention, SHGs are expected to be formed largely for the poor and marginalized to meet the objective of the study. Thus the key question that needs to be addressed is whether the intervention has helped in changing targeted family health behaviors, particularly among the most marginalized groups. Thus, while planning and presenting the analyses, marginalization has been taken as an important variable.

\section{Results}

\section{Pregnancy period}

\section{Contacts with the health system and frontline workers}

Women's contacts with different frontline workers and attending VHND during pregnancy is crucial for receiving advice on pregnancy and postpartum care, especially in rural areas. Receiving advice from a credible source is an important predictor of practice of healthy behaviors (Agrawal et al. 2012). Contact with frontline health workers is important in the context of rural UP as the majority of women have little or no exposure to any media, are illiterate and marginalized.

The findings show that during pregnancy, most women (91 percent) had some contact with at least one FLW; 81 percent reported contact with the ANM, 78 percent with an ASHA and a little over one-third with the AWW (Figure 3.1) during their last pregnancy. However, 9 percent of the women did not have any contact with a healthcare provider. Among those who had any contact, the average number of contacts with a FLW varied from two to three times during the pregnancy period - 2.4 times with the ANM, 3.2 times with the ASHA and 3.1 times with the AWW (Table 3.1).

\section{Figure 3.1: Women's Contacts with Health Workers During Pregnancy}

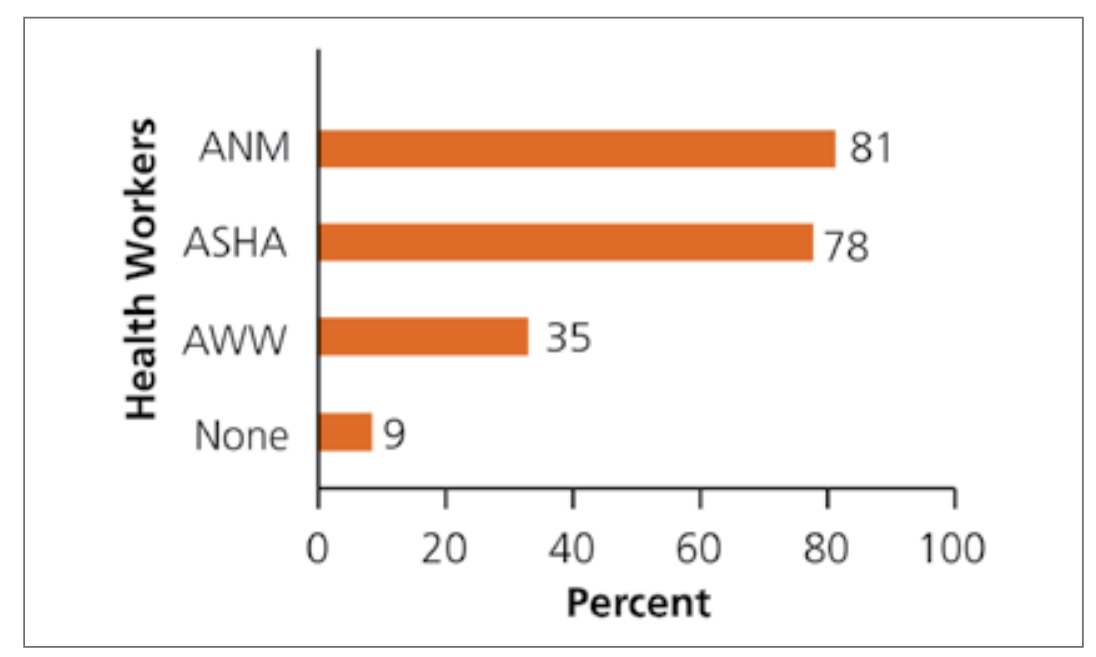

More than half (58 percent) of the women had not attended the VHND and only one-third had attended the VHND two or more times (Table 3.1). Even though pregnant women are entitled to supplementary food from the AWC, almost half of them (45 percent) had not received 
supplementary food. Among those who received supplementary food from the AWC, the majority of them either shared it with someone else in the family or gave it to others. Very few women (5 percent) had consumed it themselves.

There was no difference in contacts with different FLWs between women of the two study arms. However, VHND attendance of two or more times was slightly higher in the intervention SHG arm than the control arm (36 percent compared to 32 percent; $p<0.05$ ). But AWC supplementary food was consumed less in the intervention SHG arm, compared to the control arm (6 percent and 10 percent; $p<0.05$ respectively).

Table 3.1: Women's Contacts with FLWs and Exposure to VHND and AWC during Last Pregnancy by Study Arms

\begin{tabular}{|c|c|c|c|c|}
\hline Result & $\begin{array}{c}\text { Intervention } \\
\text { SHG arm }\end{array}$ & $\begin{array}{l}\text { Intervention } \\
\text { non-SHG arm }\end{array}$ & $\begin{array}{l}\text { Control } \\
\text { arm }\end{array}$ & Total \\
\hline \multicolumn{5}{|l|}{ Contacts with FLW } \\
\hline - ANM & 81.4 & 80.2 & 81.4 & 81.1 \\
\hline - ASHA & 79.5 & 76.2 & 77.8 & 78.1 \\
\hline - AWW & 37.2 & 35.9 & 33.2 & 35.3 \\
\hline - SHG Swasthya Sakhi & 2.4 & - & 2.4 & 2.0 \\
\hline - None & 8.6 & 10.4 & 8.8 & 9.1 \\
\hline \multicolumn{5}{|c|}{ Average number of contacts with FLW those who contacted } \\
\hline - ANM & 2.3 & 2.4 & 2.4 & 2.4 \\
\hline - ASHA & 3.3 & 3.1 & 3.0 & 3.2 \\
\hline - AWW & 3.2 & 3.0 & 3.1 & 3.1 \\
\hline - SHG Swastha Sakhi & 3.6 & - & 2.4 & 3.1 \\
\hline \multicolumn{5}{|l|}{ VHND attended } \\
\hline - Never & $55.6^{\star}$ & 56.8 & 61.8 & 58.3 \\
\hline - Once & 8.4 & 6.7 & 6.7 & 7.3 \\
\hline - Two or more times & $36.0 *$ & 36.5 & 31.6 & 34.4 \\
\hline \multicolumn{5}{|c|}{ Status of supplementary food from AWC } \\
\hline - Not received & 45.0 & 43.0 & 44.8 & 44.5 \\
\hline - Received and consumed & 3.1 & 4.7 & 5.4 & 4.3 \\
\hline $\begin{array}{l}\text { - Received but sometimes shared } \\
\text { with others in the family }\end{array}$ & 35.5 & 35.7 & 34.9 & 35.3 \\
\hline $\begin{array}{l}\text { - Received but did not consume } \\
\text { (gave to others) }\end{array}$ & 16.4 & 16.6 & 14.8 & 15.8 \\
\hline Number of women & 858 & 479 & 871 & 2208 \\
\hline
\end{tabular}

* Significant difference from control arm at $<0.05$ level

Note: Swasthya Sakhis are members of SHGs, hence are present in the intervention and control arms where SHGs have been formed. Swasthya Sakhis are not present in the intervention non-SHG arm. 
Table 3.2: Perceived Risk in Absence of ANC among Women by Study Arms (percentage)

\begin{tabular}{|l|c|c|c|c|}
\hline Response & $\begin{array}{c}\text { Intervention } \\
\text { SHG arm }\end{array}$ & $\begin{array}{c}\text { Intervention } \\
\text { non-SHG arm }\end{array}$ & $\begin{array}{c}\text { Control } \\
\text { arm }\end{array}$ & Total \\
\hline \multicolumn{5}{|l|}{ Will not be able to know if } \\
\hline - There is any risk for mother & 55.4 & 50.1 & 56.8 & 54.8 \\
\hline - There is any risk for child & 52.6 & 48.6 & 51.8 & 51.4 \\
\hline - There is any risk for delivery & 19.6 & 17.7 & 20.1 & 19.4 \\
\hline - Growth of child is normal & 17.5 & 16.1 & 19.3 & 17.9 \\
\hline - Any precautions need to be taken & 12.4 & 14.8 & 10.4 & 12.1 \\
\hline - Pregnancy is normal or not & 8.5 & 10.2 & 9.9 & 9.4 \\
\hline - Nutrition status of woman is satisfactory or not & 7.6 & 6.7 & 7.2 & 7.2 \\
\hline Do not know & 16.6 & 19.2 & 16.5 & 17.1 \\
\hline Number of women & $\mathbf{8 5 8}$ & $\mathbf{4 7 9}$ & $\mathbf{8 7 1}$ & $\mathbf{2 2 0 8}$ \\
\hline
\end{tabular}

\section{Awareness and knowledge related to antenatal care}

The knowledge of risks of not getting ANC was far from universal. Only about half of the women reported that if they did not go for ANC they would not be able to know if there was any risk for the mother or child (Table 3.2). Other perceived risks were that they would not know if there was any risk of pregnancy or delivery complications or whether the growth of the child was normal. Each of these risks was perceived by around one-fifth of women. Almost 17 percent of the women did not know the risks involved in not taking ANC check-ups. A comparison of results by different study arms did not reveal any major differences in perceived risks in this context.

More than half the women were aware that one must receive three or more ANC check-ups; 9 out of 10 were aware of the need to take two TT injections but less than one-third of the women knew about the need to consume 100 or more IFA tablets (Table 3.3). In terms of tests, 55 percent had the knowledge that during an antenatal checkup an abdominal examination needs to be done, 44 percent knew about the urine test, 41 percent knew of the blood test, and only 7 percent were aware that blood pressure and weight measurement have to be done during each ANC. About 28 percent women were not aware of any tests that are required during ANC. No significant differences were observed on these aspects across the three study arms.

\section{Table 3.3: Correct Knowledge of Maternal Healthy Behaviors among Women by Study Arms (percentage)}

\begin{tabular}{|l|c|c|c|c|}
\hline Knowledge & $\begin{array}{c}\text { Intervention } \\
\text { SHG arm }\end{array}$ & $\begin{array}{c}\text { Intervention } \\
\text { non-SHG arm }\end{array}$ & $\begin{array}{c}\text { Control } \\
\text { arm }\end{array}$ & Total \\
\hline Going for at least three ANC & 58.2 & 52.4 & 55.3 & 55.8 \\
\hline Taking at least two TT injections & 91.8 & 89.8 & 90.0 & 90.7 \\
\hline Consuming 100 or more IFA tablets & 27.5 & 27.1 & 29.6 & 28.3 \\
\hline Health examination during ANC \\
\hline - Abdominal examination & 54.1 & 52.4 & 57.5 & 55.1 \\
\hline - Urine test & 45.8 & 41.5 & 44.3 & 44.3 \\
\hline - Blood test & 41.8 & 39.2 & 40.0 & 40.5 \\
\hline - Blood Pressure measurement & 7.5 & 8.1 & 7.1 & 7.5 \\
\hline - Weight taken & 7.8 & 6.9 & 6.4 & 7.1 \\
\hline Do not know & 26.5 & 29.0 & 28.7 & 27.9 \\
\hline Number of women & $\mathbf{8 5 8}$ & $\mathbf{4 7 9}$ & $\mathbf{8 7 1}$ & $\mathbf{2 2 0 8}$ \\
\hline
\end{tabular}




\section{Maternal health advice}

Women were asked about the health advice they received during pregnancy. About one-third of the women were told the importance of rest and proper care during pregnancy. However, specific advice on the ANC tests and care was much less. It varied between 22 percent for undergoing at least three ANC check-ups to only 1 percent for deworming (Table 3.4); 21 percent women had not received any advice for the care they need to take during pregnancy. No difference was observed on these aspects between the three study arms of the study. The major sources of advice were elders in the family or friends ( 56 percent), ASHA (54 percent) and the ANM/LHV (30 percent). Few women had received advice from the AWWs (7 percent) and SHG Swasthya Sakhis (3 percent).

\section{Table 3.4: Women who Received Advice on Maternal Healthy Behavior during Pregnancy by Study Arms (percentage)}

\begin{tabular}{|l|c|c|c|c|}
\hline Advice & $\begin{array}{c}\text { Intervention } \\
\text { SHG arm }\end{array}$ & $\begin{array}{c}\text { Intervention } \\
\text { non-SHG arm }\end{array}$ & $\begin{array}{c}\text { Control } \\
\text { arm }\end{array}$ & Total \\
\hline To go for at least three ANC & 23.4 & 17.7 & 21.7 & 21.5 \\
\hline To take deworming tablets & 1.5 & 0.6 & 1.6 & 1.4 \\
\hline Importance of rest and proper care & 62.9 & 57.2 & 60.8 & 60.9 \\
\hline Symptoms of pregnancy complications & 9.4 & 8.1 & 10.0 & 9.4 \\
\hline What to do in pregnancy complications & 10.4 & 10.2 & 10.8 & 10.5 \\
\hline Benefits of delivering at a health facility & 17.4 & 17.7 & 15.3 & 16.6 \\
\hline No advice received & 19.2 & 21.3 & 22.7 & 21.1 \\
\hline Number of women & $\mathbf{8 5 8}$ & $\mathbf{4 7 9}$ & $\mathbf{8 7 1}$ & $\mathbf{2 2 0 8}$ \\
\hline
\end{tabular}

\section{Uptake of ANC checkups}

Uptake of ANC remains far from universal. Only 51 percent women received three or more ANC check-ups. However, only 19 percent had received 100 or more IFA tablets though only 8 percent had consumed 100 or more IFA tablets. Only 4 percent women had taken deworming tablets at least once (Table 3.5). The survey conducted by IDEAS in UP in 2013 reported similar findings: 75 percent women had received at least one ANC check-up, while 29 percent had received four or more ANC check-ups. In general no differences were observed in the three study arms.

\section{Table 3.5: Women who Practiced Healthy Behaviors during Pregnancy by Study Arms (percentage)}

\begin{tabular}{|l|c|c|c|c|}
\hline Result & $\begin{array}{c}\text { Intervention } \\
\text { SHG arm }\end{array}$ & $\begin{array}{c}\text { Intervention } \\
\text { non-SHG arm }\end{array}$ & $\begin{array}{c}\text { Control } \\
\text { arm }\end{array}$ & Total \\
\hline At least three ANC & 51.5 & 50.1 & 51.0 & 51.0 \\
\hline Received 100 or more IFA tablets & 18.3 & 18.8 & 20.6 & 19.3 \\
\hline Consumed 100 or more IFA tablets & 7.9 & 8.6 & 7.6 & 7.9 \\
\hline Consumed deworming tablets at least once & 3.5 & 3.5 & 4.4 & 3.8 \\
\hline $\begin{array}{l}\text { At least three tests (blood test, BP and } \\
\text { abdominal exam.) }\end{array}$ & 25.4 & 24.2 & 22.0 & 23.8 \\
\hline $\begin{array}{l}\text { All five key test(abdominal exam, urine test, } \\
\text { blood test, BP and weight taken }\end{array}$ & 15.6 & 15.4 & 12.4 & 14.3 \\
\hline Number of women & $\mathbf{8 5 8}$ & $\mathbf{4 7 9}$ & $\mathbf{8 7 1}$ & $\mathbf{2 2 0 8}$ \\
\hline
\end{tabular}

* Significant difference from control arm at $<0.05$ level 
The quality of ANC received varied. For instance, except receiving an abdominal examination (57 percent) and getting a urine test (42 percent), only one-third of women had got other important tests like blood test, BP measurement and weight measurement done at least once during the last pregnancy (Figure 3.2). Further, only one-fourth of women had received all the three key examinations at least once during their last pregnancy - blood test, BP and abdominal examination. Only 14 percent women had received all the five examinations (abdominal exam, urine test, blood test, BP and weight taken) (Table 3.5). The situation was similar in all arms.

The analysis shows that a perception that there was no need for an ANC examination for a normal pregnancy was the main reason for women not going for an ANC check-up or taking less than the three required ANC check-ups (Table 3.6). For example, 52 percent women reported that their pregnancy was normal so they did not consider going for the minimum recommended three ANC check-ups. Other reported reasons included costs, lack of awareness about where to go for the check-ups and lack of encouragement from elders for the check-up. It is important that behavior change communication messages emphasize that normal pregnancy is no guarantee that it could not become a complicated pregnancy/delivery and hence at least three ANC check-ups are a must.

Figure 3.2: Percent of Women Examined for Components of ANC During Pregnancy

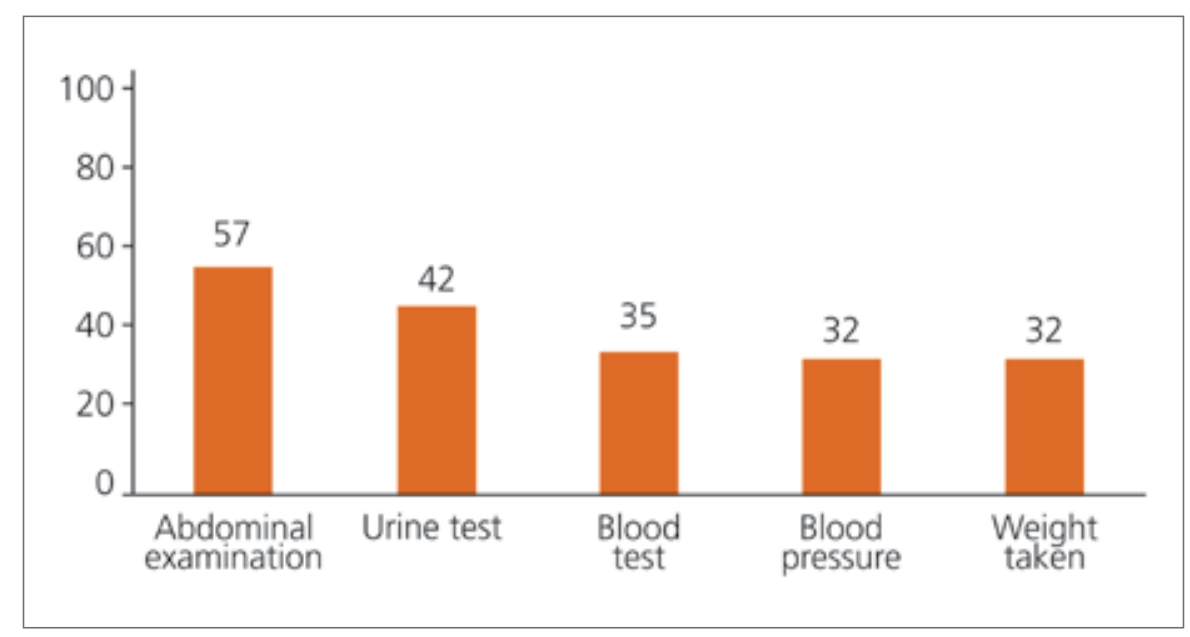

\section{Determinants of $3+$ ANC}

Table 3.7 shows the logistic regression results for the determinants for $3+$ ANC. Women who had three or more contacts with ASHAs were 2.2 times more likely to avail of three or more ANC check-ups than women who had no contact with an ASHA. Other factors such as caste, education and wealth were found to be significant determinants for availing three or more ANC checks. SC/ ST women were less likely to avail them than women from other castes; illiterate women or those with up to five years of education were almost half less likely to take them than women with 10 years or more education. Also, women who belonged to households of the fourth and lowest wealth quintiles were around 40 percent less likely to go in for three or more ANC services than women belonging to households of the highest wealth quintile. A combination of the lower levels of the three parameters (caste, education and wealth) makes the family much more vulnerable. For example, multiple marginalized women were 72 percent less likely, double marginalized women were 65 percent less likely and single marginalized women were 44 percent less likely to avail $3+$ ANC than women who were not marginalized (Figure 3.3). 
These parameters, hence, could be used for segmentation of the population for focused interventions. However, in practical terms, caste is the easiest parameter for segmentation of population for a more effective intervention.

Table 3.6: Reasons for Not Going for any ANC and 3+ ANC

\begin{tabular}{|l|c|c|}
\hline Response & \multicolumn{2}{|c|}{ Reasons for not going for } \\
\hline & Any ANC & 3+ ANC \\
\hline Pregnancy was normal & 51.6 & 52.7 \\
\hline Did not feel it is necessary & - & 24.9 \\
\hline Was not aware & - & 18.6 \\
\hline No one informed where to go & 19.9 & - \\
\hline Costs too much & 12.3 & 10.2 \\
\hline Do not know where to go & 11.5 & - \\
\hline No one available to accompany & 10.9 & 9.6 \\
\hline Elders in family did not support & 10.1 & 11.5 \\
\hline Facility too far & 6.0 & 4.6 \\
\hline ANM not visited & - & 3.9 \\
\hline Unsure of quality & 5.5 & - \\
\hline Did not get time & 3.0 & 3.5 \\
\hline No transportation & 3.0 & 2.2 \\
\hline Unsure of availability of provider & 2.7 & - \\
\hline Number of women & $\mathbf{3 6 6}$ & $\mathbf{7 1 6}$ \\
\hline
\end{tabular}

Figure 3.3: Odds Ratio of 3+ ANC According to Level of Marginalization

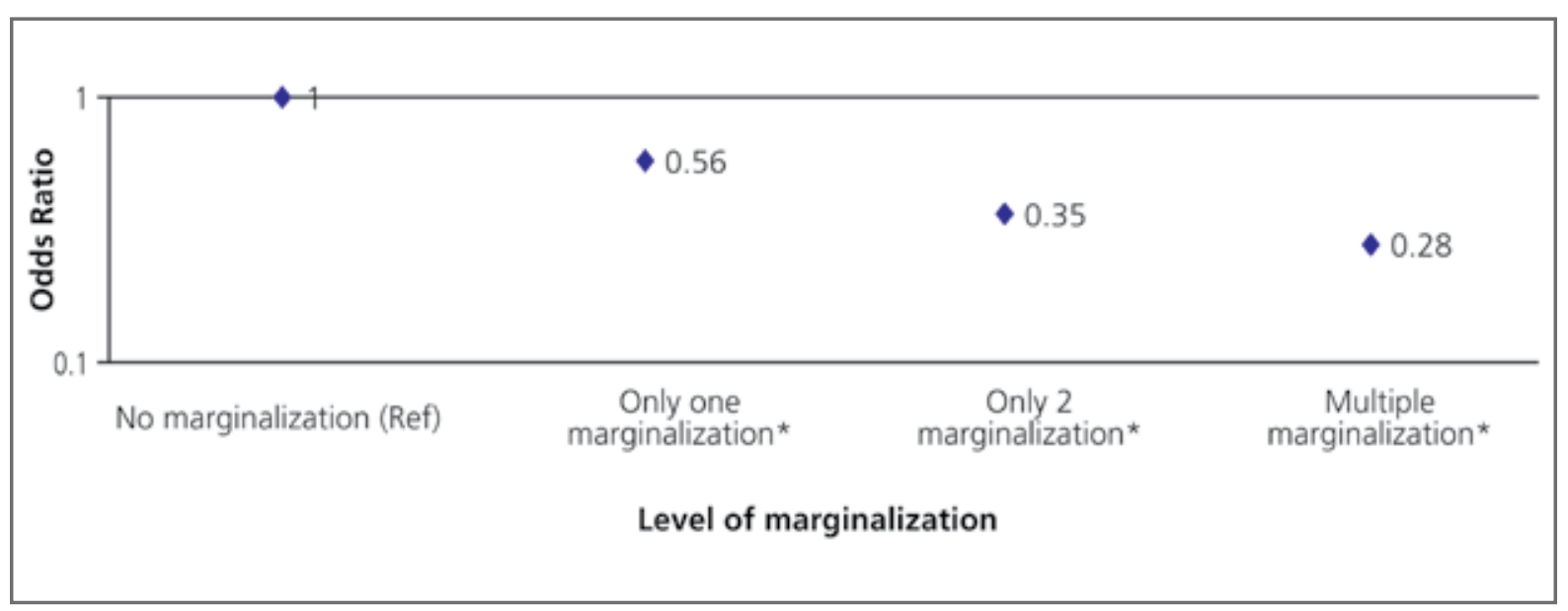




\section{Delivery period}

\section{Delivery preparedness}

Delivery preparedness has been explored on two perspectives - one, advice received on delivery preparedness and second, actual practice during the last delivery. For the study, delivery preparedness includes saving money, arranging transport, deciding place of delivery (home or institution) and identifying the institution to rush to for delivery in case of a complication.

Overall, only 43 percent women had received any advice on at least three key delivery preparedness factors (save money, arrange transport and identify institution) (Table 3.8). Except for advice on saving money (34 percent), advice on arranging transport, deciding place of delivery and identifying an institution was substantially low (ranging from 12 percent to 17 percent). Almost 60 percent women did not receive any advice on of the three key delivery preparedness factors. There was no difference between the intervention non-SHG arm and control arm about advice received on delivery preparedness. However, advice received on identifying an institution and deciding place of delivery was slightly higher in the intervention SHG arm than in the control arm (15 percent compared to 11 percent; 19 percent compared to 13 percent respectively; $p<0.05)$.

Overall, 42 percent women did at least one of the three key delivery preparedness requirements (save money, arrange transport and identify institution) (Table 3.9). Among these three, saving of money was reported in highest proportion, by 37 percent of the women. The PC landscaping survey also reported that 33 percent saved money as preparation for delivery, followed by 15 percent who arranged transport and only 8 percent identified an institution. Other practices for delivery preparedness were quite poor (ranging from 2 percent to 17 percent) in the baseline survey. The IDEAS survey also reported that 50 percent women practiced any one component of delivery preparedness. There were no differences in delivery preparedness practice between the intervention non-SHG arm and the control arm (Table 3.9). However, the practice of saving money was slightly higher in the intervention SHG arm than the control arm (45 percent compared to 40 percent; $p<$ 0.05).

Table 3.7: Determinants of Receiving Three or more ANC: Logistic Regression Results

\begin{tabular}{|c|c|}
\hline Determinants & Odds Ratio \\
\hline \multicolumn{2}{|c|}{ Number of contacts with ASHA } \\
\hline $0 ®$ & 1.00 \\
\hline 1 & 0.96 \\
\hline 2 & 0.87 \\
\hline 3 & $2.15^{\star}$ \\
\hline $4+$ & $2.27 *$ \\
\hline \multicolumn{2}{|c|}{ Exposure to any of three media } \\
\hline Not exposed® & 1.00 \\
\hline Exposed & 1.13 \\
\hline \multicolumn{2}{|c|}{ Women's age groups in years } \\
\hline $25-49 \circledast$ & 1.00 \\
\hline $15-24$ & 0.88 \\
\hline
\end{tabular}




\begin{tabular}{|c|c|}
\hline Determinants & Odds Ratio \\
\hline \multicolumn{2}{|c|}{ Caste } \\
\hline Others $®$ & 1.00 \\
\hline $\mathrm{OBC}$ & 0.66 \\
\hline SC/ST & $0.51 *$ \\
\hline \multicolumn{2}{|c|}{ Education, years of schooling } \\
\hline $10+\AA$ & 1.00 \\
\hline $6-10$ & 0.72 \\
\hline $1-5$ & $0.59 *$ \\
\hline 0 (Illiterate) & $0.46^{*}$ \\
\hline \multicolumn{2}{|c|}{ Wealth index } \\
\hline Highest $\circledast$ & 1.00 \\
\hline Second & 0.86 \\
\hline Middle & 0.74 \\
\hline Fourth & $0.59 *$ \\
\hline Lowest & $0.61 *$ \\
\hline \multicolumn{2}{|c|}{ Study arms } \\
\hline Control SHG® & 1.00 \\
\hline Intervention SHG & 0.94 \\
\hline Intervention non-SHG & 0.85 \\
\hline
\end{tabular}

${ }^{*} p<0.05$

${ }^{\circledR}$ denotes the reference category

Table 3.8: Women who Received Advice on Delivery

Preparedness by Study Arms (percentage)

\begin{tabular}{|l|c|c|c|c|}
\hline Response & $\begin{array}{c}\text { Intervention } \\
\text { SHG arm }\end{array}$ & $\begin{array}{c}\text { Intervention } \\
\text { non-SHG arm }\end{array}$ & $\begin{array}{c}\text { Control } \\
\text { arm }\end{array}$ & Total \\
\hline To save money for delivery & 35.3 & 31.7 & 33.3 & 33.7 \\
\hline To arrange transport for delivery & 18.5 & 17.3 & 16.0 & 17.3 \\
\hline To decide place of delivery & $19.3^{*}$ & 14.4 & 13.1 & 15.8 \\
\hline To identify institution for delivery & $14.5^{*}$ & 10.0 & 11.3 & 12.2 \\
\hline $\begin{array}{l}\text { At least one of three key delivery } \\
\text { preparedness practices\# }\end{array}$ & $45.2^{*}$ & 41.3 & 40.4 & 42.5 \\
\hline Number of women & $\mathbf{8 5 8}$ & $\mathbf{4 7 9}$ & $\mathbf{8 7 1}$ & $\mathbf{2 2 0 8}$ \\
\hline
\end{tabular}

\# save money, arrange transport and identify institution to rush to in case of complication * Significant difference from control arm at $<0.05$ level

\section{Place of delivery}

Almost all (96 percent) women were aware of JSY. More than two-thirds (68 percent) of the deliveries in the study area took place at institutions (Table 3.10), which is a significant rise from 44 percent reported in the 2009 landscaping survey in UP. The IDEAS survey conducted in 2013 also reported 76 percent institutional delivery in UP. The majority of the institutional deliveries had taken place in public facilities (84 percent) and around 16 percent in private facilities. The survey showed that 90 percent deliveries were reported to be normal and about 5 percent C-sections (Table 3.9). 
Table 3.9: Women who Practiced Delivery Preparedness by Study Arms (percentage)

\begin{tabular}{|l|c|c|c|c|}
\hline Response & $\begin{array}{l}\text { Intervention } \\
\text { SHG arm }\end{array}$ & $\begin{array}{l}\text { Intervention } \\
\text { non-SHG arm }\end{array}$ & $\begin{array}{l}\text { Control } \\
\text { arm }\end{array}$ & Total \\
\hline Saved money & $40.6^{*}$ & 34.0 & 35.1 & 37.0 \\
\hline Arranged transport & 17.8 & 15.9 & 17.3 & 17.2 \\
\hline Decided place of delivery & 14.5 & 10.0 & 11.3 & 12.2 \\
\hline Identified institution & 2.9 & 0.8 & 2.8 & 2.4 \\
\hline $\begin{array}{l}\text { At least one of three key delivery } \\
\text { preparedness practices\# }\end{array}$ & $45.0^{*}$ & 39.5 & 39.5 & 41.6 \\
\hline Number of women & $\mathbf{8 5 8}$ & $\mathbf{4 7 9}$ & $\mathbf{8 7 1}$ & $\mathbf{2 2 0 8}$ \\
\hline
\end{tabular}

\# save money, arrange transport and identify institution to rush in case of complication

* Significant difference from control arm at $<0.05$ level

Table 3.10: Delivery Care by Study Arms (percentage)

\begin{tabular}{|l|c|c|c|c|}
\hline Response & $\begin{array}{c}\text { Intervention } \\
\text { SHG arm }\end{array}$ & $\begin{array}{c}\text { Intervention } \\
\text { non-SHG arm }\end{array}$ & $\begin{array}{c}\text { Control } \\
\text { arm }\end{array}$ & Total \\
\hline Place of Delivery & 31.1 & 30.3 & 34.6 & 32.3 \\
\hline - Home & 21.6 & 21.1 & 21.7 & 21.5 \\
\hline - Sub centre/PHC & 16.3 & 18.2 & 27.0 & 20.9 \\
\hline - CHC & 20.7 & 19.2 & 9.2 & 15.9 \\
\hline - District hospital & 10.3 & 11.3 & 7.6 & 9.4 \\
\hline - Private hospital & 68.9 & 69.7 & 65.4 & 67.7 \\
\hline Delivered at institution & 75.3 & 70.7 & 70.0 & 72.2 \\
\hline ASHA accompanied woman for delivery & 96.4 & 96.5 & 94.6 & 95.7 \\
\hline Awareness of JSY & & & & \\
\hline Type of Delivery & 89.7 & 86.2 & 93.2 & 90.2 \\
\hline - Normal & 4.9 & 6.6 & 2.5 & 4.3 \\
\hline - Assisted by instruments & 5.4 & 7.2 & 4.4 & 5.4 \\
\hline - Caesarean section &
\end{tabular}

\section{Reasons for delivering at an institution}

The main reason for delivering at an institution was the perception that institutional delivery is safer for the mother (55 percent) and the newborn (54 percent). Figure 3.4 highlights the other reasons. In 72 percent of cases, the ASHA had accompanied women to the facility for delivery. This has also increased substantially from 41 percent reported in the 2009 landscaping survey in UP. Women who had delivered at an institution but without the ASHA accompanying them, revealed that it was primarily because they did not inform the ASHA (48 percent). About one-fourth said that they had informed the ASHA but she could not come, while some women said the ASHA was not available (12 percent) and an equal proportion reported that the ASHA does not come to their purva (12 percent) (Figure 3.5).
Figure 3.4: Reasons for Institution Delivery

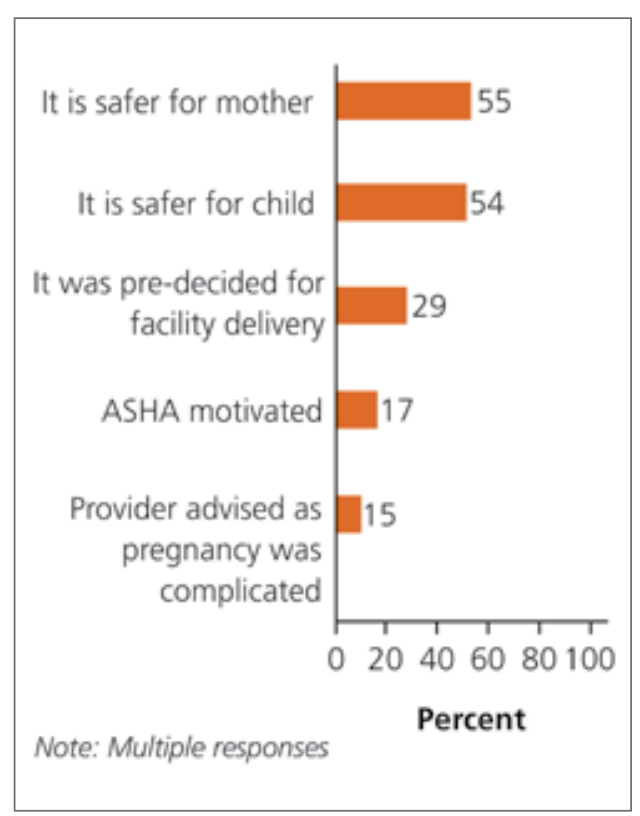




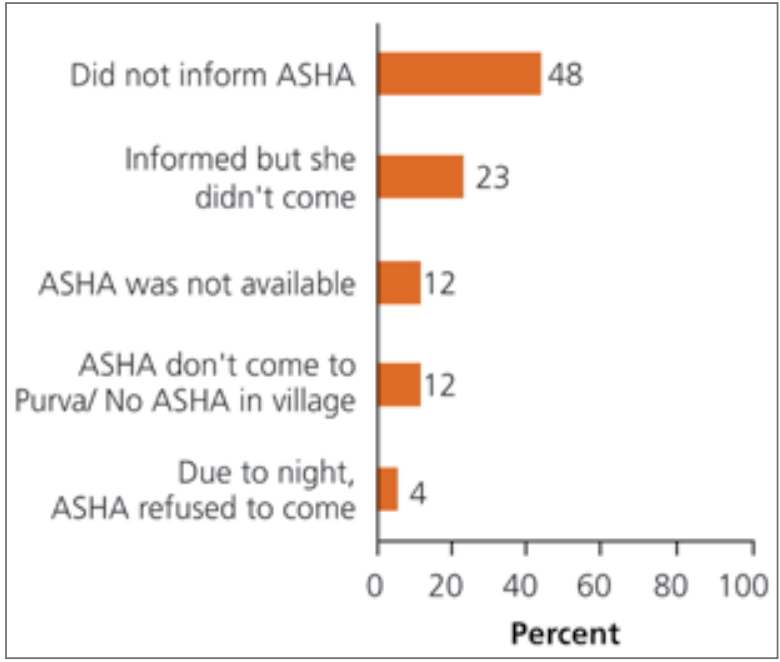

Figure 3.5: Reasons for Asha Not Accompanying Women for Delivery

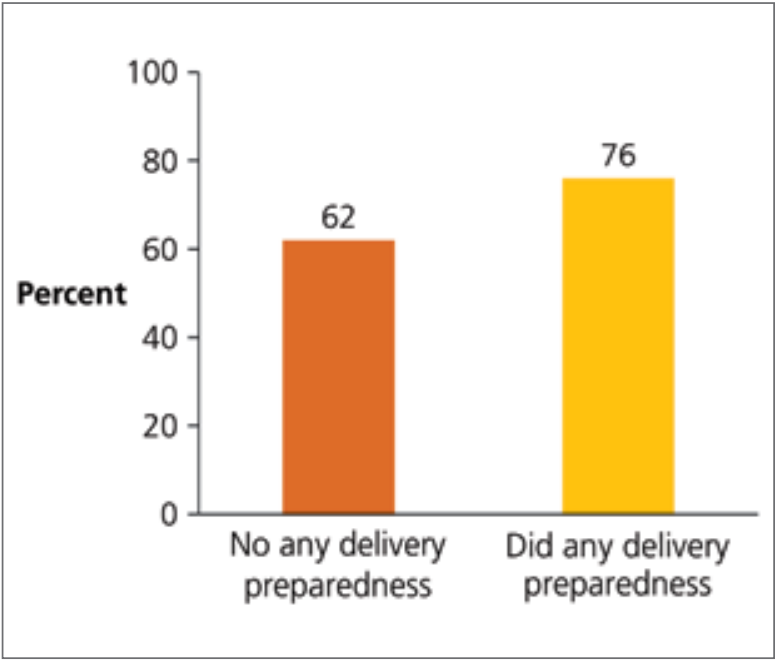

Figure 3.6: Institutional Delivery by Status of Delivery Preparedness

Delivery preparedness appears to have some influence on institutional delivery. For instance, 76 percent of the women who did at least one delivery preparation routine delivered at an institution compared to 62 percent who had not done any delivery preparation $(p<0.05)$ (Figure 3.6).

\section{Reason for delivering at home}

The 32 percent women who had delivered a baby at home were asked the reason for the home delivery. The main reasons given were the perception that pregnancy was normal (33 percent), family tradition of home delivery or previous delivery was also at home (29 percent). In case of 16 to 18 percent women, pain started at night and they could not arrange means of transportation on time. Table 3.11 highlights the other reasons for home delivery. The majority of women delivering at home belong to SC/ST households.

Table 3.11: Reasons for Home Delivery (percentage)

\begin{tabular}{|l|c|}
\hline Reasons for home delivery & Percent \\
\hline Pregnancy was normal & 33.4 \\
\hline Family tradition/ previous delivery at home & 28.7 \\
\hline Pain started at night so had no option & 18.3 \\
\hline Could not arrange transportation in time & 16.1 \\
\hline It was elders' decision & 15.3 \\
\hline No one at home to look after children & 14.3 \\
\hline Money problem & 17.3 \\
\hline No health facility close by & 6.4 \\
\hline Dai's assurance that everything will be fine & 5.8 \\
\hline Number of women & $\mathbf{7 0 1}$ \\
\hline
\end{tabular}

\section{Cost of institutional delivery}

The average total delivery expenditure was estimated around Rs. 1,800 (ranging from Rs. 1,593 to Rs. 1,939) across the arms (Table 3.12). A break-up of the expenditure shows that Rs. 567 was spent for doctor's fee, Rs. 651 on medicine, Rs. 318 for transport and Rs. 247 for other miscellaneous items. 
The amount spent was substantially higher (Rs. 4,369) for a private facility than for a public facility (Rs. 1,486). In fact, the amount spent in a public facility is almost equal to the amount given to pregnant women from the JSY scheme.

Table 3.12: Average Expenditure (in Rupees) in Institutional Delivery by Arms

\begin{tabular}{|l|c|c|c|c|c|c|}
\hline Type of expense & $\begin{array}{c}\text { Intervention } \\
\text { SHG arm }\end{array}$ & $\begin{array}{c}\text { Intervention } \\
\text { non-SHG arm }\end{array}$ & $\begin{array}{c}\text { Control } \\
\text { Arm }\end{array}$ & $\begin{array}{c}\text { Public } \\
\text { Institution }\end{array}$ & $\begin{array}{c}\text { Private } \\
\text { Institution }\end{array}$ & Total \\
\hline Doctor's fee & 640 & 598 & 474 & 395 & 2065 & 567 \\
\hline Medicine & 705 & 655 & 591 & 553 & 1503 & 651 \\
\hline Transport & 323 & 321 & 311 & 306 & 424 & 318 \\
\hline Others & 270 & 257 & 217 & 232 & 376 & 247 \\
\hline Total & 1939 & 1881 & 1593 & 1486 & 4369 & 1783 \\
\hline (SD) & $(1908)$ & $(1789)$ & $(1449)$ & $(1289)$ & $(2641)$ & $(1724)$ \\
\hline Number of women & $\mathbf{5 3 5}$ & $\mathbf{2 9 8}$ & $\mathbf{5 1 6}$ & $\mathbf{1 2 1 0}$ & $\mathbf{1 3 9}$ & $\mathbf{1 3 4 9}$ \\
\hline
\end{tabular}

\section{Determinants of institutional delivery}

Table 3.13 shows the logistic regression results for the determinants of institutional delivery. Women who received three or more ANC services were 1.7 times more likely to go for institutional delivery than women who had not received them. Similar results were observed when the number of contact with a healthcare worker was taken as an independent variable. All women who had two or more contacts with a FLW had 1.7 times higher chance of delivering at an institution than those who had no contact with a FLW. Delivery preparedness, caste, education and wealth index were other factors which influenced the decision for an institutional delivery significantly.

SC/ST women were less likely to go for institutional delivery than women from general castes. As the table shows, more than five years of schooling increases the chance of institutional delivery. Similarly, women who belonged to households of lowest wealth quintile were 63 percent less likely to go for institutional delivery than women belonging to households of the highest wealth quintile.

As observed earlier, the level of marginalization (a combination of caste, education and wealth index) makes a big difference in changing the probability of institutional delivery. The higher the level of marginalization, the lower is the chance of being able to avail institutional delivery services (Figure 3.7).

Table 3.13: Determinants of Institutional Delivery: Logistic Regression Results

\begin{tabular}{|c|c|}
\hline Determinants & Odds Ratio \\
\hline \multicolumn{2}{|c|}{ No of contacts with FLW } \\
\hline $0 \AA$ & 1.00 \\
\hline 1 & 0.93 \\
\hline 2 & $1.69 *$ \\
\hline 3 & $1.51 *$ \\
\hline $4+$ & $1.71 *$ \\
\hline \multicolumn{2}{|c|}{$3+$ ANC } \\
\hline $\mathrm{No} \otimes$ & 1.00 \\
\hline Yes & $1.66^{*}$ \\
\hline
\end{tabular}




\begin{tabular}{|c|c|}
\hline Determinants & Odds Ratio \\
\hline \multicolumn{2}{|c|}{ Delivery preparation any of three } \\
\hline $\mathrm{No} \otimes$ & 1.00 \\
\hline Yes & $1.81 *$ \\
\hline \multicolumn{2}{|c|}{ Exposure to any of three media } \\
\hline Not exposed® & 1.00 \\
\hline Exposed & 0.96 \\
\hline \multicolumn{2}{|c|}{ Women's age } \\
\hline $25-49 \circledast$ & 1.00 \\
\hline $15-24$ & $1.41 *$ \\
\hline \multicolumn{2}{|c|}{ Caste } \\
\hline Others $®$ & 1.00 \\
\hline $\mathrm{OBC}$ & 0.76 \\
\hline SC/ST & $0.50 *$ \\
\hline \multicolumn{2}{|c|}{ Education } \\
\hline $10+\circledR$ & 1.00 \\
\hline $6-10$ & 0.76 \\
\hline $1-5$ & $0.52 *$ \\
\hline Illiterate & $0.54^{*}$ \\
\hline \multicolumn{2}{|c|}{ Wealth index } \\
\hline Highest $\circledast$ & 1.00 \\
\hline Second & 0.71 \\
\hline Middle & $0.48^{*}$ \\
\hline Fourth & $0.44^{*}$ \\
\hline Lowest & $0.37 *$ \\
\hline \multicolumn{2}{|c|}{ Study arms } \\
\hline Control SHG® & 1.00 \\
\hline Intervention SHG & 1.04 \\
\hline Intervention non-SHG & 1.11 \\
\hline
\end{tabular}

${ }^{*} p<0.05$

$\circledR$ denotes the reference category

Figure 3.7: Odds Ratio of Institutional Delivery According to Level of Marginalization

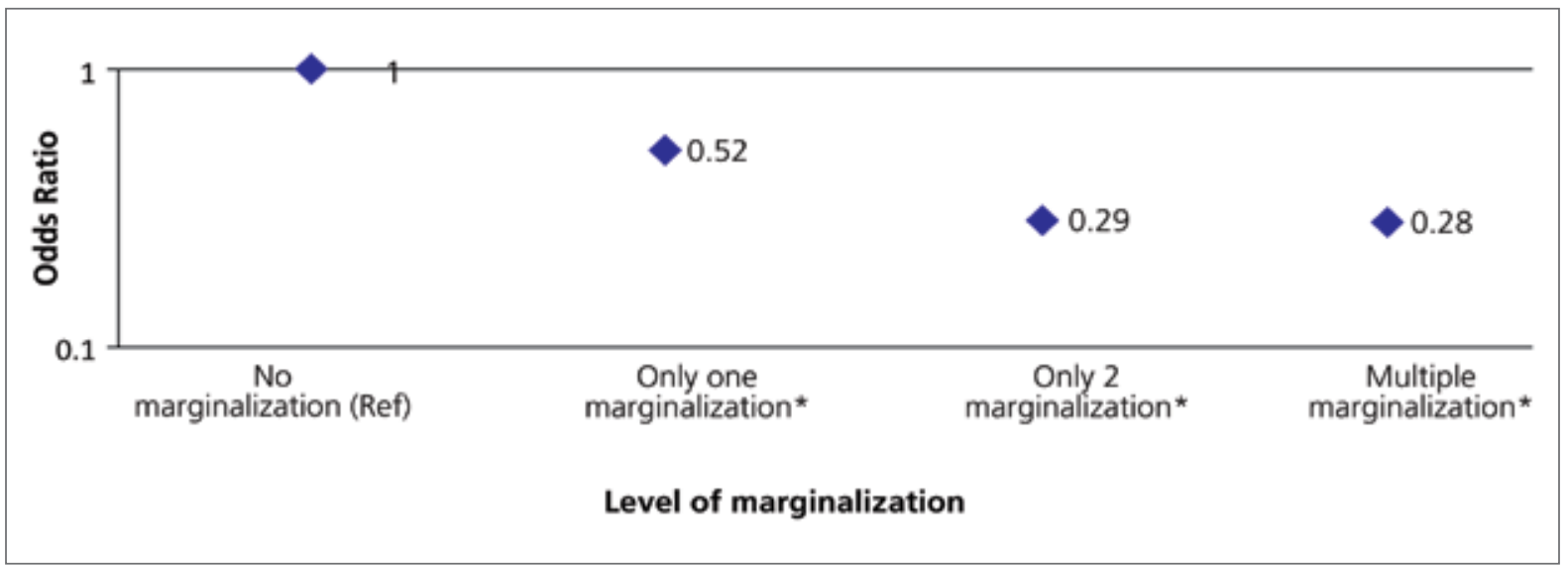




\section{Stay at facility}

A 48-hour stay at the institution after delivery facilitates postnatal checkups for the mother and child and can save them from several postpartum complications. However, the baseline survey result shows that only 33 percent of women who had delivered at an institution had stayed at the facility for more than 24 hours. Almost half (48 percent) had left the facility within 12 hours and another 19 percent between 12-24 hours (Figure 3.8).

The reasons for not staying at the facility for at least 24 hours was the perception that as both mother and the newborn were healthy (50 percent), staying longer at the facility was not required (Table 3.14). About 44 percent reported that they left the facility when asked to go back home. Other reasons included lack of support at home (17 percent) and that ASHA suggested that they could go home (11 percent).

Figure 3.8: Hours Stayed at Facility after Delivery

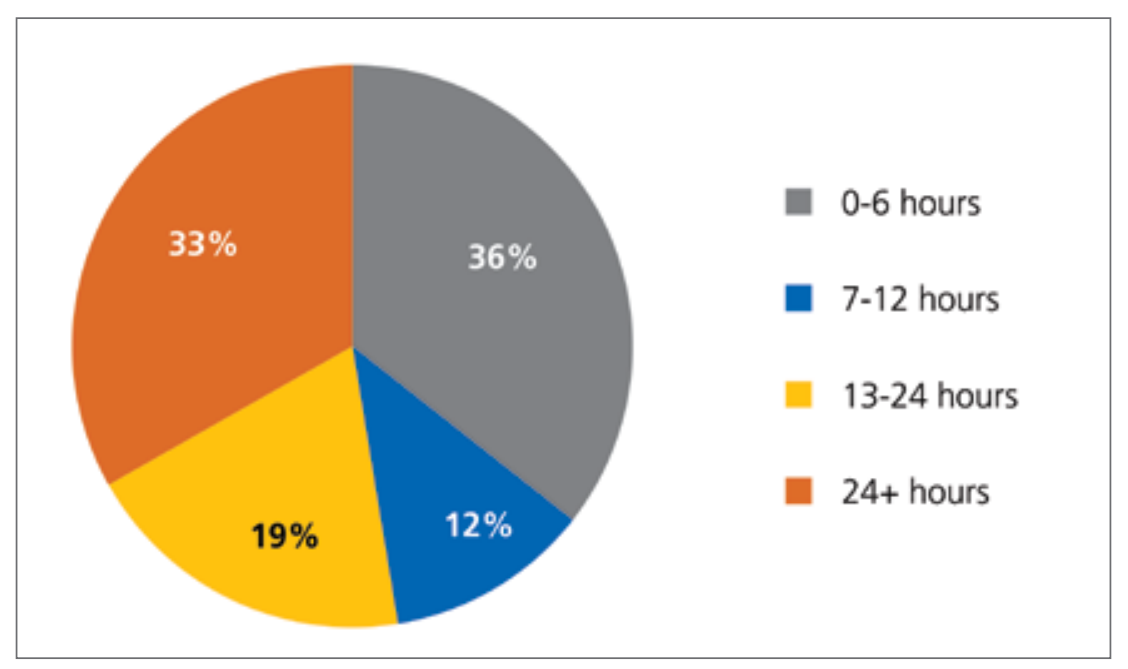

When the question was asked directly, it emerged that the facility staff and ASHA together influenced more than 70 percent women to leave the facility within 24 hours after the delivery. In such cases, perhaps lack of social capital and basic facilities at the institution play an important role (Figure 3.9).

Figure 3.9: Persons who Influence the Women to Leave the Facility within 24 Hours

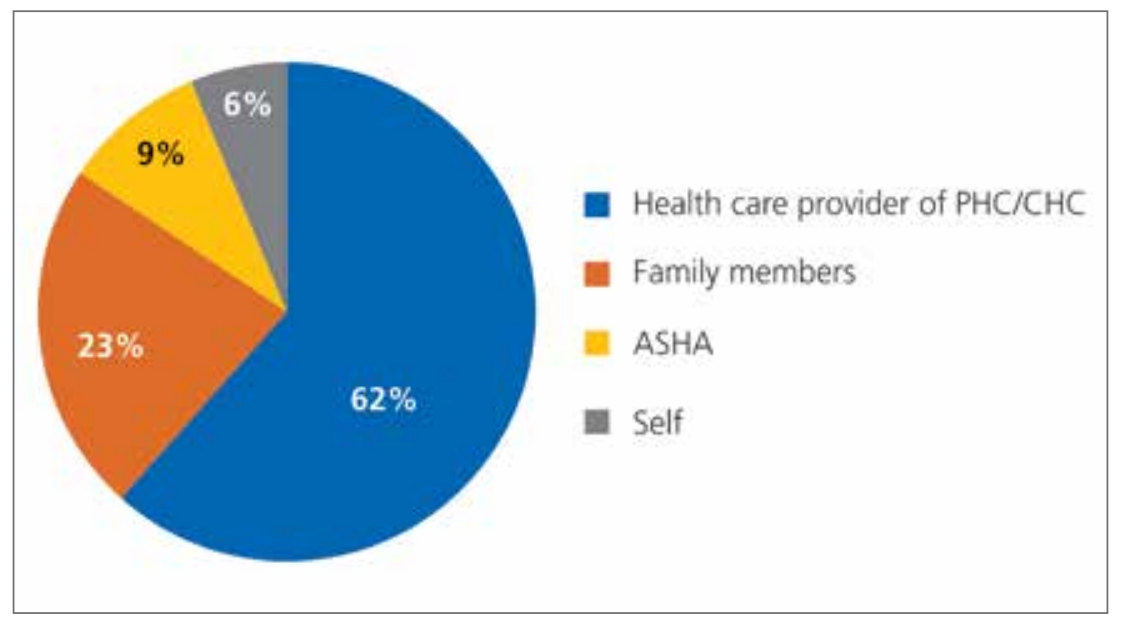




\section{Knowledge and experience of danger signs and care-seeking behavior}

A knowledge of danger signs is important for timely recognition of the complications so as to seek healthcare. The survey results show that women who had given a birth sometime in the last 15 months, were, on an average, aware of 3.6 danger signs that indicate a woman is at risk during pregnancy. The corresponding average knowledge of danger signs during child delivery and after delivery was 1.7 and 2.3 respectively. However, most of the danger signs mentioned were common problems and may not be of a serious nature.

On an average, women were able to cite only 0.7 danger signs during pregnancy, 0.5 danger signs during delivery and 0.567 danger signs after delivery. A list of each key danger sign that was cited by women (Number of women 999) is provided in Table 3.15. During pregnancy the knowledge of key danger signs included signs such as swelling of feet or hands (26 percent), excessive vaginal bleeding (15 percent) and vaginal discharge (13 percent). However, during delivery it was mainly excessive vaginal bleeding (35 percent), followed by prolonged labor over 12 hours (10 percent). Women knew mostly about excessive vaginal bleeding (41 percent) followed by severe headache (13 percent) as danger signs after delivery (Table 3.15).

Table 3.14: Facility after Delivery

\begin{tabular}{|l|c|}
\hline \multicolumn{1}{|c|}{ Reasons } & Percent women \\
\hline Both me and my child were normal & 49.9 \\
\hline Other staff suggested "you can go" & 44.1 \\
\hline Lack of support at home & 16.6 \\
\hline ASHA suggested & 10.7 \\
\hline Family members decided to take back & 9.8 \\
\hline Bad behavior of facility staff & 4.8 \\
\hline No transport to go back at a later time & 2.0 \\
\hline $\begin{array}{l}\text { Lack of Infrastructure at facility (Toilets/electricity/food and staff } \\
\text { availability/stay for accompanying person) }\end{array}$ & 13.4 \\
\hline Number of women & $\mathbf{9 9 9}$ \\
\hline
\end{tabular}

Table 3.15: Knowledge of Danger Signs during Pregnancy, Delivery and after Delivery

\begin{tabular}{|l|c|c|c|}
\hline Knowledge of key danger signs & $\begin{array}{c}\text { During } \\
\text { pregnancy }\end{array}$ & $\begin{array}{c}\text { During } \\
\text { delivery }\end{array}$ & $\begin{array}{c}\text { After } \\
\text { delivery }\end{array}$ \\
\hline Excessive vaginal bleeding & 15 & 35 & 41 \\
\hline Severe headache & 9 & - & 13 \\
\hline Vaginal discharge (foul smelling) & 13 & - & 8 \\
\hline Blurred vision/visual disturbance & 7 & - & 8 \\
\hline Convulsions & 1 & 3 & 2 \\
\hline Swelling of feet/hands & 26 & - & - \\
\hline Prolonged labor over 12 hours & - & 10 & - \\
\hline Mean (SD) & $\mathbf{0 . 7 ( 0 . 8 )}$ & $\mathbf{0 . 5 ( 0 . 6 )}$ & $\mathbf{0 . 5 ( 0 . 6 )}$ \\
\hline
\end{tabular}


The major self-reported complications during pregnancy were severe lower abdominal pain (41 percent), consistent vomiting (22 percent), breathlessness/ weakness/ dizziness (18 percent), swelling of feet/ hands (16 percent) and high fever (9 percent) (Table 3.16). Major self-reported complications during delivery were severe abdominal pain (55 percent), excessive vaginal bleeding (16 percent) and prolonged labor over 12 hours (9 percent) (Table 3.14). Major self-reported complications after delivery were high fever (36 percent), severe pain in abdomen (29 percent) and excessive vaginal bleeding (15 percent) (Table 3.16).

Table 3.16: Self-reported Complications during Pregnancy, Delivery and after Delivery

\begin{tabular}{|l|c|c|c|}
\hline Complications & $\begin{array}{c}\text { During } \\
\text { pregnancy }\end{array}$ & $\begin{array}{c}\text { During } \\
\text { delivery }\end{array}$ & $\begin{array}{c}\text { After } \\
\text { delivery }\end{array}$ \\
\hline Severe lower abdominal pain & 41.2 & 54.4 & 28.6 \\
\hline High fever & 9.2 & 4.1 & 36.2 \\
\hline Vaginal discharge (foul smelling) & 7.3 & 8.4 & 3.6 \\
\hline Excessive vaginal bleeding & 4.3 & 15.9 & 14.7 \\
\hline Consistent vomiting & 21.7 & - & - \\
\hline Breathlessness/weakness/dizziness & 18.3 & - & - \\
\hline Swelling of feet/hands/body & 19.0 & - & - \\
\hline Absence or /less movements of foetus & 4.8 & - & - \\
\hline Blurred vision/visual disturbance & 3.8 & - & 5.9 \\
\hline Convulsions & - & 1.1 & 0.9 \\
\hline Severe headache & - & & 7.9 \\
\hline Prolonged labor over 12 hours & - & 9.2 & - \\
\hline Baby in abnormal position & - & 8.5 & - \\
\hline Cord around neck & - & 3.3 & - \\
\hline Baby's hands and feet coming out first & - & 3.2 & - \\
\hline Engorged/swelling or lump in the breast & - & - & 1.4 \\
\hline Others & 5.7 & 4.7 & 1.7 \\
\hline
\end{tabular}

Overall, 86 percent women sought treatment of their delivery complications and most (64 percent) received it from a government health facility. A little less than 26 percent went to private clinics while the rest, around 11 percent, depended on unqualified village health care providers or home treatments. Around 89 percent sought treatment for post-delivery complications: 47 percent from a private facility and 23 percent from a government facility. However, 36 percent women sought treatment from an unqualified village doctor or at home (Table 3.17). All three arms were similar in treatment -seeking behavior for maternal complications. 
Table 3.17: Treatment-seeking Behavior for Complications during Delivery (percentage)

\begin{tabular}{|c|c|c|}
\hline Response & During delivery & After delivery \\
\hline Sought treatment for complications during delivery & 86.4 & 89.2 \\
\hline \multicolumn{3}{|l|}{ Place of treatment } \\
\hline - Government facility & 64.3 & 23.4 \\
\hline - Private facility & 25.9 & 46.5 \\
\hline - Unqualified village doctor & 7.3 & 26.4 \\
\hline - Home treatment & 3.2 & 6.5 \\
\hline - Other & 1.3 & 2.6 \\
\hline Number of women & 728 & 587 \\
\hline
\end{tabular}

\section{Postnatal care}

Only one-fourth of the study participants received any postnatal care. PNC within a week was limited to only 17 percent women. It is quite close to the 2009 UP landscaping survey and IDEAS survey which reported 14 percent and 19 percent, respectively. As per the Government of India guidelines for the Home Based Mother and Child Care scheme, the mother and child should receive three PNC visits by the ASHA in the first week after delivery. However, the baseline survey also shows that women received the first PNC visit on the 8th day after delivery (Table 3.18) and on an average woman received only two PNC visits by a healthcare provider. Among those who received any PNC, 17 percent received it from doctors, followed by the ANM (6 percent) and ASHA (2 percent) (Figure 3.10). There were no differences in PNC practices between the intervention and control arms.

Table 3.18: Status of postnatal care by study arms

\begin{tabular}{|l|c|c|c|c|}
\hline Response & $\begin{array}{c}\text { Intervention } \\
\text { SHG arm }\end{array}$ & $\begin{array}{c}\text { Intervention } \\
\text { non-SHG arm }\end{array}$ & $\begin{array}{c}\text { Control } \\
\text { arm }\end{array}$ & Total \\
\hline Received PNC & 26.0 & 24.6 & 27.4 & 26.3 \\
\hline Received first PNC within a week & 17.1 & 16.5 & 17.8 & 17.3 \\
\hline $\begin{array}{l}\text { First PNC on day after delivery (day) } \\
\text { Number of women }\end{array}$ & $8^{\text {th }}$ & $8^{\text {th }}$ & $8^{\text {th }}$ & $8^{\text {th }}$ \\
\cline { 2 - 5 } & 858 & 479 & 871 & 2208 \\
\hline $\begin{array}{l}\text { Mean number of PNC among those } \\
\text { who received (SD) }\end{array}$ & $2.1(1.8)$ & $1.9(1.3)$ & $2.0(1.8)$ & $2.0(1.7)$ \\
\hline Number of women & $\mathbf{2 2 3}$ & $\mathbf{1 1 8}$ & $\mathbf{2 3 9}$ & $\mathbf{5 8 1}$ \\
\hline
\end{tabular}

An analysis of the reasons for not receiving PNC within a week revealed that the main barrier was the perception that if everything was normal (72 percent), there was no need to go for PNC. One-third of the women said that they did not consider PNC necessary (33 percent) followed by 13 percent who mentioned that elders in the family did not feel it was necessary. They were unaware that any normal case could develop complications and hence PNC should be done irrespective of whether or not the mother and the newborn feel normal. Other reasons included high cost (8 percent), no home visit by ANM /ASHA for check-up ( 6 percent) and distance of health facility (3 percent) (Table 3.19). 
Table 3.19: Reasons for Not Receiving PNC within a Week

\begin{tabular}{|l|c|}
\hline Reason & Percent \\
\hline Everything was normal /did not face any problem & 72.0 \\
\hline The woman herself did not consider it necessary & 32.8 \\
\hline Elders in family did not feel it was needed & 13.2 \\
\hline PNC costs too much & 8.2 \\
\hline ANM /ASHA did not come home for check up & 5.5 \\
\hline Elder women were examining the woman & 2.9 \\
\hline Health facility was too far & 2.6 \\
\hline Number of women & $\mathbf{1 8 2 6}$ \\
\hline
\end{tabular}

Figure 3.10: Status of PNC Received by Providers

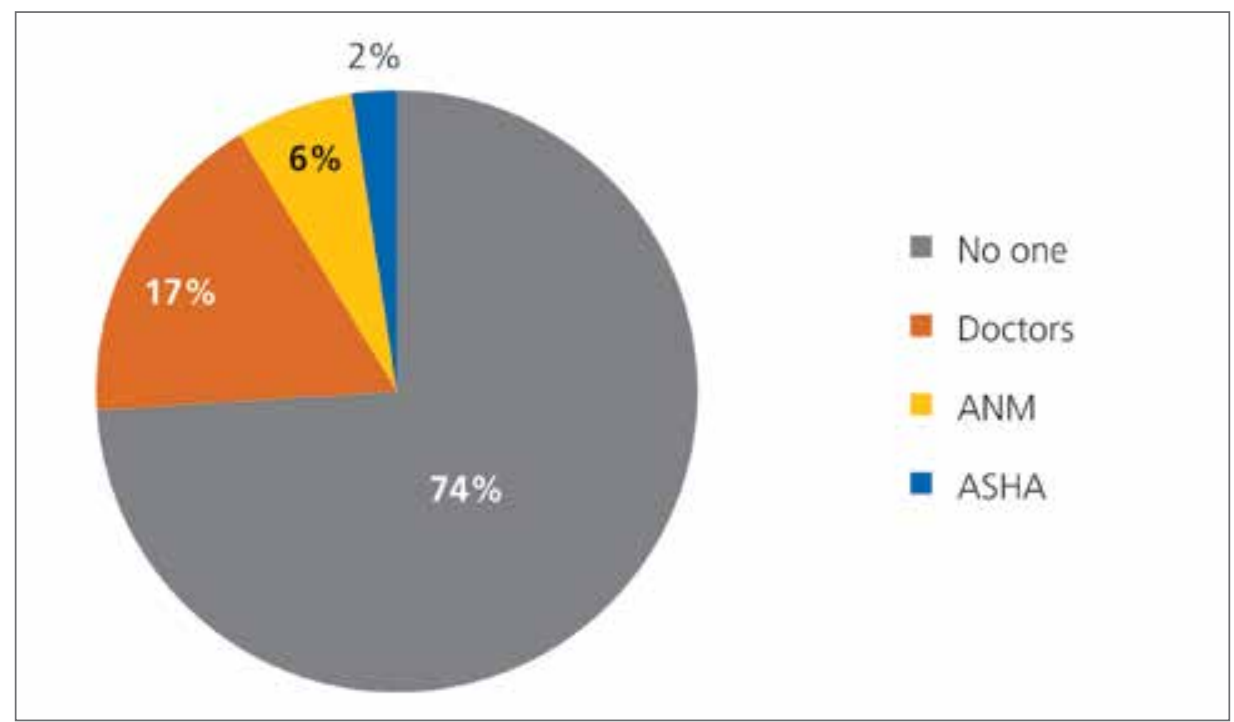

Figure 3.11: Odds Ratio of PNC within a Week According to Level of Marginalization

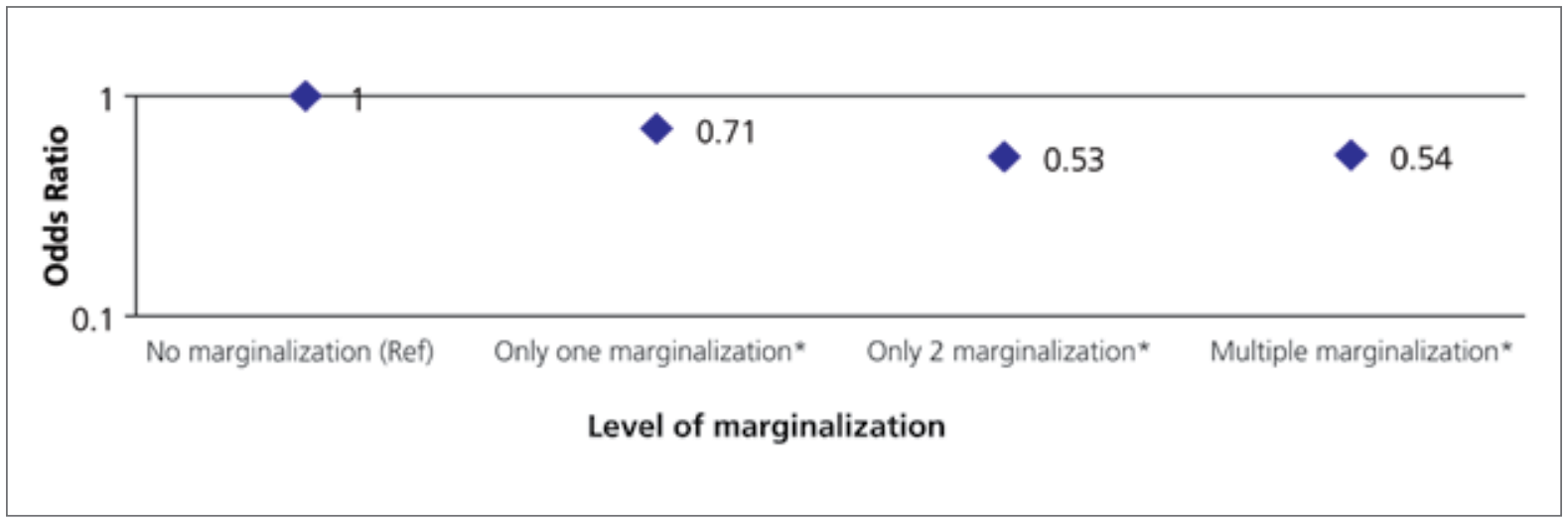

The level of marginalization influenced the behavior of seeking or not seeking PNC within one week. Women with multiple marginalization were 46 percent less likely, double marginalized women were 47 percent less likely and single marginalized women were 29 percent less likely to go for PNC within a week than non-marginalized women (Figure 3.11) 
Table 3.20: Determinants of Seeking PNC within a Week: Logistic Regression Results

\begin{tabular}{|c|c|}
\hline Determinants & Odds Ratio \\
\hline \multicolumn{2}{|c|}{ Number of contacts with FLW } \\
\hline $0 ®$ & 1.00 \\
\hline 1 & 0.76 \\
\hline 2 & 0.70 \\
\hline 3 & 0.73 \\
\hline $4+$ & 0.80 \\
\hline \multicolumn{2}{|c|}{$3+\mathrm{ANC}$} \\
\hline $\mathrm{No}$ & 1.00 \\
\hline Yes & $1.68^{*}$ \\
\hline \multicolumn{2}{|c|}{ Delivery place } \\
\hline Home® & 1.00 \\
\hline Institution & $2.19 *$ \\
\hline \multicolumn{2}{|c|}{ Exposure to any of three media } \\
\hline Not exposed@ & 1.00 \\
\hline Exposed & 1.10 \\
\hline \multicolumn{2}{|c|}{ Women's age } \\
\hline $25-49 \circledast$ & 1.00 \\
\hline $15-24$ & $0.74^{*}$ \\
\hline \multicolumn{2}{|c|}{ Caste } \\
\hline Others ${ }^{\circledR}$ & 1.00 \\
\hline $\mathrm{OBC}$ & 0.88 \\
\hline SC/ST & 0.83 \\
\hline \multicolumn{2}{|c|}{ Education } \\
\hline $10+\circledR$ & 1.00 \\
\hline $6-10$ & 0.86 \\
\hline $1-5$ & $0.64^{*}$ \\
\hline 0 (Illiterate) & 0.61 * \\
\hline \multicolumn{2}{|c|}{ Wealth index } \\
\hline Highest $₫$ & 1.00 \\
\hline Second & 0.83 \\
\hline Middle & 0.79 \\
\hline Fourth & $0.63 *$ \\
\hline Lowest & $0.59 *$ \\
\hline \multicolumn{2}{|c|}{ Study arms } \\
\hline Control SHG® & 1.00 \\
\hline Intervention SHG & 0.89 \\
\hline Intervention non-SHG & 0.82 \\
\hline
\end{tabular}




\section{Family Planning}

On an average, women had their first delivery after 24 months once they started cohabitation with the husband (Table 3.21). Spousal communication on the timing of first pregnancy was limited to only one-fourth of women. Only 42 women out of 2,208 (2 percent) used a family planning method to delay their first pregnancy. The most common family planning (FP) method used to delay first pregnancy was condoms ( 26 out of 42 women), followed by oral contraceptive pills (nine women), while seven women had relied on withdrawal and the safe period method. No difference among the study arms was observed in the above values.

Currently, 41 percent women reported that they had any discussion with their spouse on the timing of the next pregnancy (Table 3.22). One-fourth of the women (24 percent) were using a contraceptive method to delay their next pregnancy. Questions on the exposure to family planning messages reveal that only around 22 percent had received any message from any source in the previous three months on contraceptive methods for birth spacing. Very few women received any message on birth spacing in the previous three months. No difference was observed across the arms except for the percentage of women who received birth spacing messages, which was slightly higher in the intervention SHG arm compared to the control arm (26 percent compared to 18 percent, $\mathrm{p}<0.05)$.

The major source of messages promoting birth spacing were family members/relatives (41 percent), followed by friends/neighbors (36 percent), husband (33 percent), TV (26 percent), ASHA (16 percent), other healthcare providers like ANM/ LHV/ doctor (12 percent), radio ( 9 percent) and other advertisements in posters/ newspapers/ magazines (7 percent).

Table 3.21: Reproductive and Contraceptive Behavior Soon after Marriage by Study Arms (percentage)

\begin{tabular}{|l|c|c|c|c|}
\hline Response & $\begin{array}{c}\text { Intervention } \\
\text { SHG arm }\end{array}$ & $\begin{array}{c}\text { Intervention } \\
\text { non-SHG arm }\end{array}$ & $\begin{array}{c}\text { Control } \\
\text { arm }\end{array}$ & Total \\
\hline $\begin{array}{l}\text { Average delay of first delivery after } \\
\text { cohabitation (in months) }\end{array}$ & 23.8 & 23.5 & 23.5 & 23.6 \\
\hline $\begin{array}{l}\text { Spousal communication on } \\
\text { timing of first pregnancy }\end{array}$ & 25.3 & 24.6 & 24.2 & 24.7 \\
\hline $\begin{array}{l}\text { Used contraceptive to delay first } \\
\text { pregnancy }\end{array}$ & 2.1 & 2.1 & 1.7 & 1.9 \\
\hline Number of women & $\mathbf{8 5 8}$ & $\mathbf{4 7 9}$ & $\mathbf{8 7 1}$ & $\mathbf{2 2 0 8}$ \\
\hline
\end{tabular}

Table 3.22: Current FP Practices and Exposure to FP Messages (percentage)

\begin{tabular}{|l|c|c|c|c|}
\hline Response & $\begin{array}{c}\text { Intervention } \\
\text { SHG arm }\end{array}$ & $\begin{array}{c}\text { Intervention } \\
\text { non-SHG arm }\end{array}$ & $\begin{array}{c}\text { Control } \\
\text { arm }\end{array}$ & Total \\
\hline $\begin{array}{l}\text { Spousal communication on future } \\
\text { pregnancy }\end{array}$ & 41.1 & 41.9 & 39.8 & 40.7 \\
\hline Current use of modern FP methods & 24.9 & 24.2 & 23.1 & 24.0 \\
\hline $\begin{array}{l}\text { Received any message in the last } \\
\text { three months promoting birth spacing }\end{array}$ & $25.6^{*}$ & 21.9 & 18.3 & 21.9 \\
\hline Number of women & $\mathbf{8 5 8}$ & $\mathbf{4 7 9}$ & $\mathbf{8 7 1}$ & $\mathbf{2 2 0 8}$ \\
\hline
\end{tabular}

* Significant difference from control arm at $p<0.05$ level 
On the reasons for not adopting any modern FP methods, a majority of women cited side effects/ fear of side effects (33 percent), followed by very young child( "a few years old"), desire for more children, menstruation not having started and the family being opposed to use of FP methods. Each of these reasons was mentioned by 9 percent of the women (Table 3.23). Around 20 percent women did not give any reason. An analysis shows that correct knowledge on return of fertility (19 percent) and unsafe period within the menstrual cycle (12 percent) was very poor (Table 3.24). Knowledge about return of fertility was slightly higher (23 percent) in the experimental arms than in the control arm (16 percent) $(p<0.05)$.

Table 3.23: Reasons for not adopting any Modern FP Methods (percentage)

\begin{tabular}{|l|c|}
\hline Reasons & Percent \\
\hline Side effects/fear of side effects & 34.0 \\
\hline Child very small & 9.8 \\
\hline Want children & 9.8 \\
\hline Not started menstruation & 9.2 \\
\hline Family opposed to FP use & 8.5 \\
\hline Not staying with husband & 7.8 \\
\hline Do not know from where to get & 5.9 \\
\hline Dislike / inconvenient to use available FP method & 4.6 \\
\hline Not aware of any FP method & 3.3 \\
\hline FP method not easy to access & 2.0 \\
\hline Costs too much & 1.3 \\
\hline Religious prohibition & 0.7 \\
\hline Others & 2.6 \\
\hline No reason cited & 19.6 \\
\hline
\end{tabular}

Table 3.24: Family Planning Related Knowledge by Study Arms (percentage)

\begin{tabular}{|l|c|c|c|c|}
\hline Correct knowledge of & $\begin{array}{c}\text { Intervention } \\
\text { SHG arm }\end{array}$ & $\begin{array}{c}\text { Intervention } \\
\text { non-SHG arm }\end{array}$ & $\begin{array}{c}\text { Control } \\
\text { arm }\end{array}$ & Total \\
\hline Return of fertility & $20.3^{*}$ & 19.6 & 16.3 & 18.6 \\
\hline Unsafe period & 11.9 & 14.4 & 11.6 & 12.3 \\
\hline Number of women & $\mathbf{8 5 8}$ & $\mathbf{4 7 9}$ & $\mathbf{8 7 1}$ & $\mathbf{2 2 0 8}$ \\
\hline
\end{tabular}

* Significant difference from control arm at $<0.05$ level

\section{Conclusion}

This chapter illustrates that knowledge and healthy practices related to maternal care were poor among the study population. Except for a few behaviors, no differences were observed across the three study arms. In a few behaviors, although differences between the study arms were statistically significant, in programmatic terms they were very minor and of no consequences for real impact on maternal health.

From the programmatic point of view and implication for designing the interventions and behavior change management, many findings are important and should be noted. The study shows that only less than half have ever attended VHND. Even those women who had taken supplementary food, did not consume it themselves; either they shared it or gave it to others. In such cases, the 
whole purpose of providing food supplements to pregnant women to improve their nutrition status remains unsuccessful. The program needs to focus on making the VHND and AWC more attractive to increase their utilization. Similarly very few got 100 tablets of IFA and even among them only one-third consumed them. In such cases, advising women to take 100 IFA tablets will not make any difference. It is important to inform women why taking those 100 IFA tablets is important for their health, understand the barriers that are causing them to not take them and address those barriers.

The study also shows that women received very limited advice on maternal healthcare and practices; consequently most maternal health behavior was equally poor except for administration of TT injection and institutional deliveries. The percentage of women who are receiving three ANC visits/ services has also increased from previous studies. To a great extent these positive changes are due to JSY's conditional cash transfer to pregnant women for availing services like institutional delivery and the incentive payment to ASHAs for their successful community mobilization for three ANC sessions and institutional delivery. The landscaping study and the present study too show that three or more ANC visits and institutional delivery work are gateway behaviors to trigger many other positive changes. For example, three or more ANC sessions lead to institutional delivery and institutional delivery influences adoption of initiation of early breastfeeding, cord care and improvement in PNC. These findings could be strategically used in the present program for bringing about other changes from the SHG forum.

The findings show that most women believe that since pregnancy and delivery are 'normal', there is no need for ANC or PNC. There is poor knowledge of danger signs during pregnancy, during delivery and after delivery. This lack of information becomes a strong barrier against adopting healthy practices like three or more ANC visits during pregnancy and PNC within the first week after delivery. The BCM intervention needs to selectively disseminate this information. Women and community members need to be informed that normal pregnancy is no guarantee that during delivery it would not turn into a complicated case. Similarly, in the early post-delivery period any woman and newborn could develop complications and PNC protects them from such possibilities. The program should pay special attention to increasing women's knowledge on these key issues through the SHG platform.

The findings of limited knowledge among the surveyed women about the return of fertility and unsafe period as well as poor contraceptive use to delay first or future pregnancy, also call for urgent attention. It was found that newspapers/ magazines or posters/banner were the limited sources of information among women while the major sources were people around the women, such as family and friends. This suggests that the possible mode of behavior change communication to reach women in the study settings with health messages should be interpersonal communication rather than the mass media. The family appears to be a key influencer and it is important to reach out to them too.

The results from logistic regression adjusted models for healthy behaviors confirmed that marginalization is one of the significant factors in all maternal health key behaviors. This suggests that the program needs to address the barriers to adoption of healthy behaviors, particularly among the marginalized segments of the population. Belonging to SC/ ST households and illiteracy are strong predictors to poor maternal health behaviors. Therefore, for programmatic purpose in the field, segmentation can be done on the basis of caste (SC/ ST women) and, if possible, also illiteracy and these segments of women should be the focus for the intervention. 


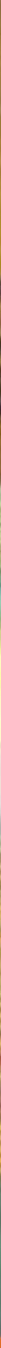

Chapter 4

Newborn Health Knowledge and Practices 
This chapter aims to study the status of knowledge and practices that have a direct bearing on the newborn's health. It presents information on the interviewed women's knowledge of newborn complications and different care-seeking behavior by study arms. The chapter also tries to identify the socioeconomic barriers in adopting healthy behaviors and brings out the key determinants of essential newborn care to provide feedback to the program.

\section{Results}

\section{Characteristics of newborn}

The characteristic of recently born children whose mother was interviewed is given in Table 4.1. The mean age of the children was close to eight months. The boys and girls were in almost equal proportion. Around 54 percent of the births were registered while less than half (44 percent) were weighted at birth. In all these aspects no difference was observed between experimental and control arms.

Table 4.1: Characteristics of Recently Born Children by Study Arms (percentage)

\begin{tabular}{|l|c|c|c|c|}
\hline Results & $\begin{array}{c}\text { Intervention } \\
\text { SHG arm }\end{array}$ & $\begin{array}{c}\text { Intervention } \\
\text { non-SHG arm }\end{array}$ & $\begin{array}{c}\text { Control } \\
\text { arm }\end{array}$ & Total \\
\hline Mean age in months (SD) & $7.8(4.6)$ & $7.2(4.3)$ & $8.0(4.5)$ & $7.8(4.5)$ \\
\hline Sex of child & \multicolumn{4}{|l|}{} \\
\hline - Male & 50.5 & 54.1 & 48.6 & 50.5 \\
\hline - Female & 49.5 & 45.9 & 51.4 & 49.5 \\
\hline Birth registered & 52.1 & 54.4 & 55.3 & 53.9 \\
\hline Birth weight taken & 43.5 & 44.9 & 44.3 & 44.1 \\
\hline Number of women & $\mathbf{8 5 8}$ & $\mathbf{4 7 9}$ & $\mathbf{8 7 1}$ & $\mathbf{2 2 0 8}$ \\
\hline
\end{tabular}

Among those newborns whose birth weight was taken, the mean birth weight was close to three $\mathrm{kg}$. One-fifth of the newborns were underweight at birth (less than $2.5 \mathrm{~kg}$ ). Though no difference was observed in the mean birth weight of different arms, the proportion of underweight children was significantly more (22.3 percent) in experimental arms as compared to control arms (16 percent, $p<0.05$ ) (Table 4.2).

Table 4.2: Birth Weight Status of Newborn by Study Arms (percentage)

\begin{tabular}{|l|c|c|c|c|}
\hline Results & $\begin{array}{c}\text { Intervention } \\
\text { SHG arm }\end{array}$ & $\begin{array}{c}\text { Intervention } \\
\text { non-SHG arm }\end{array}$ & $\begin{array}{c}\text { Control } \\
\text { arm }\end{array}$ & Total \\
\hline Underweight baby (less than 2.5 kg) & $22.3^{*}$ & 19.2 & 16.1 & 19.2 \\
\hline Mean birth weight in $\mathrm{kg}$. (SD) & $2.9( \pm 0.8)$ & $2.9( \pm 1.0)$ & $2.9( \pm 0.8)$ & $2.9( \pm 0.9)$ \\
\hline Number of women & $\mathbf{3 5 8}$ & $\mathbf{2 0 3}$ & $\mathbf{3 6 6}$ & $\mathbf{9 2 7}$ \\
\hline
\end{tabular}

* Significant difference from control arm at $<0.05$ level 


\section{Initiation of breastfeeding}

The baseline data shows that half (49 percent) of the newborns were breastfed within one hour (Table 4.3). The corresponding figure as reported by IDEAS survey was similar (51 percent). Early initiation of breastfeeding has increased two-and-a-half times from the 2009 PC landscaping survey (19 percent). There was no difference in prevalence of early initiation of breastfeeding between intervention and control arms. A delay was mostly noticed between one to six hours for more than one-fourth of the newborns. In case of one-tenth of the newborns, the delay in initiation of breastfeeding was between 7 to 24 hours. However, for the rest (14 percent) of the newborns breastfeeding was delayed for more than a day. The average delay was 19 hours.

Table 4.3: Practice of Breastfeeding Initiation by Study Arms (percentage)

\begin{tabular}{|l|c|c|c|c|}
\hline Results & $\begin{array}{c}\text { Intervention } \\
\text { SHG arm }\end{array}$ & $\begin{array}{c}\text { Intervention } \\
\text { non-SHG arm }\end{array}$ & $\begin{array}{c}\text { Control } \\
\text { arm }\end{array}$ & Total \\
\hline Breastfeeding initiation within an hour & 50.3 & 44.9 & 48.8 & 48.6 \\
\hline \multicolumn{5}{|l|}{ Delay in breastfeeding initiation } \\
\hline 1-2 hours & 15.2 & 15.6 & 16.5 & 15.8 \\
\hline 2-3 hours & 4.6 & 8.4 & 5.7 & 5.8 \\
\hline 4-6 hours & 5.2 & 6.3 & 4.6 & 5.2 \\
\hline 7-24 hours & 10.1 & 8.4 & 8.9 & 9.2 \\
\hline 1-2 days & 8.3 & 8.4 & 8.0 & 8.2 \\
\hline 3-4 days & 4.9 & 6.3 & 6.0 & 5.6 \\
\hline Average delay in breastfeeding & - & - & 19.4 & 18.8 \\
\hline initiation (SD) & $18.4(23)$ & $18.6(24)$ & $(24)$ & $(24)$ \\
\hline Number of women & 412 & 253 & 426 & 1091 \\
\hline Total Number of women & $\mathbf{8 5 8}$ & $\mathbf{4 7 9}$ & $\mathbf{8 7 1}$ & $\mathbf{2 2 0 8}$ \\
\hline
\end{tabular}

Further analysis shows that early initiation of breastfeeding within one hour was significantly high among those who were delivered in institution (57 percent) than those who were delivered at home (35 percent). However, one-fourth of babies delivered at home had delayed initiation of breastfeeding compared to 8 percent who were delivered at institutions (Figure 4.1).

Figure 4.1: Breastfeeding Initiation By Place of Delivery

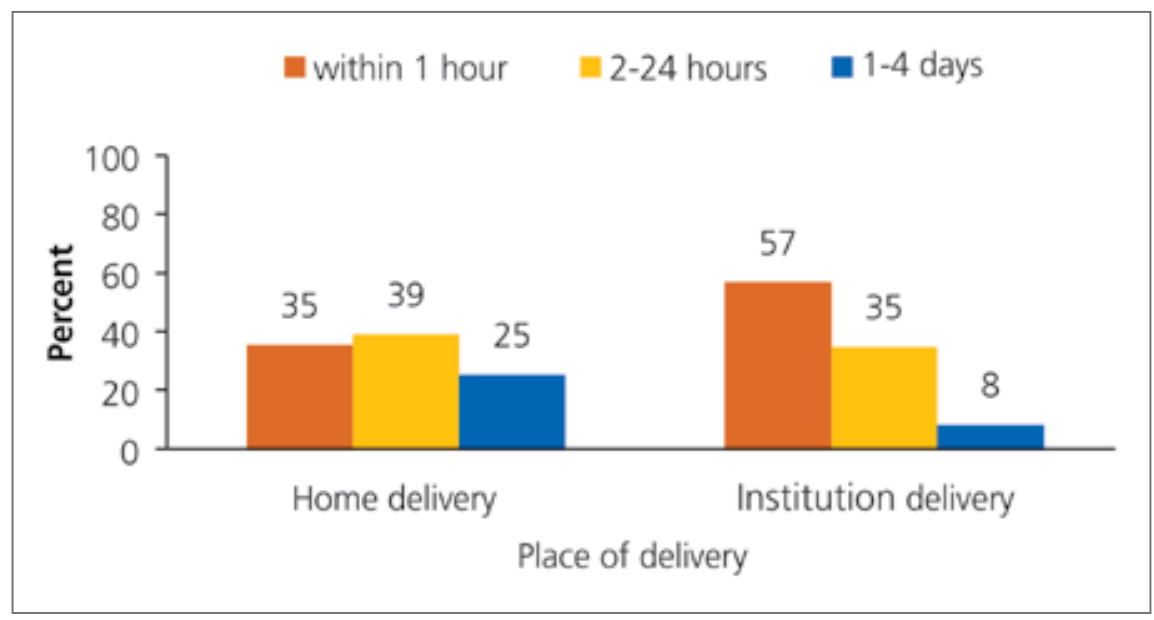


The data also shows that eight out of every 10 women who had delivered at health facilities were advised for early initiation of breastfeeding whereas less than 2 percent women who delivered at home were given any such advice. In such cases, initiating breastfeeding within one hour of delivery by women who delivered at home is a welcome sign showing that this information is either given during ANC or by now this is a desirable practice which is spreading through the community.

The major advantages of early initiation of breastfeeding as cited by mothers are that it keeps the child healthy (51 percent), followed by child's stomach gets full (38 percent) and keeps mother's breast light (18 percent) (Table 4.4).It is important to note that a benefit like quick onset of breast milk was mentioned by 8 percent of women. Maternal advantage of breastfeeding, such as prevention of post- partum bleeding, was mentioned by almost none (less than 1 percent).

Table 4.4: Advantages of Breastfeeding within One Hour as Cited by Mothers (percentage)

\begin{tabular}{|l|c|}
\hline Reasons & Percent \\
\hline Keeps the child healthy & 51.0 \\
\hline Child does not cry & 38.4 \\
\hline Keeps mother's breast light & 18.3 \\
\hline Helps in child's survival & 16.3 \\
\hline Child's throat does not get dry & 14.1 \\
\hline Milk will start coming early & 8.2 \\
\hline Prevents excessive PP bleeding & 0.6 \\
\hline Number of women & $\mathbf{2 2 0 8}$ \\
\hline
\end{tabular}

\section{Reason for delay in initiation of breastfeeding}

Almost half the newborns were not breastfed within one hour. The delay in initiation of breastfeeding ranged from two hours to four days (with an average delay of 19 hours). The major reasons for the delay as reported by mothers included: "mother's milk does not come so soon" (Figure 4.2). This was also a major knowledge gap found in the PC landscaping survey (Khan et al. 2012). Other reasons cited by 10 to 15 percent of mothers included: the mother was too weak to hold the baby, the baby was not given to the mother immediately after birth, post-delivery cleaning took time and delivery complications.

Figure 4.2: Reasons for Delay in Breastfeeding

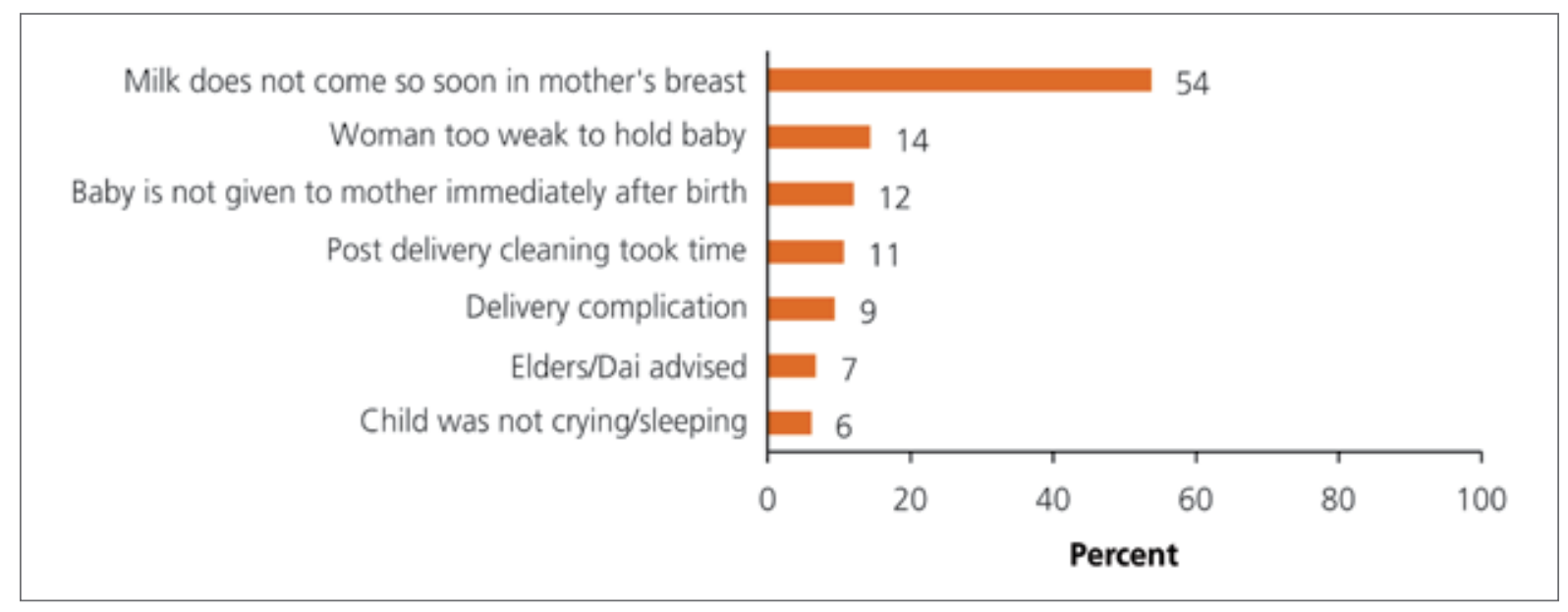




\section{Pre-lactation practices}

The analysis reveals that 44 percent of newborns were fed pre-lactation items such as animal milk (61 percent) and honey (43 percent) (Figure 4.3). Water and formula milk were also provided in some cases. Only 3 percent knew that the main constituent of mother's milk is water. No difference was observed across the arms in such practices and knowledge.

Figure 4.3: Pre-Lactation Items Provided to Newborn

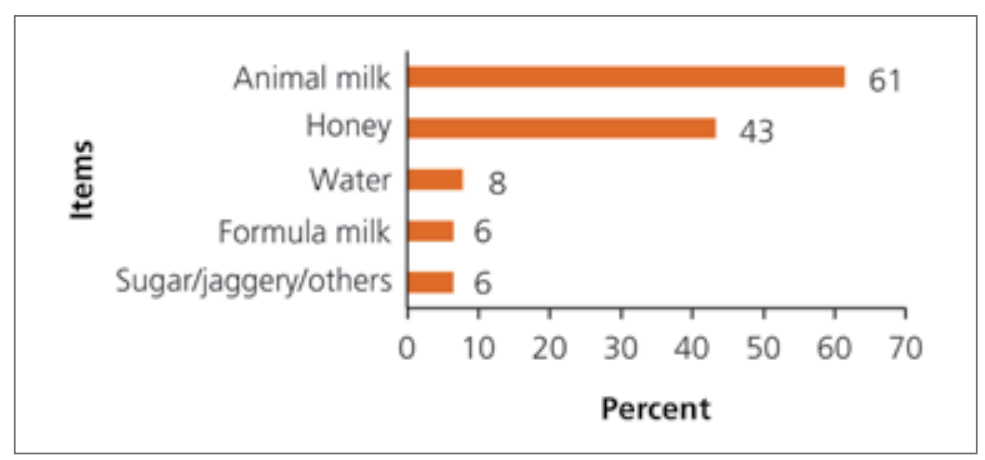

\section{Determinants of early initiation of breastfeeding}

Table 4.5 shows the logistic regression analysis results for the determinants of breastfeeding initiation within an hour using similar predictors as in the case of institutional delivery. Women who delivered in institutions were 2.4 times likely to initiate breastfeeding within an hour of delivery than women who had delivered at home. Contact with FLWs is another important predictor of early initiation of breastfeeding. The more the contact, the higher is the chance of initiating early breastfeeding. Women who were contacted four times or more by FLWS during pregnancy were two times likely to initiate breastfeeding within an hour than women who did not have any contact with a FLW. To make a significant difference in early initiation of breastfeeding, at least two such contacts are essential.

Though all other factors were not found significant, in the case of caste, Scheduled Caste women had 34 percent more chance of early initiation of breastfeeding than those categorized as "other" castes. Marginalization status by replacing socioeconomic status indicators (caste, education and wealth) was also checked in another model but was found insignificant.

\section{Exclusive breastfeeding}

Findings of the baseline survey show that 22 percent of the newborns were exclusively breastfed for six months. No change has been noticed in exclusive breastfeeding from the 2009 PC landscaping survey (23 percent). There was no difference in the "exclusively breastfed for six months" status in both intervention arms from the control arm. Also there was no difference in exclusively breastfeeding among newborns who were delivered in an institution (23 percent) or at home (20 percent). Before discharge from the health facility after delivery, 70 percent women were advised on exclusive breastfeeding for six months. 
Table 4.5: Determinants of Breastfeeding Initiation within One Hour: Logistic Regression Results

\begin{tabular}{|c|c|}
\hline Determinants & Odds Ratio \\
\hline \multicolumn{2}{|c|}{ No of antenatal contacts with FLW } \\
\hline $0 \AA$ & 1.00 \\
\hline 1 & 1.48 \\
\hline 2 & $1.64^{*}$ \\
\hline 3 & $1.78^{\star}$ \\
\hline 4 & $1.97^{*}$ \\
\hline \multicolumn{2}{|c|}{$3+$ ANC } \\
\hline $\mathrm{No}$ & 1.00 \\
\hline Yes & 0.86 \\
\hline \multicolumn{2}{|c|}{ Place of delivery } \\
\hline Home® & 1.00 \\
\hline Institution & $2.42 *$ \\
\hline \multicolumn{2}{|c|}{ Exposure to any of three media } \\
\hline Not exposed $®$ & 1.00 \\
\hline Exposed & 0.89 \\
\hline \multicolumn{2}{|c|}{ Women's age } \\
\hline $25-49 \circledast$ & 1.00 \\
\hline $15-24$ & 1.04 \\
\hline \multicolumn{2}{|c|}{ Caste } \\
\hline Others $®$ & 1.00 \\
\hline $\mathrm{OBC}$ & 1.03 \\
\hline SC/ST & 1.34 \\
\hline \multicolumn{2}{|c|}{ Education } \\
\hline $10+\circledR$ & 1.00 \\
\hline $6-10$ & 0.74 \\
\hline $1-5$ & 0.79 \\
\hline Illiterate & 0.75 \\
\hline \multicolumn{2}{|c|}{ Wealth index } \\
\hline Highest $®$ & 1.00 \\
\hline Second & 1.00 \\
\hline Middle & 0.82 \\
\hline Fourth & 1.03 \\
\hline Lowest & 0.93 \\
\hline \multicolumn{2}{|c|}{ Study arms } \\
\hline Control SHG® & 1.00 \\
\hline Intervention SHG & 1.6 \\
\hline Intervention non-SHG & 0.84 \\
\hline
\end{tabular}

${ }^{*} p<0.05$

® denotes the reference category 


\section{Determinants of exclusive breastfeeding}

Table 4.6 shows the results of logistic regression for the determinants of exclusive breastfeeding for six months. The result shows that except for media exposure, none of the factors were significant. Women who were exposed to any of the three mass media (TV, radio or newspaper) were 1.6 times more likely to practice exclusive breastfeeding for six months than women who were not exposed to any mass media.

Chapter two mentions that around 70 percent women were not exposed to any media and, hence, if mass media is making any difference, it must be among women of other' castes leaving behind the SC/ST women Logistic regression results for exclusive breastfeeding reflect the same scenario.

SC/ST women were 33 percent less likely to have breastfed their children than women of 'other' castes. It is interesting to point out that mass media exposure showed significant association only for exclusive breastfeeding but not for any other newborn health or maternal health care behaviors, as seen in the previous chapters. Correct feeding practice for newborn and infants is critical for their growth and protection from malnutrition. Table 4.7 presents the mean age of the newborn at introduction of water, animal milk and semi-solid food. The table also shows the mother's knowledge of different complementary feeding practices. The analysis shows that the mean age at introduction of water was three months. Most women introduced water to their babies very early -26 percent did it by the end of the first month, 40 percent by the end of the second month and more than two-thirds by the fifth month. In summer, 12 percent of women began feeding water to newborns within a week of delivery.

Data suggests that the mean age of introduction of milk was also before four months. All this exposes the child to the risk of diarrhea. One of the important reasons given by women for introducing water so early was the perception that the child must feel thirsty for water. This perhaps stems from the lack of knowledge that up to 80 percent of mother's milk is water and mother's milk alone could satisfy the baby's thirst. Answers to the question on the constituents of breast milk revealed that only 3 percent knew that breast milk contains water; 56 percent could not answer this question; 42 percent mentioned 'vitamins and minerals' and 18 percent mentioned 'milk'.

Table 4.6: Determinants of exclusive breastfeeding for 6 months: logistic regression results

\begin{tabular}{|c|c|}
\hline Determinants & Odds Ratio \\
\hline Number of antenatal contacts with FLW \\
\hline $0 \AA$ & 1.00 \\
\hline 1 & 1.15 \\
\hline 2 & 0.86 \\
\hline 3 & 0.80 \\
\hline $4+$ & 0.90 \\
\hline Number of postnatal contacts with FLW \\
\hline $0 ®$ & 1.00 \\
\hline 1 & 0.98 \\
\hline 2 & 0.85 \\
\hline $3+$ & 0.85 \\
\hline
\end{tabular}




\begin{tabular}{|c|c|}
\hline Determinants & Odds Ratio \\
\hline \multicolumn{2}{|c|}{$3+$ ANC } \\
\hline $\mathrm{No} \circledast$ & 1.00 \\
\hline Yes & 1.03 \\
\hline \multicolumn{2}{|c|}{ Delivery place } \\
\hline Home® & 1.00 \\
\hline Institution & 1.24 \\
\hline \multicolumn{2}{|c|}{ Exposure to any of three media } \\
\hline Not exposed® & 1.00 \\
\hline Exposed & $1.58^{*}$ \\
\hline \multicolumn{2}{|c|}{ Women's age } \\
\hline $25-49 \circledast$ & 1.00 \\
\hline $15-24$ & 1.15 \\
\hline \multicolumn{2}{|c|}{ Caste } \\
\hline Others® & 1.00 \\
\hline $\mathrm{OBC}$ & 0.87 \\
\hline SC/ST & $0.67 *$ \\
\hline \multicolumn{2}{|c|}{ Education } \\
\hline $10+\circledR$ & 1.00 \\
\hline $6-10$ & 0.91 \\
\hline $1-5$ & 0.96 \\
\hline Illiterate & 0.85 \\
\hline \multicolumn{2}{|c|}{ Wealth index } \\
\hline Highest $®$ & 1.00 \\
\hline Second & 1.15 \\
\hline Middle & 1.11 \\
\hline Fourth & 1.43 \\
\hline Lowest & 1.31 \\
\hline \multicolumn{2}{|c|}{ Study arms } \\
\hline Control SHG® & 1.00 \\
\hline Intervention SHG & 1.13 \\
\hline Intervention non-SHG & 1.07 \\
\hline
\end{tabular}

${ }^{*} \mathrm{p}<0.05$

$\circledR$ denotes the reference category

Table 4.7: General Feeding Knowledge and Practices

\begin{tabular}{|l|c|c|c|c|}
\hline Response & $\begin{array}{c}\text { Intervention } \\
\text { SHG arm }\end{array}$ & $\begin{array}{c}\text { Intervention } \\
\text { non-SHG arm }\end{array}$ & $\begin{array}{c}\text { Control } \\
\text { arm }\end{array}$ & Total \\
\hline $\begin{array}{l}\text { Mean age when water was } \\
\text { introduced (SD) }\end{array}$ & $3.2(2.2)$ & $3.2(2.1)$ & $3.0(2.2)$ & $3.1(2.2)$ \\
\hline $\begin{array}{l}\text { Mean age when animal milk was } \\
\text { introduced (SD) }\end{array}$ & $3.6(2.9)$ & $3.6(2.9)$ & $3.7(3.2)$ & $3.7(3.0)$ \\
\hline $\begin{array}{l}\text { Mean age when semi-solid food was } \\
\text { introduced (SD) }\end{array}$ & $6.9(1.9)$ & $6.9(2.0)$ & $6.7(2.9)$ & $6.8(2.9)$ \\
\hline
\end{tabular}




\begin{tabular}{|l|c|c|c|c|}
\hline Response & $\begin{array}{c}\text { Intervention } \\
\text { SHG arm }\end{array}$ & $\begin{array}{c}\text { Intervention } \\
\text { non-SHG arm }\end{array}$ & $\begin{array}{c}\text { Control } \\
\text { arm }\end{array}$ & Total \\
\hline $\begin{array}{l}\text { Number of semi-sold food to be fed } \\
\text { to children of different ages }\end{array}$ & \multicolumn{5}{|l|}{} \\
\hline $\begin{array}{l}\text { Children age } \mathbf{6 - 8} \text { months } \\
\text { - Correctly aware }\end{array}$ & 32.9 & 20.9 & 36.3 & 31.7 \\
\hline - Actually fed & 43.9 & 37.2 & 40.6 & 41.1 \\
\hline - Number of women & 155 & 86 & 160 & 401 \\
\hline Mothers of children age 9-12 months & & & \\
\hline - Correctly aware & 54.1 & 54.1 & 52.6 & 53.5 \\
\hline - Actually fed & 19.5 & 22.3 & 22.6 & 21.3 \\
\hline Number of women & $\mathbf{2 5 7}$ & $\mathbf{1 4 8}$ & $\mathbf{2 6 6}$ & $\mathbf{6 7 1}$ \\
\hline
\end{tabular}

Timely introduction of semi-solid food, number of feedings, volume and ingredients are important components to avoid malnutrition among infants. Responses to questions related to number of feeds given are analyzed and presented in Table 4.7. The age of feeding of semi-solid food was close to seven months across the study arms. The data on frequency of feeding of semi-solid food to children aged six to eight months and 9-12 months shows that about half of the mothers did not have the correct knowledge of the required frequency of feeding; therefore the prevalence of correct practice was also low. For example while 53 percent mothers with children aged 9-12 months were aware that children should be fed solid food three times a day, only 21 percent did so. This analysis shows both a knowledge gap as well as lack of translation of knowledge into practice.

\section{Thermal care}

Almost half the women in the study (49 percent) delayed the first bath of their newborn for at least two days, significantly more than 32 percent of women who delayed bathing for at least one day, as reported in the landscaping study in 2009 (Khan et al. 2012). This marked increase could be because of the rise in institutional delivery. This is well supported by the fact that 62 percent women delayed the first bath for at least two days if they delivered in an institution compared to 20 percent delay in

Figure 4.4: Thermal Care Practice Among Newborns by Place of Delivery

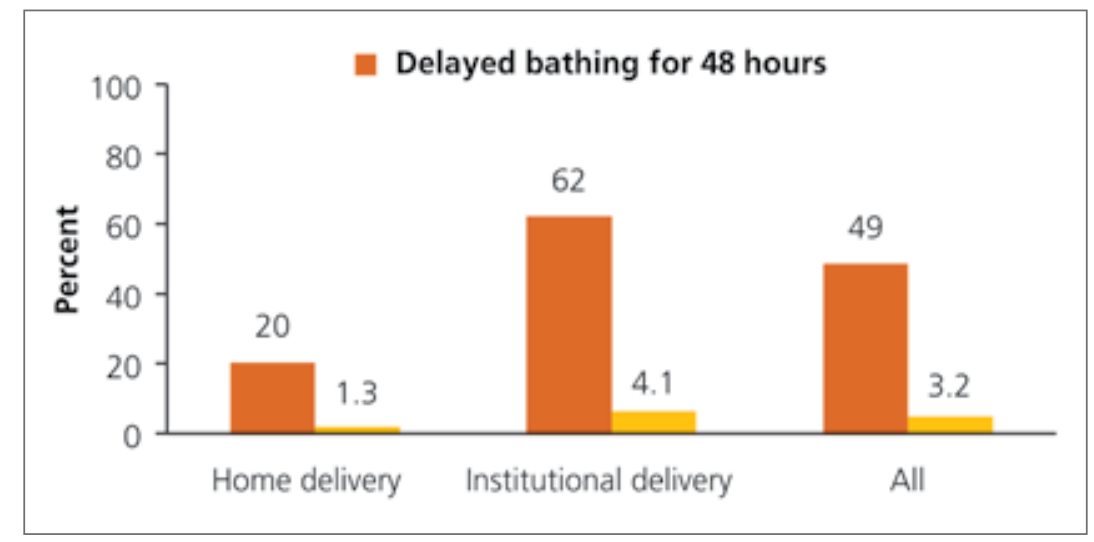


newborn bathing by women who delivered at home (Figure 4.4). However, some more probing is required to understand the reason for such an escalation of 26 percent by those who had reported a delay of three to five days, which is generally unusual. The analysis also shows that about 25 percent gave the bath within an hour while 41 percent within 24 hours. Delayed first bathing for at least two days was slightly higher in the intervention non-SHG arm than the control arm (52 percent compared to 45 percent; $p<0.05$ ).

When probed on what was done to clean the newborn, 46 percent reported that they massaged the child with mustard oil and then cleaned with a dry cloth; 19 percent massaged the child with mustard oil and then gave a bath and finally dried the baby with a clean cloth. Thus in two-thirds of the cases mustard oil massage was used to remove vernix which is a natural protective coating on the skin of the newborn baby and which keeps the baby warm. Only around 30 percent followed the desired practice of cleaning the baby with a dry cloth without giving a bath. In most of the cases after cleaning and bathing the baby, to keep the baby warm, the baby was covered with a clean cotton cloth (50 percent) or warm cloth (50 percent).

Kangaroo Mother Care or Skin to Skin Care methods to keep the newborn warm were practiced only by 3 percent of women and even among them only 63 percent did it correctly. Thus in the total sample only about 2 percent knew and practiced KMC correctly. Knowledge of KMC was equally poor among both who delivered either in an institution or at home. No change has been noticed in KMC from the 2009 PC landscaping survey that also reported only a 2 percent correct practice of KMC (Khan et al. 2012).

\section{Determinants of delayed bathing}

Table 4.8 shows the logistic regression analysis results for the determinants of delayed bathing by at least two days. The result shows that, apart from place of delivery, none of the factors were found significant. Women who delivered in institutions were six times more likely to delay the first bathing of the newborn by at least two days than women who had delivered at home. This illustrates the associated benefits of institutional delivery.

Table 4.8: Determinants of Delayed First Bathing for at least Two Days: Logistic Regression Results

\begin{tabular}{|c|c|}
\hline Determinants & Odds Ratio \\
\hline \multicolumn{2}{|c|}{ No of antenatal contacts with FLW } \\
\hline $0 ®$ & 1.00 \\
\hline 1 & 0.91 \\
\hline 3 & 1.08 \\
\hline $4+$ & 1.25 \\
\hline \multicolumn{2}{|c|}{$3+$ ANC } \\
\hline $\mathrm{No} \otimes$ & 1.00 \\
\hline Yes & 0.98 \\
\hline \multicolumn{2}{|c|}{ Delivery place } \\
\hline Home® & 1.00 \\
\hline Institution & $6.10 *$ \\
\hline
\end{tabular}




\begin{tabular}{|c|c|}
\hline Determinants & Odds Ratio \\
\hline \multicolumn{2}{|c|}{ Exposure to any of three media } \\
\hline Not exposed® & 1.00 \\
\hline Exposed & 1.19 \\
\hline \multicolumn{2}{|c|}{ Women's age } \\
\hline $25-49 \circledast$ & 1.00 \\
\hline $15-24$ & 1.04 \\
\hline \multicolumn{2}{|c|}{ Caste } \\
\hline Others $®$ & 1.00 \\
\hline $\mathrm{OBC}$ & 1.25 \\
\hline SC/ST & 1.14 \\
\hline \multicolumn{2}{|c|}{ Education } \\
\hline $10+\circledR$ & 1.00 \\
\hline $6-10$ & 1.02 \\
\hline $1-5$ & 1.20 \\
\hline Illiterate & 1.00 \\
\hline \multicolumn{2}{|c|}{ Wealth index } \\
\hline Highest $®$ & 1.00 \\
\hline Second & 0.78 \\
\hline Middle & 0.95 \\
\hline Fourth & 0.82 \\
\hline Lowest & 0.83 \\
\hline \multicolumn{2}{|c|}{ Study arms } \\
\hline Control SHG® & 1.00 \\
\hline Intervention SHG & 1.15 \\
\hline Intervention non-SHG & 1.24 \\
\hline
\end{tabular}

* $p<0.05$

$\circledR$ denotes the reference category

\section{Cord care}

Cord cutting practices among the women who had recently delivered were mostly hygienic and safe. A comparison of the findings with the Council's landscaping study shows that clean cord care practice increased by 10 percentage points - from 17 percent in 2009 to 27 percent in 2013. Use of a new blade to cut the cord was a universal practice among them. Further, the majority of women (83 percent) had used new or boiled string/thread to tie the cord. However, 15 percent women had used non-boiled string/thread, which could easily be a source of infection for the newborn. Any unhygienic practice in cord care could lead to infection and serious health consequences for the newborn. Clean cord care includes not applying anything on the cord. An analysis of the baseline data reveals that only 27 percent women had followed this; the others had applied oil/ ghee (37 percent), ash (16 percent), talcum powder (14 percent), and other materials (16 percent) (Figure 4.5).

The survey also shows that 32 percent of women who delivered in an institution practiced clean cord care, compared to 18 percent women who delivered at home (Figure 4.6). Clean cord care practice was slightly higher in the intervention SHG and intervention non-SHG arm (28 percent and 33 percent respectively), compared to the control arm (23 percent). 
An analysis of the reported symptoms of infection shows that most of them (86 percent) had not experienced any infection but 11 percent had reported symptoms like redness and discharge around the cord stump/umbilical sepsis and 5 percent had reported swelling. A direct question to assess their knowledge on how to prevent infection of the cord revealed a clear lack of knowledge and misperception. Table 4.9 shows that less than 9 percent of the women said that nothing should be applied on the cord stump or that is should be kept clean. About 15 percent said that nothing should be applied on the cord stump or that it should be kept clean. About 15 percent had suggested the use of an antiseptic solution or cream. The others all suggested substances they had actually used such as oil/ghee, ash/turmeric powder or talcum powder. All these practices are harmful. The women reported that in following these practices they were mostly influenced by the advice of family members like mother-in-laws (34 percent), other elderly members (22 percent) and neighbors ( 7 percent). The dai ( 16 percent) and other health care providers ( 15 percent) also influenced the women on cord care (Figure 4.7). Only 7 percent got their information from an ASHA.

Figure 4.5: Application of Harmful Items on Cord*

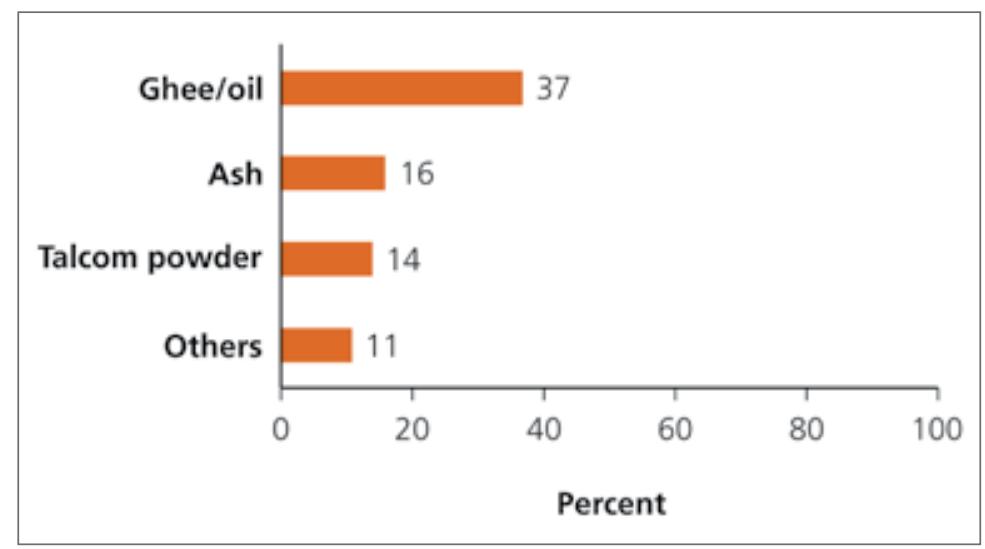

Figure 4.6: Clean cord Practice by Place of Delivery

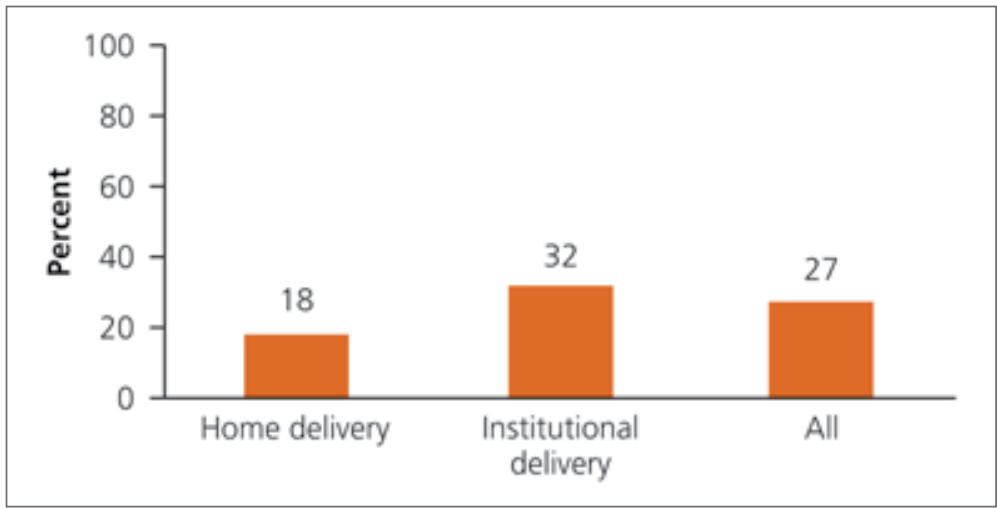


Table 4.9: Knowledge of Cord Care among Women

\begin{tabular}{|l|c|}
\hline \multicolumn{1}{|c|}{ Response } & Percent \\
\hline Apply nothing /keep cord stump clean and dry & 8.7 \\
\hline Oil/ghee & 38.3 \\
\hline Talcum powder/ash/turmeric & 29.0 \\
\hline Gentian violet/antiseptic cream & 15.7 \\
\hline Other & 17.3 \\
\hline Do not know & 15.4 \\
\hline
\end{tabular}

\section{Determinants of clean cord care}

Table 4.10 shows the results of the logistic regression analysis for the determinants of clean cord care. Possible predictors and covariates, such as number of contacts with FLW, 3+ ANC, place of delivery, media exposure, women's age, marginalization status (caste, education and wealth) and study arms have been adjusted. The result shows that women who delivered at an institution were two times more likely to practice clean cord care than women who had delivered at home. Women from the lowest wealth quintile household were almost half as likely to practice clean cord care than women from the highest wealth quintile household. Practice of clean cord care was 1.6 times more likely in the non-SHG arm than in the control arm. All other factors were not significant.

Remarkably, women's contact with FLW was also not a significant factor for clean cord care behavior.

Table 4.10: Determinants of Clean Cord Care: Logistic Regression Results

\begin{tabular}{|c|c|}
\hline Determinants & Odds Ratio \\
\hline \multicolumn{2}{|c|}{ No of antenatal contacts with FLW } \\
\hline $0 ®$ & 1.00 \\
\hline 1 & 1.00 \\
\hline 2 & 1.08 \\
\hline 3 & 1.03 \\
\hline $4+$ & 0.84 \\
\hline \multicolumn{2}{|c|}{$3+$ ANC } \\
\hline $\mathrm{No}$ & 1.00 \\
\hline Yes & 0.91 \\
\hline \multicolumn{2}{|c|}{ Delivery Place } \\
\hline Home $尺$ & 1.00 \\
\hline Institution & $2.00 *$ \\
\hline \multicolumn{2}{|c|}{ Exposure to any of three media } \\
\hline Not exposed $($ & 1.00 \\
\hline Exposed & 0.87 \\
\hline \multicolumn{2}{|c|}{ Women's age } \\
\hline $25-49 \circledast$ & 1.00 \\
\hline $15-24$ & 0.97 \\
\hline
\end{tabular}




\begin{tabular}{|c|c|}
\hline Determinants & Odds Ratio \\
\hline \multicolumn{2}{|c|}{ Caste } \\
\hline Others $®$ & 1.00 \\
\hline $\mathrm{OBC}$ & 1.00 \\
\hline SC/ST & 0.99 \\
\hline \multicolumn{2}{|c|}{ Education } \\
\hline $10+\circledR$ & 1.00 \\
\hline $6-10$ & 1.21 \\
\hline $1-5$ & 1.16 \\
\hline Illiterate & 1.25 \\
\hline \multicolumn{2}{|c|}{ Wealth index } \\
\hline Highest $®$ & 1.00 \\
\hline Second & 0.84 \\
\hline Middle & 0.72 \\
\hline Fourth & 0.81 \\
\hline Lowest & $0.54^{*}$ \\
\hline \multicolumn{2}{|c|}{ Study arms } \\
\hline Control SHG® & 1.00 \\
\hline Intervention SHG & $1.25^{\star}$ \\
\hline Intervention non-SHG & $1.63 *$ \\
\hline
\end{tabular}

* $p<0.05$

(B) denotes the reference category

\section{Newborn danger signs and complications}

A mother's knowledge of newborn danger signs is important to help her in recognizing abnormality or dangerous symptoms and seek timely treatment. A list of each newborn danger sign that was listed by women is provided in Table 4.11. On an average, women were able to mention two newborn danger signs. The danger signs that were more frequently mentioned included: fever (72 percent), diarrhea (39 percent) and difficult or fast breathing (23 percent). Other important newborn danger signs such as hypothermia/ shivering, poor sucking or feeding/ breastfeeding and chest indrawing were known to only 10 to 16 percent women. Danger signs such as redness and discharge around cord, blisters on skin/skin lesion, jaundice and red swollen eyes with discharge were mentioned by about 5 to 10 percent of the women. There were seven other danger signs that were mentioned by less than 5 percent of the women (Table 4.11). An analysis of danger signs mentioned by women against what has been given to them in SHG toolkits showed that women knew of only one to two danger signs (mean=1.6). This highlights a big scope of improvement in the knowledge of women using interventions. 
Table 4.11: Percentage of Mothers Who had Knowledge of Key Newborn Danger Signs by Study Arms

\begin{tabular}{|l|c|c|c|c|}
\hline Newborn Danger Signs & $\begin{array}{c}\text { Intervention } \\
\text { SHG arm }\end{array}$ & $\begin{array}{c}\text { Intervention } \\
\text { non-SHG arm }\end{array}$ & $\begin{array}{c}\text { Control } \\
\text { arm }\end{array}$ & Total \\
\hline \multicolumn{1}{|c|}{ Danger signs knowledge (as listed in SHG toolkits) } \\
\hline Fever & 71.3 & 70.4 & 74.1 & 72.2 \\
\hline Diarrhea & 38.1 & 35.1 & 41.1 & 38.6 \\
\hline Difficult or fast breathing & 21.9 & 21.3 & 25.9 & 23.4 \\
\hline Hypothermia/shivering & 18.6 & 13.6 & 14.6 & 15.9 \\
\hline Poor sucking or feeding/ breastfeeding & 12.6 & 11.5 & 11.4 & 11.9 \\
\hline Chest in-drawing & 11.9 & 12.5 & 11.6 & 11.9 \\
\hline Redness and discharge around the cord & 9.2 & 9.2 & 7.9 & 8.7 \\
\hline Jaundice & 6.4 & 6.1 & 6.8 & 6.5 \\
\hline Baby became drowsy/unconscious & 3.7 & 2.7 & 4.5 & 3.8 \\
\hline Convulsions or fits & 1.7 & 0.6 & 1.1 & 1.3 \\
\hline Mean (SD) knowledge of newborn danger & 1.8 & 1.5 & 1.5 & 1.6 \\
signs (as listed in SHG toolkits) & $(1.1)$ & $(1)$ & $(1)$ & $(1)$ \\
\hline \multicolumn{1}{|c|}{ Other danger signs knowledge } & & & \\
\hline Blisters on skin/skin lesion & 5.5 & 7.3 & 7.6 & 6.7 \\
\hline Red swollen eyes with discharge & 5.1 & 3.8 & 4.6 & 4.6 \\
\hline Baby very small/low birth weight & 2.6 & 1.9 & 3.7 & 2.9 \\
\hline Does not pass urine and/or stool & 2.3 & 2.9 & 3.3 & 2.9 \\
\hline Baby does not cry & 2.2 & 3.5 & 2.3 & 2.5 \\
\hline Skin color of palm/soles blue & 1.6 & 1.0 & 2.2 & 1.7 \\
\hline Congenital malformation & 0.3 & 0.8 & 0.9 & 0.7 \\
\hline Mean (SD) knowledge of newborn danger & 2.3 & 1.9 & 2.1 & 2.0 \\
signs (all) & $(1.2)$ & $(1.2)$ & $(1.2)$ & $(1.2)$ \\
\hline Do not know any danger signs & 11.8 & 12.7 & 10.4 & 11.5 \\
\hline Number of women & $\mathbf{8 5 8}$ & $\mathbf{4 7 9}$ & $\mathbf{8 7 1}$ & $\mathbf{2 2 0 8}$ \\
\hline
\end{tabular}

\section{Self-reported complications and treatment-seeking behavior among mothers of newborn}

Self-reported complications and treatment-seeking behavior among mothers of newborn is presented in Table 4.12. The highest percentage of self-reported complications was for fever (28 percent), followed by diarrhea (14 percent), redness and discharge around the cord stump (10 percent), difficult or fast breathing (7 percent), poor sucking or feeding/ breastfeeding (6 percent) and blisters on skin/skin lesion (5 percent).

An analysis of the treatment-seeking behavior shows that the majority of women (ranging from 78 percent to 96 percent depending on the complications) sought treatment for their children. In cases of very small/ low birth weight baby or a baby not crying, fewer women (43 percent and 66 percent respectively) sought treatment. Most mothers of newborns sought treatment long after noticing the problem, with the average delay varying from four hours to 29 hours (when a delay of more than two days was not taken into account for the analysis) (Table 4.12). About 10 to 20 percent newborns were treated after two days of noticing the problem. This high percentage of delay in seeking treatment is a matter of concern as it could cause serious problem for the newborns. The 
seeking of timely medical care from an appropriate healthcare provider should be an important message to the women as part of interventions and health education from the SHG forum.

\section{Table 4.12: Self-reported Complications and Treatment-seeking Behavior among Mothers of Newborns in Study Area (percentage)}

\begin{tabular}{|l|c|c|c|}
\hline Complications & $\begin{array}{c}\text { Experienced } \\
\text { complication } \\
\text { (percent) }\end{array}$ & $\begin{array}{c}\text { Sought } \\
\text { treatment } \\
\text { (percent) }\end{array}$ & $\begin{array}{c}\text { Mean duration } \\
\text { of treatment } \\
\text { sought (SD) }\end{array}$ \\
\hline Fever & 28.0 & 94.4 & $14.1(17.7)$ \\
\hline Diarrhea & 13.7 & 85.1 & $17.9(20.0)$ \\
\hline Redness and discharge around the cord & 10.2 & 78.3 & $23.4(20.6)$ \\
\hline Difficult or fast breathing & 7.2 & 91.9 & $19.7(18.9)$ \\
\hline Poor sucking or feeding/breastfeeding & 6.3 & 69.6 & $15.7(19.0)$ \\
\hline Blisters on skin/skin lesion & 5.4 & 79.9 & $27.5(20.5)$ \\
\hline Hypothermia/shivering & 4.4 & 85.8 & $11.7(14.9)$ \\
\hline Chest in-drawing & 2.7 & 98.4 & $19.3(20.5)$ \\
\hline Red swollen eyes with discharge & 2.7 & 83.1 & $21.2(20.4)$ \\
\hline Baby became drowsy/unconscious & 2.4 & 83.9 & $22.2(22.4)$ \\
\hline Baby very small/low birth weight & 2.4 & 43.2 & $15.2(17.6)$ \\
\hline Does not pass urine and/or stool & 1.2 & 83.9 & $24.8(21.7)$ \\
\hline Jaundice & 1.0 & 95.8 & $28.8(21.7)$ \\
\hline Baby does not cry & $\mathbf{2 2 0 8}$ & 65.6 & $4.3(11.5)$ \\
\hline Number of children & & - & - \\
\hline
\end{tabular}

The majority of mothers seeking treatment for complications in newborns were from private health providers (46 percent to 70 percent) and less proportionately from government health facilities (only 6 percent to 17 percent) (Figure 4.7). A substantial proportion of newborns were treated by

Figure 4.7: Place of Treatment for Complications in Newborns

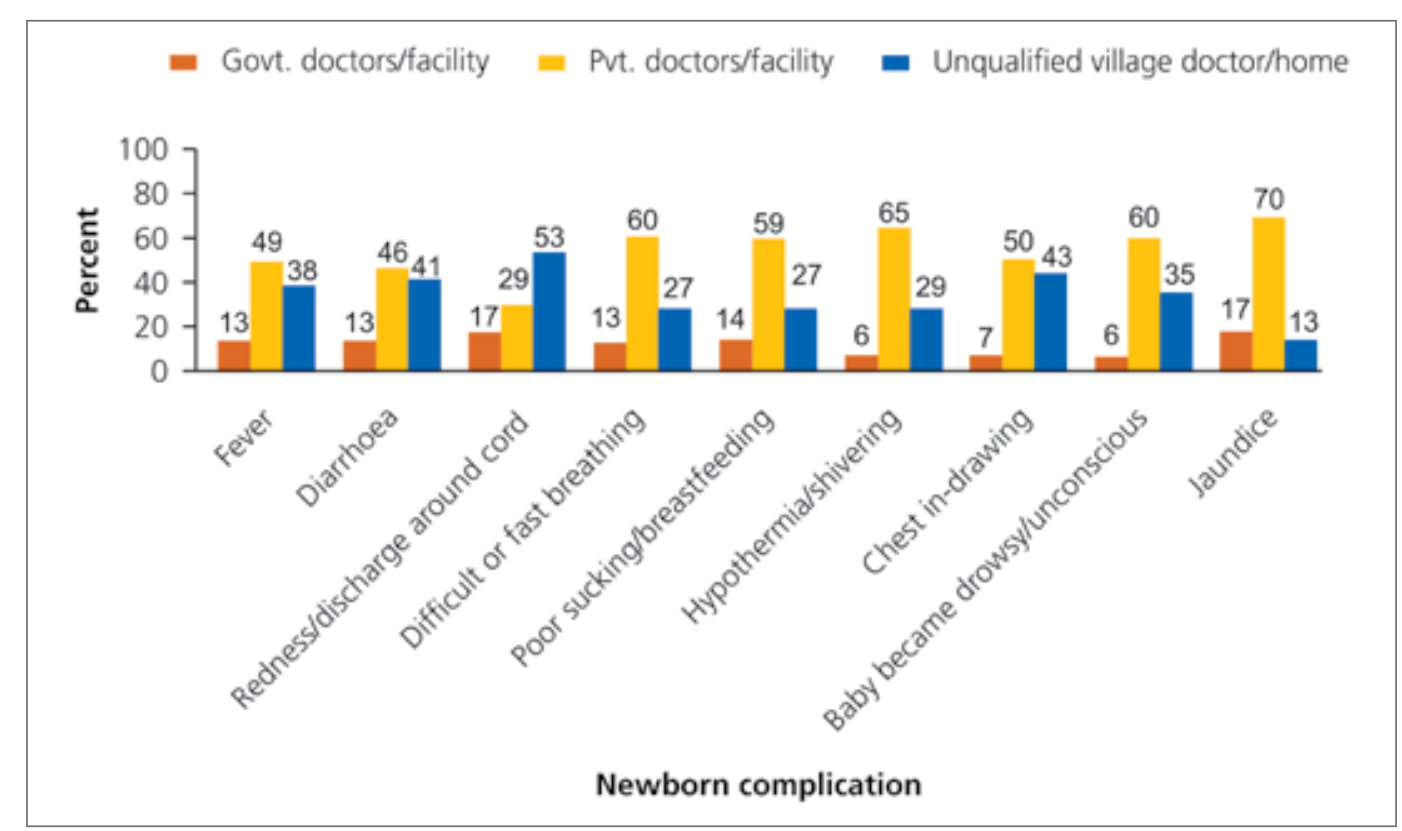


unqualified village doctors or given home treatment (13 percent to 53 percent) for most of the complications, which could be dangerous.

The average expenditure reported for treatment of complications in newborns was Rs. 795, ranging from Rs. 656 to Rs. 902 across the study arms (Figure 4.8). Average expenditure was the highest for medicine (Rs. 467), followed by doctor's fee (Rs. 199), transport (Rs. 86) and other miscellaneous expenditure (Rs. 45) (Figure 4.8). The total expenditure amount was higher in the SHG intervention arm than the control arm and lower in the non-SHG intervention arm. The expenditure for treatment in the intervention arm was a substantial amount for poor and marginalized populations.

Figure 4.8: Expenditure in Newborn Treatment by Arms (in Rupees)

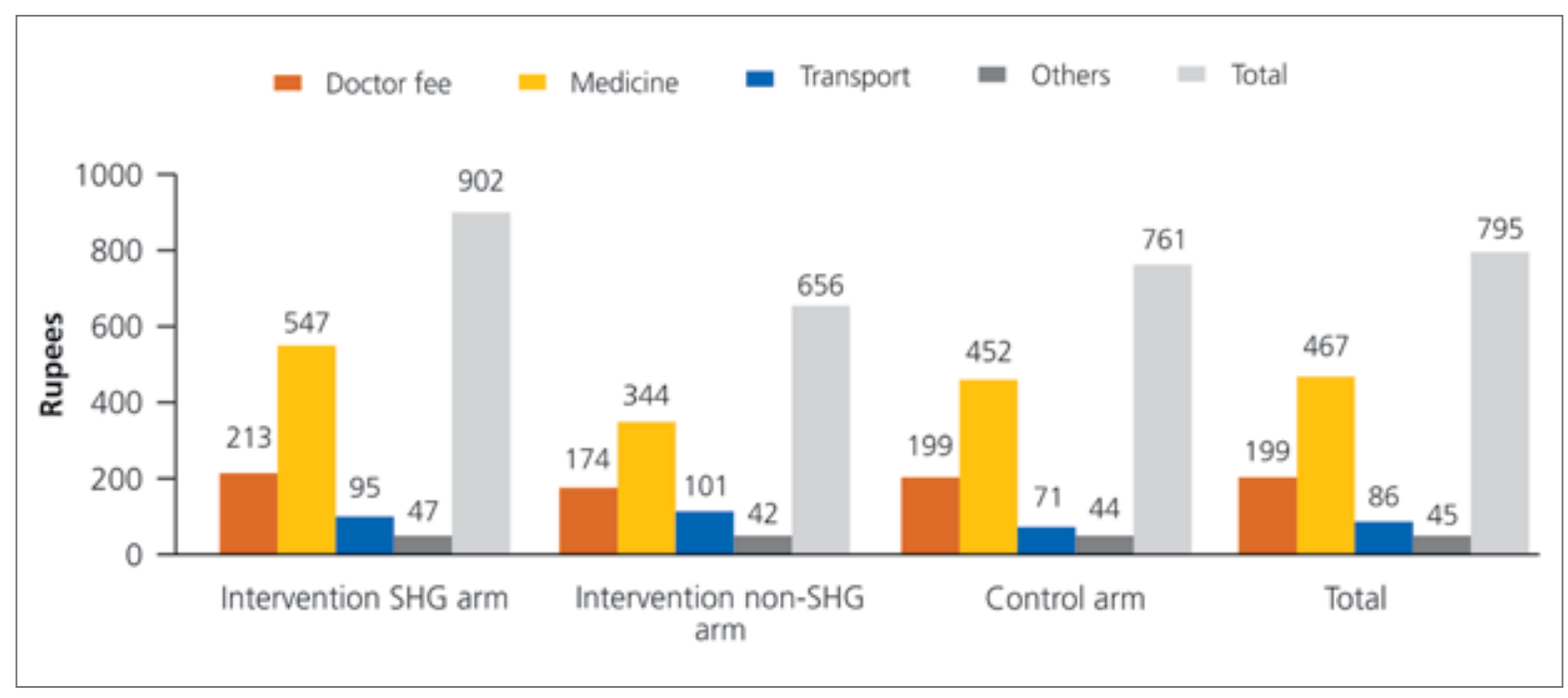




\section{Conclusion}

The findings of the study accentuate the importance of revisiting the intervention plan and the intervention messages. The findings demonstrate that the women of the study area lacked knowledge of newborn care and their newborn care practices were not healthy. The behavior pattern was same in both the experimental and control arms.

Increasing institutional deliveries has helped increase early initiation of breastfeeding and currently half of the newborns were breastfed within one hour of childbirth. Many women appreciated the advantages of early initiation of breastfeeding for the newborn. The main reason for the delay in early breastfeeding was the belief that the flow of breast milk in the mother does not start that early. So, a message needs to be given during interventions that suckling of the breast by the newborn is the key to help start the flow of mother's breast milk. The two important predictors for early breastfeeding were three or more contacts with FLWs and institutional delivery. Pre-lactation feeding was quite common and water and animal milk was given to newborns around two to four months after birth. As a result, only around 22 percent of the babies were exclusively breastfed up to six months after birth. Pre- lactation feeding exposes newborns to risk of diarrhea and other sickness quite early. Early introduction of water was based on the wrong perception that newborns feel thirsty and hence water is essential to save the baby's life. Most of the women did not know that water constitutes 80 percent of the breast milk which is sufficient to quench the baby's thirst.

The need of thermal care for the newborn was appreciated but women lack knowledge of how to provide thermal care. Women follow harmful practices that expose the baby to cold. Half of the children were given a bath within two days after birth, and in one-fourth cases almost immediately. In more than two-third cases, a mustard oil massage was applied, which removed the vernix, a natural coating on the skin which keeps the baby warm. Knowledge of KMC or STSC was almost non-existent and only 2 percent had used it correctly. Clean cord care was practiced only by about one-fourth of the women - they did not apply anything on the cord stump. Most of the women applied ghee/ oil, ash or similar substances which could prove harmful, in the wrong belief that they could protect the cord from infections and diseases and help in drying it quicker. The study also shows that the elderly women in the family were often the chief influencers and their advice not only led to harmful practices but also put barriers in the adoption of healthy behavior. This indicates that the correct information must also reach other members in the family, especially the elderly members. The whole family as a unit should be the focus of intervention.

The women's knowledge and awareness of danger signs for newborns were very poor and on an average a woman knew of only two to three danger signs. They mentioned only one to two danger signs (mean number 1.6) out of the 10 danger signs that were included in the tool kit of SHGs. This is of serious concern as the delay in recognizing danger signs, leads to a delay in treatment. For newborns, most danger signs need immediate medical intervention and any delay could lead to serious consequences. The baseline survey results show that the average delay in getting treatment was one to two days. Further, most women said that they preferred private healthcare providers and in a substantial number of cases, they consulted unqualified healthcare providers who may not be able to manage the complications and further delay the medical intervention required for the newborn.

Advance planning is needed to meet the challenges identified in the project by this study. These include understanding barriers to delay in seeking treatment, educating women about the importance of seeking early treatment, importance of treatment by appropriate healthcare providers, including government health facilities which are rarely used at present. 


\section{References}

Agrawal, P. K., Agrawal, S., Ahmed, S., Darmstadt, G. L., Williams, E., Rosen, H. E., .. Baqui, A. H. (2012). Effect of knowledge of community health workers on essential newborn health care: A study from rural India. Health Policy and Planning, 27: 115-126.

Azad, K., Barnett, S., Banerjee, B., Shaha, S., Khan, K., Rego, A.R., Costello, A. (2010). Effect of scaling up women's groups on birth outcomes in three rural districts in Bangladesh: A cluster-randomised controlled trial. Lancet 375: 1193-1202.

Bajpai, N., \& Sachs, J. D. (2011). India's decade of development: Looking back at the last 10 years and looking forward to the next 20 CGC. SA Working Paper No. 3.

Baqui, A. H., Rosecrans, A. M., Williams, E. K., Agrawal, P. K., Ahmad, S., Darmstadt, G. L.,... Santosham, M. (2008). NGO facilitation of government community-based maternal and neonatal health programme in rural India: improvements in equity. Health Policy and Planning, 23: $234-243$.

Darmstadt, G.L., Kumar, V., Yadav, R., Singh, V., Singh, P., Mohanty, S.,... Santosham M. (2006). Introduction of community-based skin-to-skin care in rural Uttar Pradesh, India. Journal of Perinatology, 26:597-604.

Government of India (GOI). (2010). National health profile of India 2010. Government of India New Delhi.

Government of Uttar Pradesh. (2012). National rural health mission: State action plan, Uttar Pradesh, 2012-13, Department of Medical Health \& Family Welfare, Govt. of Uttar Pradesh.

Houweling, T. A. J.,Tripathy, P., Nair, N., Rath, S., Rath, S., Gope. R., ...Prost A., (2013). The equity impact of participatory women's groups to reduce neonatal mortality in India: Secondary analysis of a cluster-randomized trial. International Journal of Epidemiology, 42:520-532.

IDEAS (2003). Maternal and newborn health care: Baseline findings from Uttar Pradesh, India, April 2013 Retrieved from ideas.Ishtm.ac.uk

Khan M.E., Darmstadt, G., Tarigopula, U.K., \& Ganju, D. (eds.) (2012). Shaping demand and practices to improve family health outcomes: Designing a behavior change communication strategy in India, Volume 1: Uttar Pradesh. New Delhi: Sage Publications.
Khan, M. E., Hazra, A., \& Bhatnagar, I. (2010). Impact of Janani Suraksha Yojana on selected Family Health Behaviors in Rural Uttar Pradesh, The Journal of Family Welfare, Special Issue, 56: 9-22

Khan, M. E., Mosquera, M., Mefalopulos, P., Mozumdar, A. \& Sharma, R. (eds.) (2014). Social and Behavior Change Interventions Implemented in South Asia: Evidence from a Literature Search. New Delhi: USAID, UNICEF and Population Council.

Kumar, V., Mohanty, S., Kumar, A., Awasthi, S., Ahuja, R.C., Singh, P.,... Saksham Study Group. (2008) Effect of community-based behaviour change management on neonatal mortality in Shivgarh, Uttar Pradesh, India: A cluster-randomised controlled trial. Lancet, 372:1151-1162.

Manandhar, D. S., Osrin, D., Shrestha, B. P., Mesko, N., Morrison, J., Tumbahangphe, K.M., ... members of the MIRA Makwanpur trial team (2004). Effect of a participatory intervention with women's groups on birth outcomes in Nepal: Cluster-randomised controlled trial. Lancet, 364: 970-979.

Ministry of Health and Family Welfare (MoHFW) (2013). A strategic approach to reproductive, maternal, newborn, child and adolescent health $(\mathrm{RMNCH}+\mathrm{A})$ in India. New Delhi, India: Government of India

Office of the Registrar General \& Census Commissioner, India (ORGI). (2011). Primary census abstract - data highlights. New Delhi, India: ORGI.

Office of the Registrar General \& Census Commissioner, India (ORGI). (2012). Sample registration system, statistical report. New Delhi, India: ORGI.

Office of the Registrar General \& Census Commissioner, India (ORGI). (2013). A presentation on maternal mortality levels (2010-12). New Delhi, India: ORGI.

Rajiv Gandhi Mahila Vikash Pariyojona (RGMVP). (2014, April 9). Home page of RGMVP. Acccessed from www.rgmvp.org/programmes-health.asp/.

Tripathy, P., Nair, N., Barnett, S., Mahapatra, R., Borghi, J., Rath, S... Costello, A. (2010). Effect of a participatory intervention with women's groups on birth outcomes and maternal depression in Jharkhand and Orissa, India: A cluster-randomised controlled trial. Lancet, 375:1182-1192. 


\section{Appendix}

\section{Appendix 1: List of indicators measured in the baseline survey of learning phase}

\begin{tabular}{|c|c|}
\hline Behavior & \\
\hline ANC & $\begin{array}{l}\text { 1. Percentage of women who received advice during pregnancy on at least three } \\
\text { ANC, deworming, delivery preparedness } \\
\text { 2. Percentage of women who received at least three ANC } \\
\text { 3. Percentage of women who had contact with ASHA during pregnancy } \\
\text { 4. Percentage of women who consumed } 100 \text { IFA tablets } \\
\text { 5. Percentage of women who consumed deworming tablets at least once } \\
\text { 6. Percentage of women who underwent different check-ups like BP, blood test } \\
\text { 7. Percentage of women who did delivery preparedness }\end{array}$ \\
\hline $\begin{array}{l}\text { Knowledge of } \\
\text { danger signs, } \\
\text { experience of } \\
\text { complications } \\
\text { and care-seeking } \\
\text { behavior }\end{array}$ & $\begin{array}{l}\text { 8. Percentage of women with knowledge of key danger signs during } \\
\text { pregnancy, during and after delivery } \\
\text { 9. Percentage of women with knowledge of key danger signs in newborns } \\
\text { 10. Percentage of women who experienced complications during pregnancy, } \\
\text { during and after delivery } \\
\text { 11. Percentage of newborns who experienced complications } \\
\text { 12. Percentage of women who sought treatment in respective complications } \\
\text { 13. Percentage of women who sought treatment after noticing complications }\end{array}$ \\
\hline $\begin{array}{l}\text { Institutional } \\
\text { delivery }\end{array}$ & $\begin{array}{l}\text { 14. Percentage of women who delivered at institution } \\
\text { 15. Percentage of women who stayed at facility for at least } 24 \text { hours }\end{array}$ \\
\hline PNC & $\begin{array}{l}\text { 16. Percentage of women who received PNC within a week of delivery } \\
\text { 17. Percentage of newborns weighed after delivery } \\
\text { 18. Percentage of women who received advice to practice high-impact healthy } \\
\text { behaviors (early initiation of breastfeeding, delaying first bath, KMC/STSC, } \\
\text { keeping cord stump clean and dry, exclusive breastfeeding for first six } \\
\text { months) }\end{array}$ \\
\hline $\begin{array}{l}\text { Immediate } \\
\text { newborn care and } \\
\text { practice }\end{array}$ & $\begin{array}{l}\text { 19. Percentage of women who initiated breastfeeding within an hour } \\
\text { 20. Percentage of women who did not apply anything on the cord stump } \\
\text { 21. Percentage of women who delayed bath to their baby by at least } 48 \text { hours } \\
\text { 22. Percentage of women with correct knowledge of KMC } \\
\text { 23. Percentage of women who correctly practiced KMC }\end{array}$ \\
\hline $\begin{array}{l}\text { Exclusive } \\
\text { breastfeeding and } \\
\text { complementary } \\
\text { feeding }\end{array}$ & $\begin{array}{l}\text { 24. Percentage women who exclusively breastfed (not even water) } \\
\text { in first six months } \\
\text { 25. Percentage women who initiated complementary feeding at six months }\end{array}$ \\
\hline
\end{tabular}




\begin{tabular}{|l|l|}
\hline Behavior & \multicolumn{1}{|c|}{ Indicators } \\
\hline Family planning & $\begin{array}{l}\text { 26. Percentage of non-pregnant women using modern contraceptive } \\
\text { methods } \\
\text { 27. Percentage of women with correct knowledge of return of fertility }\end{array}$ \\
\hline $\begin{array}{l}\text { Exposure to mass } \\
\text { media }\end{array}$ & $\begin{array}{l}\text { 28. Percentage of women with exposure to mobile } \\
\text { 29. Percentage of women with exposure to newspaper, radio, and/ or TV }\end{array}$ \\
\hline $\begin{array}{l}\text { SHG emberships, } \\
\text { meetings and } \\
\text { exposure }\end{array}$ & $\begin{array}{l}\text { 30. Percentage of women who are members of SHGs } \\
\text { 31. Average number of SHG meetings attended by women in a month } \\
\text { 32. Percentage of women exposed to health messages at SHG meetings }\end{array}$ \\
\hline
\end{tabular}

\section{Appendix 2: Calculation of sample size for the baseline survey of learning phase}

\begin{tabular}{|l|c|c|c|c|c|}
\hline Indicators & $\begin{array}{c}\text { Baseline } \\
\text { value } \\
(\%)\end{array}$ & $\begin{array}{c}\text { Expected } \\
\text { value } \\
\text { after } \\
\text { learning } \\
\text { phase }\end{array}$ & $\begin{array}{c}\text { Required } \\
\text { sample size } \\
\text { (intervention } \\
\text { + control } \\
\text { arm) }\end{array}$ & $\begin{array}{c}\text { Additional } \\
\text { Sample for } \\
\text { diffusion } \\
\text { (Intervention } \\
\text { arm) }\end{array}$ & $\begin{array}{c}\text { Total } \\
\text { sample } \\
\text { size }\end{array}$ \\
\hline At least three ANC & 34 & 41 & 1650 & 413 & 2063 \\
\hline Institutional delivery & 44 & 51 & 1756 & 439 & 2195 \\
\hline $\begin{array}{l}\text { Postnatal care within } \\
\text { seven days }\end{array}$ & 14 & 21 & 1352 & 338 & 1690 \\
\hline Cord care & 19 & 26 & 1227 & 307 & 1534 \\
\hline Delayed bathing by a day & 32 & 39 & 1612 & 403 & 2015 \\
\hline Early breastfeeding & 19 & 26 & 1227 & 307 & 1534 \\
\hline Colostrum feeding & 68 & 75 & 1434 & 359 & 1793 \\
\hline Exclusive breastfeeding & 24 & 31 & 1403 & 351 & 1754 \\
\hline Complementary feeding & 24 & 31 & 1403 & 351 & 1754 \\
\hline Modern FP method use & 28 & 31 & 7980 & 1995 & 9975 \\
\hline Full immunization & 50 & 57 & 1751 & 438 & 2189 \\
\hline
\end{tabular}

\section{Notes:}

1. For all indicators except modern FP use, the assumption is 7 percentage point annual increase during first year of intervention (assuming 20 percentage point increase over three years).

2. For modern FP use, assumption is 3 percentage point increase during first year of intervention.

3. The sample size calculation considers 80 percent power, 95 percent significance level and 10 percent non-response rate. 




\section{COMMUNITY MOBILIZATION PROJECT}

The Uttar Pradesh Community Mobilization Project is a five years initiative (2011-2016), funded by the Bill \& Melinda Gates Foundation. The initiative is being implemented by a consortium led by the Public Health Foundation of India. The other members of the consortium are Rajiv Gandhi Mahila Vikas Pariyojana, Population Council and Centre for Global Health and Development. The project's goal is to develop and scale-up a package of family health interventions through social platforms in Uttar Pradesh for reducing neonatal mortality rate and improving family health behaviors.

\section{POPULATION} COUNCIL

\section{Ideas. Evidence Impact.}

Zone 5-A, Ground Floor, India Habitat Center Lodhi Road, New Delhi - 110003, India

Tel: 91 - 11 - 24642901/2 Fax: 91 - 11 - 24642903

Email: info.india@popcouncil.org, Web: popcouncil.org 